\title{
OSTEOLOGY OF THE WATERFOWL
}

\author{
By
}

GLEN E. WOOLFBNDEN

\begin{abstract}
A DISSERTATION PRESENTED TO THE GRADUATE COUNCIL OF THE UNIVERSITY OF FLORIDA

IN PARTIAL FULFILLMENT OF THE REQUIREMENTS FOR THE DEGREE OF DOCTOR OF PHILOSOPHY
\end{abstract}

UNIVERSITY OF FLORIDA

August, 1960 


\section{ACKNOWLEDGEMENTS}

I wish to extend my deepest appreciation to Professor Plerce Brodkorb for his valuable and untiring supervision throughout the course of the problem.

Sincere thanks are also due the other members of the faculty who critically read the manuscript, Drs. J. C. Dickinson Jr., Roland F. Hussey, Caspar Rappenecker, and especially Dr. James $N$. Layne, who was helpful in many other ways.

To Ted T. Allen, who made the drawings, and J. H1ll Hamon, who did the photographic work, I am also grateful. Finally, I wish to acknowledge financlal ald from Lester B. Woolfenden and Gwen S. Woolfenden. 
TABLE OF CONTENTS

Page

ACKNOWLEDGEMENTS . . . . . . . . . . . . . . 11

LIST OF TABLES ................... IV

LIST OF ILIUSTRATIONS . . . . . . . . . . . v v

INTRODUCTION .................... . . 1

MATERIALS AND METHODS . . . . . . . . . . . 3

DESCRIPTIVE OSTEOLOGY •. . . . . . . . . . . 7

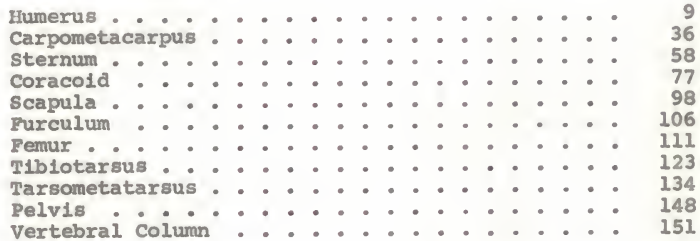

DISCUSSION AND CONCLUSIONS . . . . . . . . . . 159

SUMMARY .... . . . . . . . . . . . . . 211

LITERATURE CITED . . . . . . . . . . . . . . 213

APPENDIX . . . . . . . . . . . . . . . 218

BIOGRAPHICAL SKETCH . . . . . . . . . . . 225 
$$
\text { LIST OF TABLES }
$$

Table Page

1. Classiflcation of Anatidae . . . . . . . 8

2. Waterfowl vertebral Counts .... . . . . 154

3. Classification of the Anseriformes . . . . 209 


\section{LIST OF ILLUSTRATIONS}

Plate Page

I. Phylogeny of the Anseriformes . . . . . . 210

II. Ligaments of Pectoral Girale . . . . . . 224 


\section{INTRODUCTION}

It seems $\log 1 \mathrm{cal}$ that the waterfowl, as the Anatidae are commonly known, would be a well-studied group. They have great economic and recreational value, many species are easily reared in captivity and, as a check of Delacour's monograph $(1954,1956,1959)$ reveals, no species completely new to science has been discovered since 1894. But, as Delacour and Mayr (1945) pointed out, the internal anatomy of waterfowl is a completely neglected field. Until Verheyen's osteological work (1955) no modern comparative anatomical study of all the taxa within the family was ever undertaken.

Verheyen based his classification almost entirely on the number of vertebrae in the different regions of the column and on relative lengths of various 1 imb elements. He admitted that structural details of the individual bones are of great importance to paleontologists but further stated, somewhat antipathetically, that such features rarely serve to distinguish one waterfowl from another. Prevlous work with anatid fossil material convinced me that much could be learned concerning waterfowl phylogeny through a detailed analysis of the structure of the bones.

Many osteological studies have been conducted in which emphasis has been placed on the relative length of $11 \mathrm{mb}$ 
bones. This procedure may be valld when studying closely related specles, but with anclent and diverse groups such as the waterfowl it seems likely that similar proportions could have arisen independently several times. The concept that structural features of the different elements may be more conservative underlies this study.

As the skull has been treated by other investigators (Verheyen, 1955; Goodman and F1sher, 1960), the present study is based primarily on qualitative, structural differences in ten postcranial elements. The taxonomic usefulness of these elements is respectively: humerus, carpometacarpus, coracold, sternum, tarsometatarsus, femur, ttbiotarsus, scapula, pelvis, and furculum. Size and other characters of a specific nature variable within a genus are disregarded. Anatomical nomenclature follows Howard (1929). In a few Instances it has been necessary to name other features. When an additional term is first used, it is defined or a reference is c1ted. 
MATERIATS AND METHODS

The skeletal collection of Plerce Brodkorb was supplemented by material borrowed from the American Museum of Natural H1story, United States National Museum, National Museum of V1ctoria, Australia, and Peabody Museum of Natural History, these specimens were obtained through the kindness of Dean Amadon, Herbert Friedmann, A. R. McEvey, and Ph1lip s. Humphrey, respectively. Additional material was donated by Ethel L. Woolfenden, Joseph R. Jehl, Jr., Will1am o. WIrtz II, and Henry M. Stevenson, Jr. Norman L. Ford sent data from certain specimens in the University of Michigan Museum of zoology. I wish to thank all of these people for their help.

Over 85 per cent of the currently recognized genera were studied. Only elght of the 62 genera recognized by Peters (1931) were unava1lable, namely Cyanochen, Asarcorn1s, Stictonetta, Pseudotadorna, Nesonetta, Salvadorina, Camptorhynchus, and Thalassorn1s. Under the classification of Delacour only five of his 41 genera were lacking, namely: Cyanochen, Stictonetta, Iophonetta, Camptorhynchus, and Thalassorn1s.

The assembled collection of 422 specimens represents 104 of the 167 species of waterfowl recognized by Peters. Those species and subspecies examined, and the number of 
specimens involved, are 11sted below: Cygnus cygnus 2, Cygnus columb1anus 24, Cygnus buccinator 1, cygnus olor 2, Cygnus melancoriphus 3, Chenopis atrata 4, Anseranas semipalmata 1 complete +1 body skeleton, Plectropterus gambens1s 2 , Cereopsis nn.hollandiae 2, Chen caerulescens 1, Chen hyperborea 2, Chen rossi1 9, Anser anser 1, Anser albifrons albifrons 1, Anser fab1118 1, Eulabela indica 1, Cygnops18 cygno1d 2, Philacte canagica 1, Branta bernicla hrota 6 , B. b. nigricans 1, Branta canadensis canadensis 8, B. ‥ hutchinsi1 2, Branta ruficollis 1, Nesochen sandvicensis 1, Chlor phaga melanoptera 4, Chlotphaga leucoptera 1, Chloephaga dispar 3, Chenonetta Jubata 2, Dendrocygna bicolor bicolor 1, Dendrocygna 1avanica 2, Dendrocygna autumnalis autumnal1s 1 , D. a. d1scolox 1 body skeleton, Dendrocygna arborea 3, Alopochen aegyptiaca 3, Neochen Jubata 1 complete +1 body skeleton, Sarkidiornis melanota 1, Cairina moschata 4, Coscoroba coscoroba 1, Casarca cana 2, Casarca tadornoides 1 , Casarca varlegata 2, Tadorna tadorna 4, Anas platyrhynchos platyrhynchos 6, Anas poecilorhyncha 1, Anas luzonica 1 , Anas mellex1 1, Anas fulvigula fulvigula 7, A. E. maculosa 1. Anas rubripes 6, Anas undulata 1, Anas cyanoptera cyanoptera 3. Anas discors 10, Anas querquedula 4, Anas castnea 2, Anas crecca crecca 1, ㅅ․ crecca carolinensis 9, Anas formosa 1, Anas falcata 1, Anas leucophrys 1, Anas brasiliensis 1, Anas acuta tzitzihoa 5, Anas anqustirostris 1 body skeleton, Anas bahamensis rubirostris 2, Mareca penelope 14, Mareca americana 4, Mareca s1bilatrix 1, Chaulelasmus streperus 9. 
Spatula clypeata 5, Spatula platalea 1, Malacorhynchus membranaceus 1 complete + 1 partlal skeleton, Rhodonessa caryophyllacea 1 body skeleton, A1x sponsa 16, Dendronessa galericulata 5, Cheniscus coromandellanus coromandelianus 4, Chen1scus pulchellus 1, Nettapus auritus 1, Pteronetta hartlaub11 1, Heteronetta atricap1lla 1, Netta rufina 2, Metopiana peposaca 3, Aythya ("Nyroca") valisineria 3, Aythya ferina 1, Aythya americana 5, Aythya collar1s 14, Aythya ful1gula 6, Aythya nyroca 1, Aythya marila mar1la 21, ㅅ․ 프. nearctica 6, Aythya affinis 21, Tachyeres brachyptera (1.e., pteneres) 1, Bucephala clangula clangula 2, B. ‥ americana 5, Bucephala albeola 5, Clangula hyemalis 5, Histrionicus histrionicus pac1ficus 1, Somateria mollissima v-nigra 1 , s. ㅍ. Aresser1 6, Somateria spectabilis 3, Arctonetta E1sheri 1, o1demia nlgra nigra 3, ‥ ․․ americana 1, Melanitta fusca fusca 1, M. f. degland1 5, Melanitta perspicillata 1 , Polysticta stelleri 1, Eymenolaimus malacorhynchos 1 , Nomonyx dominicus 2, oxyura famalcensis jama1cens1s 11, Oxyura vittata 1, B1zlura lobata 1, Mergellus albellus 1 , Lophodytes cucullatus 7, Mergus merganser merganser 2, ㅆ. ․․ americanus 2, Mergus serrator 18, Merganetta armata armata 2.

All the ratios presented below are intramembral. They reflect relative proportions within a given element. These are formed by dividing the width or depth of varlous portions of the element by its length, so that the ratios are expressed in percentages of the length. Linear measurements were taken to the nearest tenth of one millimeter. The 
method of taking the measurements on which the ratios are based are explained where first mentioned under the respective element. 


\section{DESCRIPTIVE OSTEOLOGY}

Table 1 11sts the genera of Anatidae according to Peters (1931), arranged in the subfamilies and tribes of Delacour (1954, 1956, 1959), Two generic changes (Aythya for Nyroca, cf. American Ornithologists' Union, 1945;

Lampronetta for Arctonetta, cf. Parkes, 1955), and two additions (Lophonetta and Amazonetta from Anas, cf. Delacour and Mayr, 1945) are incorporated. Parentheses enclose the genera not recognized by Delacour, and these follow the genera with which they were synonymized. An asterisk marks the genera not avallable for this study. Where additional genera are mentioned in the text an authority is listed. The vernacular names of certain of the tribes and the arrangement of the tribes in the subfamily Anatinae have been altered slightly by me. The presentation of osteological data follows the arrangement as given in this table. 
TABLE 1

CLASSIFICATION OF ANATIDAE

ANSERANATINAE. Pled Goobe Anseranas

ANSERINAE.

Dendrocygnini. Whistling Ducks

Anserini. Swans and Geese

Coscoroba

Cyanus

(Chenopis)

Anser

(Cygnops 1s)

(Chen)

(Ph11acte)

(Eulabela)

Branta

(Nesochen)

ANATINAE, Ducks

\begin{tabular}{|c|c|}
\hline Shelarakes & Cairinini (cont.) \\
\hline Cereopsis & Sarkidiornis \\
\hline Chloepphaga & Cairina \\
\hline Cyanochen* & Asarcorn1s) * \\
\hline Neochen & (Pteronetta) \\
\hline Alopochen & Plectropterus \\
\hline Tadorna & Aythylni. Pochards \\
\hline (Casarca) & Netta \\
\hline (Pseudotadorna) * & (Metopiana) \\
\hline Lophonetta * & Aythya \\
\hline Tachyereg & somateriini. Elders \\
\hline Anatini. Dabbling Ducks & Polysticta \\
\hline Anas & Sumater1a \\
\hline (Nesonetta) * & (Lampronetta) \\
\hline (Chaulelasmus) & Mergin1. Sea Ducks \\
\hline (Mareca) & Melan1tta \\
\hline (Spatula) & Oidemia) \\
\hline (Salvador 1 na $)$ * & Camptorhynchus* \\
\hline Rhodonessa & H18trion1cus \\
\hline Malacorhynchus & Clangula \\
\hline Eymenolaimus & Bucephala \\
\hline Merganetta & Merqus \\
\hline Stictonetta & (Mergel1us) \\
\hline Cairinini. Perching Ducks & (Iophodytes) \\
\hline Amazonetta & oxyurin1. Stiff-ta1led Ducks \\
\hline Chenonetta & Oxyura \\
\hline $\mathrm{A1x}$ & Nomonyx) \\
\hline (Dendronessa) & Thalassornis \\
\hline Nettapus & B1ziura \\
\hline (Chen1scus) & Heteronetta \\
\hline
\end{tabular}

mot examined

Names in parentheses synonymized by Delacour (1954-1959) 


\section{Humerus}

Paleontologists and osteologists generally consider the humerus in birds to be extremely useful taxonomically. of the ten elements described herein, it shows the greatest number of characters of systematic value.

\section{Anseranatinae}

The pled goose (Anseranas semipalmata) differs from all other Anatidae by three humeral characteristics. (1) The prominent capital shaft ridge (Ashley, 1941) is situated more medially than in all other anatids. Correspondingly, the attachment of the external head of the triceps 18 very restricted; it barely extends proximally to the base of the internal tuberosity. In other waterfowl it extends past the tuberosity toward the head of the humerus. (2) The pneumatic fossa is greatly reduced. The fossa does not extend to the humeral head, and the floor is elevated from the bicipital surface. (3) The facet for the anterior articular ligament is less elevated, particularly along the inner margin, than in other anatids.

Anseranas was treated as an aberrant member of the perching ducks by Delacour and Mayr (1945) because of 1ts superficial resemblance to plectropterus. Further consideration resulted in Delacour (1954) placing Anseranas in a separate subfamily, a conclusion based on anatomical evidence presented by Boetticher (1943), who considered several skeletal features important. The structure of the humerus 
of Anseranas indicates it is a primitive anatid, and its removal from the Anatinae is completely warranted.

\section{Anserinae}

Delacour and Mayr place the whistling ducks and swans and geese in the same subfamily. Similarity in the form of the humeral head in Dendrocygna and certain geese has previously been noted (Wetmore, 1924). The prominent capital shaft ridge directed towards the humeral head, coupled with an area of attachment for the external head of the triceps that extends virtually to the humeral head, characterizes the subfamily. In the Anserinae and Anseranatinae the area of pectoral attachment on the external tuberosity is elevated and somewhat circular; in the Anatinae 1t lies essentially flush with the proximal portion of the shaft and is elongate. Furthermore, in the first two subfamilies the capital groove is not extensive, whereas in the Anatinae the groove is extended laterally over the anconal surface and excavates the head considerably.

Tribe Dendrocygnini.

\section{Whistling Ducks}

Whistling ducks can be distinguished from the swans and geese, and also from Anseranas, by the width of the space between the external condyle and the facet for the anterior articular ligament in relation to the width of the latter. In the whistling ducks the space is narrower than the facet, whereas in the others the reverse is true. 
The small size of the humerus and prominent capital shaft ridge have been considered distinctive of Dendrocygna. However, only the more subtle feature listed above separates the genus from the smaller geese.

\section{Tribe Anserint.}

\section{Swans and Geese}

The prominent capital shaft ridge, the area of attachment for the external head of the triceps that extends almost to the humeral head, and the facet for the attachment of the anterior articular ligament that is narrower than the space between it and the external condyle define the tribe.

Features of the humerus indicate the tribe is comprised of two distinct units. One contains the swans and coscoroba, the other the geese. These two units are distinguishable by the relative width of the distal end of the humerus. In the swans the relatively narrow distal end constitutes 12.2 to 13.9 per cent of the total length, and in Coscoroba 13.9 per cent. In geese the range is from 14.1 to 15.6 per cent.

Further characteristics which distinguish these two groups pertain to the configuration of the internal tuberos1ty and enteplcondyle. (1) The entepicondyle is not extended distally as far in swans as in geese. (2) The entep1condylar prominence 1s more produced laterally in swans, in part the result of a more medially situated entepicondyle. (3) The internal tuberosity is shorter and more rounded at the tip in swans.

In true swans a short, but wide furrow leads transversely from near the proximal end of the capital groove onto 
the Internal tuberosity; this furrow is indistinct in coscoroba.

The genus olor was not recognized as distinct from cycnus by Peters (1931) or Delacour. Other authorit1es (Wetmore, 1951) considered the separation of the swans into two or more genera valid. Several distinguishing features of the humerus were 11sted by Howard (1946). (1) The intermuscular line, on the capital shaft ridge, is short, indefinite, and not turned inward below the head in cygnus. In olor the line runs along the ridge and turns inward about one-quarter of an inch below the head. (2) The area of attachment of the supraspinatus is clear-cut in outline and situated below the pneumatic foramen; it $1 \mathrm{~s}$ bordered by a raised line continuous with the median crest in cygnus (poorly marked in c. melancoriphus). In olor the attachment is less clearly marked and spreads past the median crest, and it lacks the raised bordering line at the edge. (3) The ligamental furrow is broad and less deeply cut in cygnus olor, but not in c. melancoriphus; whereas in olor it is narrower and deeper. (4) The attachment of the anterior articular ligament is short, broad, and heavily bordered on its outer edge next to the attachment of the pronator brevis in cygnus. In olor the attachment is long, narrow, and smoothly rounded at the edges. (5) The impression of the brachialis anticus in olor is short, broad, particularly at the proximoexternal edge, clearly outlined, and usually deeply depressed. In cyanus the impression is less clearly outlined. The series of swans available to me confirm these features, the last of which 
proves particularly useful. Chenopis is similar to gyonus In all of these features.

The humeri of the true geese, Branta, Nesochen, Anser, Cygnopsis, Eulabela, Philacte, and Chen are very similar. Two specimens of Cygnopsis, unfortunately both from aviary birds, are distinguishable from the other genera through possession of a larger, more rounded, and distally extended pneumatic fossa that excavates more of the shaft and the bone forming the median rim of the fossa.

Miller (1937), who was unable to distinguish the humeri of Philacte, Anser, and Chen, one from another, found the impression of the external head of the triceps sorewhat useful in separating Nesochen and Branta from these three genera. The impression has a distinct border in Nesochen and Branta, whereas in Philacte, Anser and Chen it is most often indistinct. Cygnopsis and Eulabeia resemble the latter group in this respect. Miller also remarked that Branta showed greater curvature distally; with my series this feature is not particularly useful. Brodkorb (1960b) mentioned that the deltoid crest, in anconal view, shows a distinct bend in the middle in Branta, whereas in Philacte, Anser, and Chen it 1 more rounded. For a now larger series of geese we find this feature useful in most cases, but not Infallible. Nesochen and Eulabeia resemble Branta in this respect.

One feature of the humerus frequently separates Chen from Anser and Philacte. In Chen the humerus, in anconal view, has the head rotated toward the internal side, and as 
a result the lip of bone extending from the head over the capital groove is more prominent. Since only two specimens of Anser are available it 18 difficult to assess the value of this character.

\section{Anatinae}

The humerus of ducks is characterized by 1ts lack of a prominent capital shaft ridge directed towards the head. In addition, the capital groove extends laterally over the anconal surface and deeply excavates the head. The difference in size and position of the capital shaft ridge seems to result from a difference in the attachment of the external head of the triceps, which is stronger in the Anatinae. Miller postulates that greater strength of the muscle is indicated by the more lateral position of the riage in Chlocphaga (here placed in the Anatinae) as compared with certain true geese.

The structure of the humerus of the Anatinae indicates that the sheldrakes and stiff-talled ducks are the two most distinct tribes; whereas the dabbling ducks, perching ducks, pochards, elders, and sea ducks are more closely related.

Varlation in the position and size of the pits on the inner and outer surfaces of the distal end of humerus is useful in defining certain genera and generic groups within the Anatinae. Names for certain of these pits are not readily avallable, and thus those to which reference is made are described. On the internal side of the entepicondyle are three distinct pits, two of which lie about equally distad, 
the third more proximad. The distal pit nearest the attachment of the anterior articular ligament 18 the origin of the pronator longus. The other distal pit, situated anconal to the first named, is the origin of the flexor carpi ulnaris. The third and more proximal, whlch 1s labeled in Howard (1929), is the place of origin of the pronator brevis. On the external side, immediately proximal to the ectepicondylar prominence is a depression marking the origin of the extensor metacarpi radialis.

\section{Tribe Tadornint. Sheldrakes}

The sheldrakes have the following humeral characteristics. (1) The capital shaft ridge is fairly prominent as in Anserinae, but is directed towards the external tuberosity. (2) The area of origin of the external head of the triceps is narrower than in other ducks; as a result there is an elevated area between the attachment of the muscle and the external tuberosity. (3) The deltold crest is larger and more flaring than in other ducks. Furthermore, when compared in lateral view, the entire crest tends to be more rounded, and if an abrupt bend is present it lies more posteriad. (4) The deltoid crest extends farther distally (most evident when the distal borders of deltoid and bicipital cresta are compared). (5) The head is rotated so that the external tuberosity is usually higher in relation to the head than in other ducks. Th1s feature 18 best seen by viewing the proximal end of the bone with the palmar surface lying on a plane. The external tuberosity represents more 
than 89 per cent of the helght of the head in the sheldrakes, with Tachyeres and Neochen as exceptions. In Neochen the head is rotated as in other members of the tribe, but a robust head results in the external tuberosity constituting only 87.2 per cent of the head height. Tachyeres measured 86.2 per cent and showed no indication of the rotation present in the other genera assigned to this tribe. Miller remarked on the striking modifications of Chlorphaga, namely the much broader depression of the triceps, which is directly related to the more lateral position of the capital shaft ridge and the external flaring of the deltoid crest. A feature he did not mention that further distinguishes Chlosphaga from the true geese and relates it to the other sheldrakes is the greater elevation of the facet for the anterior articular 11gament. Miller felt that Chloephaga would prove to be more closely related to some anserine other than the North American geese. The relationship appears even more distant than he suspected since the recent monographers place the genus in a subfamily apart from that containing the true geese.

Based on humeral characteristics, the seven avallable genera of sheldrakes fall into five distinct groups:

Tadorna and Casarca form one, Chloephaga and Alopochen another, and Neochen, Cereops18, and Tachyeres respectively, form the other three.

Tadorna and Casarca cannot be separated by features of the humerus. Together they differ from Chloephaga and Alopochen as follows. (1) The external tuberosity is less 
prominent as a result of its distal portion lying almost flush with the shaft. (2) The external head of the triceps is narrower; correspondingly the capital shaft ridge curves Inward, being directed toward the external edge of the head. In Alopochen and Chlobphaga, where the external head of the triceps is wider, the capital shaft ridge is straight and directed towards the median edge of the external tuberosity. (3) The distal end of the humerus possesses characters that tend to distinguish Tadorna and Casarca from Alopochen and Chloephaga, but none is constant. The lack of an anconal protuberance on the entepicondyle is the most reliable of these.

Alopochen can be distinguished from Chlouphaga as follows. (1) The capital shaft ridge is more prominent in Alopechen; correspondingly the area between the ridge and the pneumatic fossa is a much more steeply inclined surface in Chlorphaga. (2) The internal tuberosity 18 less elevated in Alopochen (best observed by looking along the shaft towards the pneumatic fossa). (3) The facet for the anterior articular ligament is a rounded knob in Alopochen; in Chloephaga the surface is flat.

The humerus of Neochen 1s quite different from those of other sheldrakes, and certain features indicate a relationship to the dabbling ducks. (1) The depression for the external head of the triceps extends laterally to the external tuberosity. This is characteristic of ducks other than sheldrakes; all avallable specimens of the latter have a space between the area of muscle attachment and the 
tuberosity. (2) The 1ip extending from the head over the impression formed by the external head of the triceps is curved. In most dabbling ducks it is almost straight and perpendicular to the shaft. Chloephaga and Alopochen show curvature in this area. (3) The deltold crest is less flarIng and more abruptly bent in the middle as in the dabbling ducks, but extends farther distally, and this is character1stic only of the sheldrakes. (4) The head is rotated as mentioned previously. This feature is unique to the sheldrakes among the ducks. From the characters of the humerus the position of Neochen remains uncertain, although its strongest affinities do seem to lie with the sheldrakes.

The humerus of Cereopsis is more like that of the swans and geese than any of the sheldrakes. It resembles them in the following ways. (1) The capital shaft ridge is extremely prominent and directed towards the head. (2) The surface for pectoral attachment on the external tuberosity is elevated from the shaft and, therefore, less elongate than in sheldrakes. (3) The facet for the anterior articular ligament is less elevated than in sheldrakes. (4) The entepicondylar prominence 1s laterally produced as in swans. Cereopsis differs from the swans and geese as follows. (1) the deltold crest 18 more evenly curved throughout 1ts length. (2) The head blends in with the shaft instead of being delimited by a depression on the anconal surface. Thus the features of the humerus of cereopsis point toward a strong affinity with the swans and geese. 
The feature that best distinguishes the sheldrakes from the other ducks, the rotation of the head, is lacking in the aberrant Tachyeres. In sheldrakes the external tuberosity comprises over 89 per cent of the helght of the head. In Tachyeres the external tuberosity constitutes only 86.2 per cent. Tachyeres has the following additional characteristics. (1) The excavation for the external head of the triceps is very deep. The depth results in a prominent capital shaft ridge which is directed towards the external tuberosity. The surface upon which the muscle attaches, which lies mediad to the ridge, is steeply inclined, and the proximal extent of the muscle forms a deep cavity beneath the head. (2) The internal tuberosity is bent distad so that it considerably overhangs the pneumatic fossa. This striking feature is most evident when the bone is viewed from the internal side. (3) The deltold crest has the proximal portion concave in anconal view, the distal portion flaring widely, and the confluence with the shaft forming an abrupt angle. (4) The brachial depression is indistinct, but covers a wide area. (5) The facet for the attachment of the extensor metacarpi radialis is more mediad than in other ducks. Tribe Anatint. Dabbling' Ducks

The humerus of the dabbling ducks can be defined as follows. (1) The capital shaft ridge is obsolete, in contrast with the sheldrakes. (2) The pneumatic fossa is ovalold and unrimmed with heavy bone, in contrast with the perchers (see perching ducks for additional detalls). (3) The 
pneumatic fossa is open and contains bony struts (Woolfenden, 1959). In the pochards (except lletta and usually Metoplana), elders, sea ducks (except Mergus and Lophodytes). and stiff-tailed ducks the fossa is closed.

In dabblers the ectepicondyle is equal or subequal in height to the entepicondyle when the humerus is placed on a plane, palmar surface down. In the pochards, including Metoplana and Netta, the entepicondyle is distinctly higher.

Dabblers differ from mergansers in the form of the internal tuberosity. In the mergansers, and this is essentially true of all sea ducks, it is shorter; the length (measured perpendicular to the shaft from the ligamental furrow to the tip) 1s less than the wiath (measured from the capital groove to the area of attachment of the infraspinatus).

No humeral features are to be found that enable the separation of Chaulelasmus, Mareca, and Spatula from the genus Anas. Specimens of Mareca frequently display a robust shaft and a compressed distal condylar area, but these features do not seem consistent enough in a large series to merit generic distinction.

on the basis of the humerus alone the species Anas leucophrys deserves segregation in a separate genus. The distal condylar area 1s grossly different from that of the twenty-two available species of typical dabblers (Anas, Chaulelasmus, Mareca, Spatula). The name Callonetta, proposed as a subgenus by Delacour (1936) for this little-known specles can be used. Its humerus differs from those found 
In the aforementioned genera as follows. (1) Shaft is more sigmold than in Anas. (2) The distal and is rotated so that the ectepicondyle is much more elevated than the entepicondyle. (3) In anconal view, the entepicondyle appears distally elongated. The humerus of typical dabblers is characterized by an entepicondyle that is generally as high as the ectepicondyle and never distally elongated. (4) The deltold crest is more rounded distally from the bend, instead of being angular as in typical dabblers. Features one, two, and three and also a robust shaft $(8.0$ per cent of total length), strongly oppose Delacour's suggestion (1956) of the possible affinities of Callonetta to the pochards (wherein the shaft varies from 6.0 to 7.0 per cent). In certain perching ducks (Nettapus, Cheniscus, and Amazonetta), and sea ducks (Histrionicus and Clanqula), however, the rotation of the condyles and thickness of the shaft resemble that of callonetta. Of these two tribes only the perching ducks have the open fossa found in Callonetta.

The affintties of Malacorhynchus are inconclusive from a study of 1ts humerus. The bone has the following characteristics. (1) The pneumatic fossa 18 closed as in the diving tribes. (2) The $\mathrm{rim}$ of the pneumatic fossa is ovaloid and lacks heavy bone, thus contrasting with typical perching ducks. (3) The facet for the anterfor articular ligament is elevated as in dabbling and perching ducks. (4) The rotation of the condyles, which results in the ectepicondyle being slightly higher than the entepicondyle, contrasts with the pochards. (5) The position of the pits for the muscles 
that attach to the internal surface of the entepicondyle resembles that found only in dabbling and perching ducks.

Bymenolaimus and Merganetta have several features in common that distinguish them from all other dabbling ducks. The fact that both genera habitually dive may account for their similarities. (1) The entepicondyle is less flaring and less extended distally. (2) The area for the attachment of the external head of the triceps is more deeply and broadly excavated. (3) The deltold crest is reduced and more rounded and thus less angular at the bend. (4) The biclpital crest joins the shaft at a much wider angle than in other dabblers. This is particularly true in Merganetta. (5) The internal tuberosity is less produced anconally, and possesses a distally directed flexure.

These two genera are best distinguished from each other by comparing the depth of the ligamental furrow. In Merganetta it is extremely shallow, more so than in any other anat1d; whereas in Hymenolaimus it appears to be of normal depth. The brachial depression, although not deep in Merganetta, covers a larger area than is characteristic of the tribe. Lastly, Merganetta has the facet for the anterior articular ligament less elevated than Hymenolaimus.

Rhodonessa has humeral characteristics intermediate between those of the dabbling ducks and the closely related pochards. The following features are worthy of note. (1) The shaft is intermediate in width $(7.0$ per cent of total length) between dabbling ducks (average 7.44 per cent) and pochards (average 6.33 per cent).

(2) The facet for the 
anterfor articular liganent is less elevated than in dabblers, but more elevated than in pochards. (3) The entepicondyle has a more prominent process on the anconal surface than in any other dabbling duck. In this respect Rhodonessa resembles the pochards, for when the humerus is viewed from the distal end with the palmar surface lying on a plane, the entepicondyle is more elevated than the ectepicondyle. The reverse is true of the dabbling ducks.

Tribe cairinint.

Perching Ducks

The most trenchant feature of perching-duck humeri pertains to the rim of the open pneumatic fossa. There is a definite trend in this tribe toward a reduction of the fossa to a restricted, circular opening rimed with heavy bone. In the extremely similar humeri of dabbling ducks the fossa becomes ovaloid by an upward extension into the internal tuberosity. The shaft of the humerus tends to be more robust in many species of perching ducks so that the range for the ava1lable genera (all but Asarcorn1s) 18 from 6.7 to 8.7 per cent of the total length, with an average of 7.81 . The ratio in the aberrant Plectropterus is 5.7 and 6.3 per cent.

Chenonetta, Nettapus, and Cheniscus are similar and can be distinguished from other perching ducks in several ways. (1) The proximal end of the humerus is inflected to give a more slgmold appearance of the shaft. (2) The prominent deltoid crest is more flaring and the head is seemingly less prominent. (3) The pneumatic fossa is more restricted. When the humerus is viewed from the internal side, down a 
Iine perpendicular to the shaft and passing through the internal tuberosity, the fossa can scarcely be seen. In other perching ducks one can normally see into the fossa when the humerus is so oriented. (4) The distal condyles are rotated so that in distal view the ectepicondyle is elevated above the entepicondyle. Sarkidiornis and Amazonetta also have this feature.

Nettapus and Cheniscus, whose humeri are indistinguishable on qualitative features, have the entepicondylar prominence distally produced, and the facet for the anterior articular ligament more flush with the shaft than does Chenonetta. Otherwise, the similarity between these three genera is striking.

Chenonetta, Nettapus, and Cheniscus share with Aix, Dendronessa, Cairina, and Pteronetta a difference in the form of the head as compared with other perchers. In these genera the depression formed by the external head of the triceps is indistinct along the internal edge of the external tuberosity, and blends with the external portion of the head. In Amazonetta and Sarkidiornis the depression is distinct and extends to the external tuberosity, as in the dabbling ducks.

Alx, Dendronessa, Cairina, and Pteronetta have additional similarities in the form of the humerus. The shaft is curved in these genera In contrast to Sarkidiornis, but the head is not inflected, in opposition to Chenonetta, Nettapus, Cheniscus, and Amazonetta. 
Calrina and Pteronetta differ from Aix and Dendronessa through greater overhang of the lip over the capital groove. Otherwise the humeri of these four genera are qualitatively extremely similar. Furthermore, all would be very difficult to separate from the typical dabblers if it were not for differences of the fossa, and the area of attachment of the external head of the triceps.

The humeri of $\underline{A}$ ix and Dendronessa prove indistinguishable.

A few minor differences associated with the proximal end exist between pteronetta and Cairina. (1) In Pteronetta the depression for the external head of the triceps extends farther laterally, whereas in Calrina there is an elevated area immediately medial to the external tuberosity. (2) In pteronetta the deltoid crest extends farther out the shaft than in Cairina. This is best realized by comparing its distal extent with that of the bicipital crest.

The humerus of Amazonetta can be distinguished from those of typical dabblers quite easily. Amazonetta has the same pronounced sigmold curvature of the shaft, with the flaring deltoid crest and inflected head as 18 found in Chenonetta aná Nettapus. Furthermore, there is a tendency In Amazonetta for the distal condyles to be rotated so that in distal view the ectepicondyle is elevated above the entepicondyle, as in callonetta.

Certain features of the humerus of Amazonetta show greater resemblance to the dabbling ducks than to the perching ducks. (1) The pneumatic fossa is ovaloid. (2) The 
depression for the external head of the triceps is excavated to the external tuberosity instead of blending with the head laterally. The humeral characteristics of Amazonetta leave its position in the Anatinae somewhat in doubt, but certainly it is generically distinct from Anas.

Sarkidiornis has the constricted, round pneumatic fossa that characterizes the tribe, but differs from typical perchIng ducks in having the depression for the external head of the triceps distinct and extending to the external tuberos1ty. Th1s is a feature of the dabbling ducks. Sarkidiornis differs from all other members of the perching ducks in that the shaft of the humerus is very straight. The species also has the distal portion of the external tuberosity elevated, with the result that the plane which passes through the area of pectoral attachment almost parallels the plane of the shaft. Furthermore, the bicipital crest is more rounded in Sarkidiornis thus meeting the shaft at almost a right angle. From the appearance of the humerus it seems doubtful that plectropterus should be assigned to the perching ducks. Several of the humeral features suggest a closer affinity to the sheldrakes. The head is rotated as in the sheldrakes. although the external tuberosity measures less than 89 per cent of the total height of the head in the two specimens available. Furthermore, there is a rather prominent capital shaft ridge directed towards the external tuberosity; another feature found in sheldrakes. As mentioned earlier, the shaft of the humerus tends to be thick in the perching ducks. The thin shaft of Plectropterus $(5.7$ to 6.3 per cent of the 
total length) falls outside the range for the perching ducks and the smaller measurement is even less than that found in the sheldrakes.

\section{Tribe Aythyini. Pochards}

The important differences between the pochards and the closely similar eiders and sea ducks are associated with the distal end of the element. The pochards have the following characteristics. (1) The impression for the brachialis anticus is usually a well-formed depression with the distal medial rim sharply defined. Stettenheim (1958) used this feature to distinguish Aythya from similarly-sized clangula and Lophodytes. (2) The distal condyles are rotated so that the entepicondyle is higher than the ectepicondyle when the palmar surface 1s lyling on a plane. As a result the palmar floor of the olecranal fossa lies almost parallel to the plane in the pochards, whereas in the elders and sea ducks a considerable angle is formed. The angle in elders and sea ducks results from pronounced rotation of the condyles in the opposite direction from that found in pochards. (3) In pochards the intercotylar furrow is essentially confluent with the olecranal fossa without the transverse ridge that forms a boundary in the elders and sea ducks.

With the exception of the closed pneumatic fossa, the humeri of Aythya are similar to humer 1 of members of the dabbling ducks. There are, however, two additional features that seem useful. (1) The shaft is relatively thinner, ranging from 6.0 to 6.9 per cent of total length (average 
6.33) than in typlcal dabblers in which the width of the shaft varles from 6.7 to 8.4 per cent (average 7.44 ) of the length. (2) The facet for the anterior art1cular 11gament Is less elevated.

Humer1 of species in the genus Aythya are extremely similar, varying significantly only in total length. For example, the width of the shaft and the width through the distal end, glven as percentages of the total length, range from 6.0 to 6.9 and from 13.9 to 15.3 , respectively, for 27 specimens of Aythya mar1la. The ranges for 45 specimens of seven other specles of Aythya fall within those obtained for the one species.

Metoplana and Netta, which posess open fossae, show their affillations to the genus Aythya In the shape and elevation of the anconal portion of the enteplcondyle. As previously mentioned, in distal view the entepicondyle is higher than the ecteplcondyle. In Metoplana (6.8 to 6.9$)$ and Netta (6.7 to 7.0$)$, the shaft is intermediate in width between Aythya (6.33 average) and the typical dabblers (7.44 average). Elevation of the facet for the anterior articular 11gament is also intermediate between the low one found in Aythya, and the high one found in the typlcal dabblers.

There are differences of generic magnitude between the humeri of Metopiana and Netta. In Metopiana the bicipital crest arises more abruptly from the shaft, and the head is more robust than in Netta. In Metoplana the head comprises from 7.6 to 7.8 per cent of the total length, whereas both specimens of Netta have a percentage of 6.6 . 
Tribe Somateriln1. Elders

Delacour and Mayr (1945) formerly placed the elders and sea ducks in one tribe. In his later work Delacour (1956) indicated that the affinities of the elders lie more with the dabbling ducks and placed them in a separate tribe near this group. Humphrey (1958a) published evidence in support of the change.

structurally the humert of elders and sea ducks are very similar. They differ from those of the dabbling ducks in a number of significant characters. (1) The pneumatic fossa is closed in elders and, with two exceptions, in the sea ducks. (2) The internal tuberosity is short and deep. (3) The facet for the anterior articular 11gament 18 lower. (4) The pit for the origin of the pronator longus extends farther proximally. (5) The pit for the origin of the pronator brevis is situated farther distally. The last three features serve to reduce the area occupled by the entep1condylar prominence, a trait characteristic of sea aucks. Delacour and Mayr (1945) placed the four eider species In one genus, Somater1a. Humphrey agreed that Lampronetta should be synonymized, but maintained that polysticta is generically distinct, a decision followed by Delacour (1959).

The form of the humerus supports this conclusion of Humphrey and of Delacour. No features of the humerus were found to separate Lampronetta from Somateria, but Polysticta is easily characterized. In the latter genus the distal end is much more strongly rotated. As a result the anconal portion of the external condyle is elevated above the 
entepicondyle. The only other ducks with a similar degree of rotation of the distal end are Clangula and Histrionicus of the sea ducks. Thus the distinctness of polysticta brought forth by Humphrey also points to a close relationship of the genus to certain sea ducks. Because elders and sea ducks are similar in the form of the humerus, the eiders will be included in the discussion of the sea ducks which follows.

Tribe Mergini. Sea Ducks

There is a great deal of variation in the form of the humerus in sea ducks. Two features which are quite obvious and, In addition, seem to have phylogenetic significance are the degree of rotation of the distal condyles and the shape of the deltoid crest.

Histrionicus and Clangula, which Delacour and Mayr once belleved occupied a central position among sea ducks ("They lead to the scoters and elders on one side and to the goldeneyes and mergansers on the other. "), and Polysticta of the elders are the only genera in the group that show extreme rotation of the distal condyles. In distal view even the anconal portion of the external condyle 18 elevated above the entepicondyle.

Polysticta differs from Clanqula, and particularly 뵤strionicus, in having greater excavation of the humeral head for the external head of the triceps. The degree of excavation in Polysticta is matched only by Bucephala. 
Clangula differs from Histrion1cus, and most other genera, in that the entepicondyle is produced distally.

The deltoid crest in scoters (Melanitta and oldemia) and In mergansers (Lophodytes, Mergellus, and Mergus) is characteristic in each of these groups. In scoters, in distinction to elders and other sea ducks, the deltold crest extends farther distad, and 1ts distal portion 18 more flaring. In addition, the crest maintains a sharp edge to the most proximad point of the external tuberosity, whereas in other genera, and particularly the elders, the crest ends before reaching the external tuberosity. In lateral view, the crest in scoters is gently curved, without the more proximal, sharper bend found in other genera.

Oldenla differs from Melanitta only in the relative width through the distal condyles. In oldemia this measurement varies from 13.9 to 14.4 per cent of the total length; In Melanitta the range 1814.5 to 15.8 per cent.

In mergansers the deltold crest is large and sharply angular. Typically, when the humerus of a merganser is placed palmar surface down on a plane, only the angle in the midale of the crest touches the surface. This contrasts sharply with the humerus of the closely related Bucephala, In which the deltold crest 18 small and rounded at the bend.

Mergellus is the most distinct of the merganser genera, according to qualitative features of the humerus. The deltold crest, although angular, is not as large as in Mergus and Iophodytes. Furthermore, the pneumatic fossa is closed, whereas it is always open (Mergus), or almost always open 
(Lophodytes) In the others. Mergellus differs from the similarly-sized Lophodytes in still other ways. The relative width of the shaft is 6.4 per cent of the total length in Mergellus, in zophodytes the range is from 7.1 to 7.7 per cent. In the relative width of the distal condyles Mergellus is 14.4 per cent of the total length, In Lophodytes the range is 15.6 to 17.3 per cent.

Other than size the most obvious feature for separating Lophodytes and Mergus is the shape of the humeral shaft. In Lophodytes, in anconal view, the shaft is distinctly more sigmold than in Mergus, In which it is straighter than in most other ducks.

The humer1 of the two species of Merqus examined are rather easily separated by the width of the shaft relative to Its total length (Wetmore, 1948). Four specimens of ㅆ‥ merganser range from 7.0 to 7.3 per cent. In 17 specimens of ㅆ. serrator the range 185.6 to 6.9 per cent.

Bucephala differs from Somaterla and Lampronetta in having greater curvature of the shaft, and a more restricted, closed pneumatic fossa. In Somaterla, although the fossa is closed, it is rather deep.

Tribe oxyurint.

\section{Stiff-talled Ducks}

The humerus of the stiff-tailed ducks Indicates the tribe is a very distinct one among the Anatinae. Howard (1946) commented on the ease with which oxyura lamaicensis can be distinguished from all other [North American] ducks, and this species has many features in common with the other 
genera assigned to the tribe. The tribe is unique in the following ways. (1) The pneumatlc fossa is shallow, barely reaching the head, and has numerous foramina piercing the walls. In other ducks the fossa may be closed or open, but if closed it is not as shallow, nor is it plerced by an abundance of foramina. (2) The scar for the latissimus dorsi posterioris lies essentially in line with the outer edge of the pectoral attachment. In all other Anatidae the scar lies far mediad to the outer edge of the pectoral attachment. (3) The entepicondyle $1 \mathrm{~s}$ reduced, as is the pit for the flexor carpi ulnaris.

Oxyura possesses the following unique features. (1) The surface for the external head of the triceps 1 s deep, and broady excavated. (2) The distal portion of the external tuberosity is elevated so that the surface for pectoral. attachment lies in a plane that almost parallels the plane of the shaft. (3) The shaft is thin (5.2 to 6.0 per cent of the total length). (4) The facet for the anterior articular ligament 1 s only slightly elevated from the shaft, and is distinctly turned towards the internal edge of the element. (5) The external condyle has a ridge extending toward the brachial depression.

Nomonyx appears less speclalized than oxyura. It may be distinguished from the latter as follows. (1) The internal tuberosity is elongate instead of very short. (2) The facet for the anterior articular ligament is more elevated and faces palmad instead of internally. (3) The depression for the external head of the triceps is less excavated. 
(4) The distal portion of the external tuberosity is less elevated and therefore less distinct from the shaft. The one available complete humerus has the shaft thin (6.0 per cent of total length), but thicker than in most of the 13 specimens of oxyura.

B1zlura, as shown by the form of the humerus, 1s definitely a stiff-talled duck. (1) The pneumatic fossa is shallow and perforated. (2) The distal portion of the external tuberosity is elevated from the plane of the shaft. (3) The shaft $1 \mathrm{~s}$ thin (5.5 per cent of the total length). (4) The facet for the anterior articular ligament is turned towards the internal edge of the element.

Abundant features of generic magnitude occur on the humerus of B1zlura. (1) The depression for the external head of the triceps is restricted to an area well below the head and mediad to the capltal shaft ridge. Thus the head blends in with the shaft instead of being delimited by a distinct $11 \mathrm{p}$ as in oxyura. (2) The external tuberosity has the distal portion even more elevated than in oxyura, and as a result, the area of pectoral attachment is more rounded and less elongate than in other genera. The external tuberosity 1s further accentuated because the proximal portion of the deltoid crest is bent inward under the tuberosity. (3) The scar for the latissimus dorsi posterioris lies largely distal to the bicipital crest. (4) The ectepicondyle is greatly reduced, without the groove between it and the external condyle which 18 present in all other ducks. (5) The entepicondyle is very small, and on the internal edge only one large 
pit is evident. (6) The brachial depression 18 broad and rounded distally. In other stiff-talls the distal end of the depression is usually pointed. (7) The ridge extending from the palmar tip of the external condyle, described above for oxyura, 18 indistinct.

There is strong evidence that the genus Heteronetta is properly classified when placed with oxyura, Nomonyx, and B1zlura. The humerus has the trenchant characteristics of the tribe, namely the shallow, abundantly perforated, pneumatic fossa and the laterally situated scar for the latissimus dorsi posterioris.

The degree of development of certain of the features of Heteronetta indicate it is the least specialized member of the tribe. (1) The entepicondyle is reduced, but not to the extreme exhibited by oxyura and Blzlura. (2) The shaft is thin ( 6.3 per cent of total length), but thicker than in any other stiff-tail. (3) The facet for the anterior articular ligament is low, but not as low as in other stiff-talled ducks. (4) The plane of the surface for the pectoral attachment is inclined to the plane of the shaft, more as in Anatinae other than the stiff-talled ducks. (5) The area of attachment of the external head of the triceps 18 reduced and blends in with the head, and 1t lacks the depression or overhanging $11 p$ of the other stiff-tails. (6) The scar for the latissimus dorsi posterioris is situated laterad, but not as far as in other stiff-tails.

The stiff-tailed ducks, including Heteronetta, are a very distinct group, but the latter genus gives indication, 
from the structure of the humerus, of being a link to some other tribe, possibly the dabbling ducks.

\section{Carpometacarpus}

The carpometacarpus is very useful taxonomically because of its many articulating surfaces and muscular attachments.

\section{Anseranatinae}

The carpometacarpus of Anseranas possesses several characteristics that distinguish it from those of all other waterfowl. (1) The carpal trochlea has the lower portion of the external $\mathrm{rim}$ unnotched. In all other anatids the outer $\mathrm{r} 1 \mathrm{~m}$ is distinctly notched below. (2) A large pneumatic foramen Is present in the internal 11gamental fossa. A similarly situated foramen is present in other waterfowl, but none have it as large. (3) The process of metacarpal I is amall. (4) Metacarpal II curves upward distally more than in other waterfowl. (5) The facet for diglt II is wider and has a more extended lower, lateral process in correspondence with feature 4. (6) Metacarpal III is more curved throughout its length, particularly distally. (7) Metacarpal III is ungrooved on the lower proximal surface. (8) The facet for diglt III protrudes farther distally. In most other anatids this facet does not extend beyond that for digit II.

\section{Ans erinae}

Two traits seem characteristic of the Anserinae. (1) The upper surface of metacarpal II, and part1cularly 
the distal half, is flat; and the angle formed with the external surface is correspondingly rather sharp. In the Anatinae the upper surface is rounded, without sharp angles. (2) The extensor attachment is confined to the tip of the short, but high, process of metacarpal I. In the Anatinae the extensor attachment is longer and extends distally onto the distal edge of the process.

Tribe Dendrocygnint.

Whistling Ducks

The thin, elongate carpometacarpus of whistling ducks has the following three features to distinguish it from those of all other anatids. (1) Metacarpal II in dorsal view 18 strikingly incurved. (2) The external rim of the carpal trochlea is only slightly notched. In all other anatids, except Anseranas, the external rim is notched distinctly. This character may be evidence of the primitive position of the whistling ducks. (3) A prominent neck 1s present between the carpal trochlea and metacarpal III.

Tribe Anserini. Swans and Geese

The carpometacarpus of swans and geese agree in the following characteristics. (1) Metacarpal III has a distally progressive rotation toward the medial side. (2) The pollical facet has a small lateral articulating surface.

Swans may be distinguished from geese by several traits. (1) In lateral view the external rim of the carpal trochlea slopes sharply downward from the process of metacarpal I. In geese the angle between the posterior edge of the process 
of metacarpal I and the upper, external $\mathrm{rim}$ of the carpal trochlea is smaller. (2) The pit on the Internal side below and distal to the pisiform process is separated by a raised area from the intermetacarpal space. (3) The process of metacarpal I is lower and has a proximal edge that usualiy slopes toward the carpal trochlea. In geese the process is higher and the proximal edge is nearly perpendicular to the shaft. (4) Matacarpal II has only a slight depression on the external surface inmediately proximal to the facet for digit II; in geese the depression is deeper. (5) The external rim of the facet for digit II is widely rounded; in geese this edge is almost straight.

Coscoroba resembles the true strans in all five characteristics discussed above. It can be separated from them by differences in the lower, distal portion of the carpal troch1ea. (1) The cuneiform fossa (Brodkorb, 1958b), which lies between the rims of the carpal trochlea distally, is delimited proximally by a ridge that extends medlally from the external rim of the carpal trochlea. In true swans the ridge is lacking and the fossa extends proximally between the two rims.

Howard (1946) listed three criterla for separating the carpometacarp1 of $010 x$ and cygnus; all are very weak as indicated by the series of specimens available to me. These are 11 sted in a sequence of decreasing usefulness. (1) cygnus has the external crest of the trochlea short, and the lobe at its distal edge appears aborted in comparison with olor. (2) cygnus has the process of metacarpal I straighter and more evenly swollen at the tip, whereas in 이으 the 
process inclines more definitely toward the inner side.

(3) Cygnus has the area below the pisiform process excavated Into a distinct pltlike depression, the posterior rim of which is marked. In 이을 the area is roughened, sometimes depressed, but it tends to slope away toward the posterior face without an intervening rim.

Additional criteria were found more useful in the present series. (4) The cunelform fossa is deeper, and has a distinct proximal and medial rim in cygnus. In olor the $\mathrm{rim}$ is indistinct, the fossa gradually inclining to the surroundIng areas. (5) Metacarpal I has a deeper depression on the external surface immediately proximal to the facet for digit II in cygnus, and thereby more closely resembles geese. In olor this area is noticeably shallower. Chenop is is similar to Cygnus in all of the characters discussed above.

No criteria of the carpometacarpus are apparent to enable qualitative separation of the several genera of true geese. Furthermore; the shorter, broader facet for digit III attributed to Chen (M11ler, 1937) does not hold.

The true geese have considerable external resemblance to several genera assigned to the sheldrake tribe by Delacour and Mayr (1945). There are, however, a number of features of the carpometacarpus that support the allocation of these superficially gooselike species to a position near the sheldrakes Tadorna and Casarca, as well as the other duck genera.

The following four characteristics of geese serve to separate them from the sheldrakes.

(1) The external rim of 
the carpal trochlea has the upper portion extending proximally before curving downward.

(2) The external $\mathrm{rim}$ of the carpal trochlea is shallowly notched below. In sheldrakes the notch is noticeably deeper, as is generally true of all ducks. (3) The internal rim of the carpal trochlea is less rounded and usually grades more smoothly into the ridge of bone lying distal to $1 t$. In sheldrakes the more rounded $r$ in falls off sharply. (4) The process of metacarpal I is lower, the height through the process ranges from 19.7 to 24.4 per cent of the total length of the carpometacarpus. In sheldrakes the process is typically higher (23.3 to 28.6 per cent), a feature that Miller (1937) used to separate Chlotphaga from the North American genera of true geese.

The process of metacarpal I frequently has a rugose cap in both geese and sheldrakes. Shufeldt (1892) attributed the condition to disease. Miller (1937) felt that a pathological origin was unlikely because it occurred so frequently. Fighting with the wings is a trait common to many waterfowl, and it seems probable that the occurrence of the knob can be correlated with such behavior. Chloephaga, Alopochen, and Neochen almost always have the knob, and all were 11sted as very quarrelsome by Delacour and Mayr. Caps were also found on the carpometacarpi of Cygnus, Chenopis, Branta, Anser, Tachyeres (large), Mymenolaimug (large), Merganetta (large), and Sarkidiornis.

Two genera, Merganetta and Plectropterus, have developed carpal spurs (Rand, 1954), and the latter is known from captivity to be aggressive. In addition to a metacarpal I 
process seemingly designed for a spur, one specimen of Merganetta, listed as a juvenile male (U.S.N.M. 346808) possesses a sharp claw, three millimeters in length, on the tip of the pollex, a fact apparently unrecorded in the literature (Fisher, 1940).

\section{Anatinae}

The Anatinae can be distinguished from the Anseranatinae and Anserinae by the following two carpometacarpal features. (1) The upper surface of metacarpal II 1s rounded, without sharp angles. (2) The extensor attachment on the tip of the process of metacarpal I is longer and extends distally onto the anterlor edge of the process (a weak character for sheldrakes).

With the ducks the most critical region of the carpometacarpus is the external surface of the trochlea. The shape and location of the attachments for two ligaments and the ridges on the bone associated therewith are particularly significant. Howard (1929) labeled an external ligamental attachment on her drawings. In waterfowl the ligament attached thereon extends to the cunelform (ulnare). Another place of ligamental attachment lies distal to the aforementioned one; a ligament extends from here to the scapholunar (radiale). The external scapholunar ligament crosses over the external cuneiform 1 igament.

According to Delacour's classification (1954, 1956, 1959) there are seven tribes in the Anatinae. Features of the carpometacarpus separate the subfamily into five groups: 
(1) sheldrakes, (2) dabbling and perching ducks, (3) pochards, (4) eiders and sea ducks, and (5) stiff-talled ducks. Although the carpometacarpl of dabbling and perching ducks (group 2), pochards (group 3), and eiders and sea ducks (group 4) are very similar, combinations of the characteristics IIsted at the beginning of each should make possible the proper determination of all specimens, assuming comparative material is available.

Tribe Tadornini.

\section{sheldrakes}

Sheldrakes have three features of the carpometacarpus that distinguish them from other ducks. All three features are common to the true geese, perhaps an indication of an intermediate position of the sheldrakes between the geese and ducks. (1) The external scapholunar ligamental attachment is broad, usually prominent, and situated higher and more distad than in other ducks. It always lies distal to the ridge that extends from the external cunelform ligamental attachment to the proximal fornix (the point of fusion of metacarpal II and III proximally). (2) The lobe at the distal end of the external rim of the carpal trochlea is lar ger. (3) The process of metacarpal I is higher, shorter, and frequently has a rugose cap.

The carpometacarpus of Cereopsis resembles those of the true geese. Two unique features distingulsh the specles. (1) In the process of metacarpal I the proximal edge slopes forward, and the distal edge is more concave, so that the 
tip is more pointed. (2) The distal metacarpal symphysis is approximately twice as long as that found in geese.

With Cereopsis removed because of its resemblance to the true geese, there remain three major groups within the sheldrakes. Chloëphaga, Alopochen, and Neochen form one group; Tadorna and Casarca another; and Tachyeres the third. No qualitative features separating Casarca from Tadorna are evident, but the two as a unit can be distinguished from Chloerphaga, Alopochen, and Neochen by a combination of characteristics. (1) The process of metacarpal I 18 lower, thinner in proximal view, nearly perpendicular to the shaft, and usually without a rugose cap. In the other three genera the process is higher, thicker, bent proximally, and frequently it possesses a rugose cap. (2) The cunelform fossa is longer, extending proximally beyond the lobe that marks the distal extent of the external rim of the carpal trochlea. In the others the fossa ends rather abruptly at a point opposite the lobe. (3) The tuberosity of metacarpal II is more prominent in dorsal view, and does not rise up from the shaft as high in the three gooselike genera. (4) The facet for digit III falls decidedly short of the facet for digit II. In the other three genera the two facets are almost equal in distal extent.

Alopochen seems the most distinct of the three gooselike genera. The following features set it apart from the other two. (1) The external surface situated below the external cuneiform ligamental attachment is deeply grooved. (2) The anterior carpal fossa is shallow. In Chloephaga 
and Neochen the anterior carpal fossa forms an obvious pit at the edge of the carpal trochlea. (3) The flexor attachment is more distal. In the other two genera the flexor attachment 11es farther proximad. A ratio of the distance to the midpoint of the flexor attachment from the proximal end divided by the carpometacarpal length ranges from 27.5 to 30.3 per cent with only one specimen of elght having a greater percentage than 29.3. The same ratio ranges from 29.5 to 31.4 in three specimens of Alopochen.

Although the three genera of goosellke sheldrakes are very similar, Neochen seems slightly closer to Chloephaga. The flexor attachment rat10 $1 \mathrm{~s} 28.6$ per cent for the one specimen, and the anterior carpal fossa is deep. The groove below the external cunelform 1 igamental attachment, however, seems deeper than in most specimens of Chloesphaga.

Delacour (1954) included Tachyeres in the sheldrakes, but it differs from that tribe in two dignostic features of the carpometacarpus. (1) The external scapholunar 11gamental attachment 11 es on the diagonal ridge that passes from the external cunelform ligamental attachment to the proximal fornix. In sheldrakes the attachment 11 es distal to the ridge. (2) The lobe at the distal end of the external rim of the carpal trochlea is essentially lacking. All true sheldrakes have a prominent lobe. In Tachyeres the process of metacarpal I is long as in most ducks. The process appears high, as in sheldrakes, but this may be due to foreshortening of the element, correlated with a flightless condition. Although a rugose cap is present as is typical of 
sheldrakes, this condition is found sporadically throughout the Anatidae.

Tribes Anatini and Cairinini. Dabbling and Perching Ducks

(1) The distal portion of external rim of the carpal trochlea has a noticeable prominence, but it is usually smaller than that found in eiders and sea ducks. The lateral outline of the area is convex. (2) The cuneiform fossa is deeper than in pochards, but usually shallower than in eiders and sea ducks. (3) The external scapholunar ligamental attachment is prominent and larger than in pochards, and usually lies on a conspicuous ridge that extends from the external cuneiform ligamental attachment to the proximal fornix. (4) The flexor attachment extends distally beyond the proximal fornix. The extent of the proximal end of the flexor attachment is variable. (5) The process of metacarpal I is higher and straighter than in eiders and sea ducks.

Tribe Anatini.

Dabbling Ducks

Features of the carpometacarpus do not support the recognition of Chaulelasmus, Mareca, and Spatula as distinct genera. Some differences do occur, but none was found that has a high constancy. Many characters that appear useful in a small series break down when additional specimens are compared. Sixteen specimens of Mareca were compared with seven of Chaulelasmus, five of Spatula, and over forty of numerous species of Anas. Mareca is the most distinct of the three, some specimens being assignable without comparative study. 
The straight, robust shaft and the recessed condition of the facet for dig1t III are the best criteria. However, not all the specimens could be 1dentifled even with the ald of comparative material.

Wetmore (1944) and Brodkorb (1958a) mentioned that the carporetacarpus of Anas (Nettion) carolinens1s can be separated from that of Anas (Querquedula) discors as follows. (1) Nettion has the anterior carpal fossa very shallow, whereas it 18 deeply excavated in Quercuedula. (2) In Nettion the length of the distal metacarpal symphysis $1 \mathrm{~s} 6.0 \mathrm{~mm}$. or less, whereas in Querquedula it $1 \mathrm{~s}$ approximately $7 \mathrm{~mm}$. or more. The feature pertaining to the depth of the anterior carpal fossa readily separates 17 of 25 specimens (Nettion 9, Querquedula discors 10, ‥ cyanoptera 3, … querquedula 3), but for three of these (Nettion 2, ․ discors 1) the character is reversed, and in five others 1 appears intermediate. It is difficult to be certain how Wetmore measured the distal metacarpal symphys1s, but some of the avallable specimens of Querquedula apparently measure less than $7 \mathrm{~mm}$., so even this character is not entirely constant.

Qualitative features of the carpometacarpus indicate that four of the avallable genera of dabbling ducks are distinct from Anas, namely Callonetta, Malacorhynchus, Hymenolaimus, and Merganetta.

Callonetta has three distinctive features. (1) The process of metacarpal I has its distal edge sloping sharply proximally, and has only a small attachment surface at the t1p. (2) The base of metacarpal III is narrower in ventral 
view. (3) The external rim of the carpal trochlea is slightly longer and narrower.

Malacorhynchus also has three criteria that distinguish it from typical dabblers. (1) The process of metacarpal I appears decidedly shorter in lateral view and has only a small extensor surface. (2) The base of metacarpal III is very narrow and does not extend laterally around the cuneiform fossa. (3) The shaft of metacarpal II is noticeably thinner in dorsal view.

Bymenolaimus is very different from other dabbling ducks. (1) The internal rim of the carpal trochlea is enlarged: it curves farther downward and is thicker. (2) The groove between the rims of the carpal trochlea and the cuneiform fossa is very deep. (3) The external scapholunar ligamental attachment is larger and situated farther distally. In this respect Hymenolaimus resembles the sheldrakes. (4) The external portion of the base of metacarpal III fuses with metacarpal II farther distad. (5) The tuberosity of metacarpal II is reduced. (6) The facet for digit III is enlarged with the lateral end bent downward and both ends extended distally. (7) A rugose knob is present on the process of metacarpal $I$. Although present in many distantly related waterfowl, a knob is most typical of the sheldrakes. The very short carpometacarpus of Merganetta resembles that of pymenolaimus in a number of features. Since both are inhabitants of mountain streams, convergence of some features might be expected. The following characteristics distinguish the genus. (1) Both rims of the carpal trochlea 
are enlarged, and especially the internal one; they curve farther downward, and the internal rim is thickened. (2) The groove between the rims of the carpal trochlea and the cune1form fossa is very deep. (3) The base of metacarpal III is narrower and does not extend as far laterad. (4) The tuberosity of metacarpal II is greatly reduced. (5) The facet for digit II has the external edge more rounded. (6) The facet for digit III is distally produced. (7) The process of metacarpal I is larger, curves sharply proximad, and sometimes has a large knob.

Tribe Calrinini. perching Ducks

The perching ducks are only weakly differentiated from the dabblers. Two features of the carpometacarpus are somewhat useful in separating the tribes. (1) The external scapholunar ligamental attachment tends to be obscure. (2) The process of metacarpal I tends to be higher, shorter, and straighter.

Features of the carpometacarpus of plectropterus ind1cate the genus is a sheldrake and not a perching duck. (1) The external scapholunar ligamental attachment is situated distal to the ridge that passes from the external cune1form ligamental attachment to the proximal fornix. This feature is typlcal of the sheldrakes. (2) The lobe at the distal end of the external rim of the carpal trochlea 18 large. In ducks other than sheldrakes the lobe is small or absent. 
Although plectropterus does not have the enlargement of metacarpal I typical of the sheldrakes, a process of the scapholunar (f1gured in Rand, 1954) serves its quarrelsome nature.

On the basis of carpometacarpal features, the two most distinct of the remaining genera are Sarkidiorn1s and pteronetta. Calrina, Chenonetta, A1x, and Dendronessa are all very similar to each other.

Sarkidiornis can be characterized as follows. (1) Metacarpal I 18 located farther distad with 1ts highest point above the pisiform process. In other perchers the peak is proximal to the pisiform, and the anterior carpal fossa more extensive. (2) The external rim of the carpal trochlea 18 rounded proximally. In the others the rim tends to be accuminate, the point occurring immediately proximal to the external cunelform ligamental attachment. (3) The groove on the external surface below the external cuneiform ligamental attachment is deeper.

Pteronetta is rather easily distinguished from other perching ducks, including Cairina. (1) The process of metacarpal I is higher. (2) The curve of the internal rim of the carpal trochlea is situated so that the lowest point underlies the pisiform process, whereas in the others the lowest point is more proximal.

The large, robust carpometacarpus of calrina has one distinctive feature. The process of metacarpal I is slightly excavated by a depression that lies along the external edge of the base. 
No qualitative features useful in distinguishing Aix, Dendronessa, and Chenonetta were found.

Nettapus and Cheniscus, for which I find no mutually exclusive characteristics, differ from other perching ducks in the following way. (1) The prominence proximal to the external cuneiform ligamental attachment is higher and extends proximally to the posterlor $x 1 \mathrm{~m}$. In other perchers it is lower and 1 t terminates distal to the proximal $\mathrm{rim}$.

Features of the carpometacarpus of Amazonetta strongly support 1 ts recognition as a genus distinct from Anas. The process of metacarpal I 18 higher and straighter, a feature characteristic of the perching ducks. In addition, the external $\mathrm{r} 1 \mathrm{~m}$ of the carpal trochlea appears longer and narrower than in Anas. In order to separate Amazonetta from other perchers, as well as the dabblexs, the following feature is useful. The facet for dig1t III is reduced in size and recessed; and thus 1t does not extend distally as far as the facet for digit II.

Tribe Aythyin1. Pochards

The carpometacarpus of pochards is rather distinct; it has the following characteristics. (1) The distal portion of the external rim of the carpal trochlea $1 \mathrm{~s}$ usually without a swelling, and generally so greatly reduced that the outline in lateral view is concave. (2) The cuneiform fossa 1s shallow. (3) The external scapholunar 1 Igamental attachment is usually prominent, but small. The diagonal ridge from the external cuneiform ligamental attachment to the 
proximal fornix is usually obscure. (4) The flexor attachment always lies entirely proximal to the proximal fornix. (5) The process of metacarpal I is high and straight as in the dabblers.

Metoplana and Netta are near Aythya, especially as indicated by the position of the flexor attachment, but certain features of the carpometacarpus indicate an intermediate position between Aythya and the dabblers. (1) The bone is shorter and more robust than in Aythya. (2) The process of metacarpal I is straighter. In Aythya the process curves more proximad. (3) The distal portion of the external rim of the carpal trochlea is more prominent. The area is more reduced in Aythya. (4) The region on the external surface, situated proximal to the external cunelform ligamental attachment, is larger. In Aythya th1s area is much reduced. The carpometacarp1 of Metoplana and Netta are very $81 \mathrm{~m}-$ 1lar, but the following qualitative feature will separate most individuals. The tuberosity of metacarpal II, and the external $\mathrm{rim}$ of the facet for digit II in dorsal view are produced farther laterally in Metopiana than in Netta.

It is indeed unfortunate that no carpometacarpus of Rhodonessa is avallable since features of the humerus indicate that the genus belongs with the pochards and not with the dabblers.

Tribes Somateriin1 and Mergini. E1ders and Sea Ducks

Elders and sea ducks form a group easily distinguished from the pochards. It seems more closely related to the 
dabblers and in particular to the perchers. The carpometacarpus has the following characteristics. (1) The distal portion of the external rim of the carpal trochlea has a prominent swelling that is usually larger than in dabblers and perchers. (2) The cunelform fossa 1 s deeper than in the other groups, and it frequently excavates under or around the internal rim of the carpal trochlea. (3) The external scapholunar 11gamental attachment $1 \mathrm{~s}$ obscure, and the diagonal ridge is frequently absent. (4) The flexor attachment is variable with the genera. (5) The process of metacarpal I is lower, wider, and curved proximally. This feature 18 not useful for separating Bucephala, Lophodytes, or Mergellus, but is extremely useful for the other genera. The carpometacarp1 of 70 specimens of eiders and sea ducks were examined. Two basic facts were revealed: (1) the elders show greater similarity to the sea ducks, and part1cularly to the scoters and Histrionicus, than to the dabblers; and (2) the most obvious division of the genera is into two units, one contalning Bucephala and the mergansers, the other the elders, scoters, Histrionicus, and Clangula. Th1s same division is also evident from features of the humerus.

The important features for separating the two units are found in the process of metacarpal $I$, and in the position and shape of the pollical facet. In Bucephala and the mergansers the process tends to be higher, and the extensor attachment on the tip is shorter. In the other group of genera the process is lower, longer in lateral view, and the extensor attachment extends down the sloping distal edge of 
the process. These features are most distinct in Bucephala, Lophodytes, and Mergellus at one extreme, and Clangula at the other. Some specimens of Mergus are very similar to certain scoters and eiders, but the inclusion of the followIng criterion should result in 100 per cent separation. In Bucephala and the mergansers the pollical facet lies in line with or proximal to the internal $\mathrm{rim}$ of the carpal trochlea. In the other genera the pollical facet lies distal to the internal rim of the carpal trochlea. Furthermore, Bucephala and the mergansers have only a small lateral lobe on the pollical facet, best compared in proximal view, whereas in the other genera the lobe is larger and has a prominent pit or groove between it and the shaft of metacarpal II.

With some features the division within the Bucephala and merganser group appears to lie between Bucephala and the mergansers, but for other criteria the break occurs between Mergus and the other three genera. This is the case with humeral features and it indicates that Bucephala and the mergansers have been previously placed in separate taxa only because of plastic features such as the shape of the bill.

As explained above, there is a basic difference between the shape of the process of metacarpal I in the two units within the sea ducks. Within the Bucephala and merganser group, where the shape is basically the same, there is a significant difference in the relative height of the process. In 18 specimens of Bucephala, Lophodytes, and Mergellus the range for the height through the process of metacarpal I is 22.5 to 23.9 per cent of the total length of the bone. 
Nineteen specimens of Mergus ( $17 \underline{M}$. serrator, $2 \underline{M}$. merganser) range from 21.0 to 22.6 per cent, except for one adult male M. serrator which measures 17.9 per cent. Only one individual of the latter group overlaps the minimum for the other genera. Fourteen of the 17 avallable specimens of $\underline{M}$. serrator are from Florida, and all of these are Immature birds. It seems ikkely that the ratio would be even more significant 1f the sample were not biased in respect to age.

The small size of the lobe at the distal end of the carpal trochlea separates Bucephala from the mergansers. In Lophodytes, Mergellus, and Mergus the lobe is large. An additional feature useful for separating Bucephala from Mergus is the structure of the plsiform process. In proximal view it curves sharply upward in Bucephala, forming a deep groove for the flexor digltorum profundus. In Mergus the pisiform process is directed medially, forming more of a shelf than a groove. Specimens of Lophodytes and Mergellus are intermediate for this feature.

With Mergus distinguished by the relative height of the process of metacarpal. I, the best characters for separating Bucephala from Lophodytes and Mergellus are: (1) the feature pertaining to the external rim of the carpal trochlea mentioned above, and (2) the shape of the facet for digit II. In Bucephala the external portion of the facet for digit II is larger and extends farther down into the groove between the facets for digits II and III. In Lophodytes and Mergellus it is smaller and does not extend down as far. 
No valld feature for separating Mergellus from Lophodytes was found on the carpometacarpus.

of the remaining members of the elder and sea duck group, Clangula seems the most distinct. It has the followIng characteristics. (1) The process of metacarpal I 1s very low, with the distal edge thick and curving sharply proximally. (2) The carpal trochlea is depressed, the external $\mathrm{rim}$ forming only a slight angle with the trend of the shaft, and the internal rim has only a relatively small depression between $1 t$ and the base of metacarpal III. (3) The pit distal to and below the pisiform process is very deep. (4) The tuberosity of metacarpal II is situated more med1ally, and as a result the external edge of the facet for digit II appears more rounded. (5) The shaft of metacarpal II is robust ( 7.8 to 8.8 per cent of the total length). The range for the others is 6.5 to 7.9 , except for Histrionicus which measures 8.0 per cent.

Two character 1stics of the elders separate them from the scoters and Histrionicus. (1) The flexor attachment is nearly twice as long as in the others, and is situated farther distad. (2) The upper surface of the shaft of metacarpal II in medial view is arched.

The carpometacarpus of Lampronetta appears indistinguishable from that of Somaterla, but polysticta differs from both in the following ways. (1) The notch in the external $\mathrm{rim}$ of the carpal trochlea is smaller in ventral view. (2) The lobe immediately distal to the notch is smaller. (3) The cuneiform fossa is shallower. 
The carpometacarpus of oidemia is slimmer than that of Melanitta (width of metacarpal II relative to the total length 6.5 to 7.1 per cent in o1demia, 7.0 to 7.9 per cent In Melanitta), but otherwise it appears indistinguishable from that genus.

Histrionicus has a thick shaft of metacarpal II 18.0 per cent of the total length), and a larger lobe at the distal end of the external rim of the carpal trochlea.

Tribe oxyurini.

Stlff-tailed Ducks

The stiff-tailed ducks are the easiest of the Anatinae to define on the basis of the carpometacarpus. (1) The distal margin of the internal rim of the carpal trochlea appears nearly parallel to the shaft in ventral view. In the others the rim is deflected laterally. (2) Metacarpal III is narnower at the base. In members of the other three groups metacarpal III widens at the base, and thus reaches, or virtually reaches, the external side of the element. (3) The area on the external surface below the external ligamental attachments is deeply grooved. Although a groove is present in other ducks it is not nearly as deep. (4) The facet for digit II is narrow, crescent-shaped, and has the lower margin concave (Heteronetta is an exception). In the other ducks the facet is broader, and the lower marg in is nearly straight.

Features of the carpometacarpus strongly support the close relationships of Heteronetta, Nomonyx, oxyura, and B1ziura proposed by Delacour (1959). 
Heteronetta is the least specialized member of the tribe. The features that separate it from the other stifftalls are generally those found in other ducks. (1) The process of metacarpal I is higher, and in lateral view, noticeably narrower. (2) The distal margin of the internal rim of the carpal trochlea is deflected laterally in ventral view. In other stiff-talls the process is nearly parallel to the shaft; in other tribes it is even more deflected than in Heteronetta. (3) The facet for digit II is broadly rounded externally and has the lower margin straight. (4) The tuberosity of metacarpal II 1s smaller. (5) The prominence on the Internal edge of the base of metacarpal III is situated nearer to the proximal fornix. In other stiff-talls it lies more proximad.

Nomonyx resembles oxyura less than it does Bizlura in features of the carporetacarpus. It can be separated from these two genera by the following features, all of which seem to indicate a lesser degree of specialization. (1) The process of metacarpal I is noticeably narrower in lateral view. (2) The distal margin of the internal rim of the carpal trochlea in ventral view has a slight lateral deflection greater than that found in the oxyura and B1ziura but less than in Heteronetta. (3) The tuberosity of metacarpal II is smaller. (4) The external $\mathrm{xim}$ of the carpal trochlea is not as deeply grooved as in other stiff-talls.

Blzlura has the following carpometacarpal features to separate 1t from oxyura. (1) The external rim of the carpal trochlea 1s extremely deeply grooved, more so than in all 
other anatids, so that the bottom of the cunelform fossa can be seen in lateral view. (2) The distal portion of the internal rim of the carpal trochlea is thickened. In oxyura the rim is of uniform thickness throughout. (3) The tuberosity of metacarpal II curves more laterad.

\section{Sternum}

The sternum has recelved an exaggerated amount of attention from avian taxonomists. It is not as useful as the humerus, carpometacarpus, or coraco1d; however, some features of phylogenetic significance do occur.

Certain structural features of the sternum and pectoral girdle may be better understood by reference to the ligaments described in the Appendix.

The posterior margin of the sternum varies considerably. Most Anatidae have sternal notches, but in a few genera the notches are characteristically ossified posterlorly to form fenestrae. Other genera may, on occasions, have one or both notches so enclosed.

\section{Anseranatinae}

The primitive Anseranas is easily distinguished from all other anatids by the following criteria, the first five of which are unique among the waterfowl. (1) The costal margin is over 50 per cent of the length of the basin (measured from the dorsal sulcal lip to the postpectoral line). (2) The sternal basin is deep. (3) The dorsal surface of the sternal plate is pierced by numerous foramina and crossed by transverse ridges.

(4) The sternum is trilobed 
posterlorly, because of very shallow sternal notches and a rounded $\mathrm{xiphisternum.}$

(5) A stout, median bar extends from the dorsal sulcal 11p into the basin. (6) The dorsal and ventral manubrial spines are lacking.

\section{Anser Inae}

The Anserinae can be distinguished from the Anseranatinae in the following ways. (1) The costal margin is shorter, always less than 50 per cent of the basin length.

(2) The sternal basin is shallower. (3) The pneumatic foramina are confined to the area posterior and ventral to the dorsal sulcal 11p, and to the anterior median portion of the basin. (4) The xiphisternum flares laterally, 1ts posterior margin is truncate or slightly concave, and the sternal notches are deeper. (5) There is no stout bar as described for Anseranas.

From the Anatinae, the Anserinae can be distinguished in the following way. The dorsal sulcal lip overhangs the sternal basin medially, and forms a large concavity at the anterior end of the sternal plate. The overhanging $11 p$ and the rather prominent costal margins cause the sternal basin to appear deeper. Th1s character is least developed in Nesochen.

\section{Tribe Dendrocygnint.} Whistiling Ducks

The sternum of whistling ducks shares the greatest number of similarities with that of the pied goose. The costal margin is almost as long as in Anseranas, the sternal basin 
is almost as deep, and the manubrial spines are lacking. Dendrocygna differs from Anseranas in the characteristics 11sted for the Anserinae; numbers 1, 4, and 5 are particularly useful.

The whistling ducks can be distinguished from the swans and geese by their lack of a ventral manubrial spine.

Tribe Anserini.

Swans and Geese

Swans and geese can be separated into two very distinct units on the basis of the sternum. Swans and Coscoroba form one group, the geese form the other. The sterna of these two units are so different as to suggest they might be treated as separate tribes.

The sternum of swans is unique in the position of the intermuscular line delimiting the supracoracoideus from the pectoralis superficialis as noted by stejneger (1883). In swans the line extends along the sternal plate only a short distance, usually less than 75 per cent of the carinal length, before it curves down onto the carina. In all other waterfowl the intermuscular line extends along the plate essentially to the posterior end of the carina. The reduction in the relative length of the line is indicative of the reduction of the supracoracoldeus muscle. Further indication of a reduction in this muscle is apparent when the sternum is viewed in ventral aspect. In swans the intermuscular line angles sharply toward the carina; in geese the line essentially parallels the carina throughout its length. 
The supracoracoldeus functions to ralse the wing. In the Cathart1dae F1sher (1946) associated a reduced supracoracoldeus with a decrease in speed of wing flapplng. It seems 11kely that the same principle applies to the swans which also have a slow wing beat.

The swans are further distingulshed as follows. (1) The sternal notches are shallow. (2) The posterior lateral processes rarely extend beyond the xiph1sternum. (3) The posterior lateral processes are nearly in a line with the costal margin. (4) The costal margin is elongate, forming from 40 to 50 per cent of the basin length. (5) A ventral manubrial spine $1 \mathrm{~s}$ present which serves to distingulsh swans from Anseranas and Dendrocygna. (6) A p1t is present in the dorsal portion of the anterior carinal margin in some spec1mens of all species. In olor columblanus, ㅇ․ buccinator, ㅇ. ygnus, and 으. bewicki1 the pit becomes a huge cavern for a loop of the trachea. In Cygnus olor, ‥ melancortphus, and Chenopis the pit 18 small or absent, and does not contaln the trachea.

only one feature of the sternum, additional to the cavern for the tracheal loop, supports the recognition of olor as distinct from Cygnus, and this may be a result of widening of the carina in olor. The posterior portion of the pectoralis superficialis 11 es close to the carina in Cygnus, but far laterad to the carina in olor.

The sternum of coscoroba indicates it is closely related to the swans. The intermuscular ine, although more extensive than in the true swans, curves down onto the carina 
well anterior to its posterior termination. In ventral view the line gives additional indication of a reduction of the supracoracoldeus by distinctly angling toward the carina throughout 1ts length as shown in stejneger (1883). Further evidence for considering Coscoroba near the swans comes from the fact that some specimens possess a pit in the dorsal portion of the carinal margin.

Coscoroba can be distinguished from the true swans by the following criteria. (1) The intermuscular line extends beyond 75 per cent of the carinal length (usually about 90 per cent). (2) The posterior lateral processes extend well beyond the xiphisternum. Both features were figured in Stejneger (1883).

of all the Anserinae, the true geese are closest to the Anatinae. Geese may be distinguished from Anseranas and other Anserinae in the following manner. (1) The costal margin 18 less extensive (usually less than 40 per cent of the basin length). (2) The sternal notches are deeper (more than 33 per cent of the basin length). (3) The posterior lateral processes flare from the costal margins. (4) The xiphisternum is normally widened posteriorly. (5) A dorsal manubrial spine 18 present. In the other Anserinae and in Anseranas the notch is enlarged and eliminates the spine. These characters, except the last, are also present in the Anatinae.

The sterna of geese show little generic variation. Miller (1937), in his comparison of Nesochen with Branta, Anser, Chen, and Phllacte, found several features to 
distinguish Nesochen, but found no constant characters to separate the remaining four genera one from another.

Nesochen is characterized by the following features. (1) The sternum is narrower, the w1dth (narrowest extent between the costal margins) varying from 37 to 40 per cent of the basin length. In all other geese the minimum 18 over 41 per cent. (2) The carina is visibly lower. As Miller stated, the difference in carinal height is evident only posterior to the apex where no fixed points for measurements can be selected. (3) The ventral manubrial spine is a transverse ridge less thick than the buttonlike prominence of other genera. (5) The pneumatic foramen is very small, less than a millimeter wide. (6) In addition to these features, which have been verified in the present serles, the one avallable Nesochen has a less prominent intermuscular line, especially posteriorly. Possibly all of the above features, and certainly 1,2 , and 6 , can be attributed to curtailed flight.

One character that allows the separation of Branta from Anser, Chen, Philacte, and Nesochen 1s the shape of the ventral manubrial spine. In Branta the spine is compressed into a vertically spatulate process, whereas in the other four it is of the normal peglike shape. Two specimens of Cygnopsis and one of Eulabela are intermediate in this respect.

\section{Anatinae}

In the ducks the sternal basin is distinctively flattened. The reduced posterfor surface of the dorsal sulcal 
lip and the less prominent costal margins eliminate the large concavity at the anterior end of the sternal plate. Miller found the above-described character the best means of distinguishing Chloephaga, here considered in the Anatinae, from the true geese.

It 1 s not possible to separate all the tribes of ducks solely on sternal characteristics. There are, however, a number of features that asd in setting apart these groups or parts thereof. For those tribes that cannot be character1zed by the sternum alone, the varlous genera w111 be discussed under the tribal units used by Delacour (1954, 1956, 1959). Similarities to genera in other tribes will be mentioned.

Tribe Tadornint. Sheldrakes

Within the Anatinae the sheldrakes are most like the true geese in features of the sternum, particularly in the rather prominent dorsal sulcal $11 \mathrm{p}$ and the numerous pneumatic foramina in the sternal basin.

In addition to lacking a distinct concavity beneath the dorsal sulcal 11p, the sheldrakes may be separated from the closely similar true geese as follows. (1) The costal facets number six or less, except in the aberrant cereopsis and Tachyeres (in geese a minimum of seven is present). (2) The costal margin typically tapers postertorly. The sternum of sheldrakes is narrowest immediately adjacent to the last costal process, whereas in geese the narrowest point, which 
is sometimes difficult to establish, always 11 es anterlor to at least two costal processes. The difference is undoubtedly a manifestation of the above characteristics.

M1ller used the shape of the sterno-coracoldal process to ald in separating Chloephaga from the true geese; in Chloephaga 1t is longer and projects more anterlorly. Although the process is variable, the differences between Chloephaga and true geese are generally those between Anatinae and Anserinae, and therefore $1 t$ serves to separate the two subfamil1es. Miller's other criterion for separating Chloephaga from the true geese was the relative length of the posterlor lateral processes, extending well beyond the xiphisternum. A few goose specimens, however, show the same feature; and thus it is not an infallible character. The sheldrakes form a rather distinct tribe. The sternal basin is deeper than in other ducks, although there is overlap with some dabblers and perchers. The shape of the pneumat1c fossa is also of limited use. The fossa is typically a large opening bordered laterally by stout bars, which frequently are fused with the sternal plate. The resulting fossa does not have the round or elliptical shape of other ducks, but instead it is a constricted opening that is elther oval or somewhat rectangular in outline. The sterno-coracoldal process is shorter and has a more prominent posterior extension in the sheldrakes than in other ducks. Tachyeres differs strongly from other sheldrakes in its broad, flat sternum. (1) The width is 55.6 per cent of the basin length. (2) The ventral manubrial spine barely 
protrudes beyond the ventral sulcal lip. (3) The carina 18 greatly reduced, with the posterior two-thirds of its margin virtually a straight line. (4) The posterior lateral process curves mediad more than in other sheldrakes. (5) The pneumatic fossa is elliptical and small. (6) The sterno-coracoldal process is longer and lacks a prominent posterior extension. The very shallow basin, ducklike sterno-coracoldal process, possible the elliptical fossa, and the seven costal processes indicate that Tachyeres may be incorrectly located in the sheldrake tribe.

Characteristics of the sternum of Cereopsis disclose little more than the fact that it is aberrant. The element has qualities of both the sheldrakes and the true geese. The following features were noted. (1) The sternal basin is deeper than in sheldrakes, but lacks the concavity beneath the dorsal sulcal 11p found in geese. (2) The dorsal manubrial area is notched as in many sheldrakes, whereas no geese have a distinct notch. (3) The ventral manubrial spine 1s lacking. All geese have such a spine, as do most sheldrakes. (4) The xiphisternum is not flared posteriorly as is true of all sheldrakes and most geese. (5) The costal processes number six or seven. A minimum of seven was counted for geese, and a maximum of $\mathrm{six}$ for sheldrakes, Tachyeres excluded. (6) The carinal margin is more curved throughout 1 ts length than in members of either of the other two tribes.

Among the more typical sheldrakes, Chloephaga has the widest sternum ( 46.9 to 50.8 per cent of basin length), 
Tadorna and Casarca the narrowest (40.1 to 45.1 per cent), whereas Alopochen (44.9 to 49.8$)$ and Neochen (45.3 to 45.8$)$ are intermediate.

Chloeppaga usually has abundant pneumatic foramina; Tadorna and Casarca have only the large, centrally located one; Alopochen and Neochen are intermediate, but nearer Chloephaga.

In Chlokphaga, Alopochen, and Neochen the posterlor lateral processes extend well beyond the xiphisternum. In Tadorna and Casarca, where they are shorter, they normally extend less than 5 millimeters beyond.

Chloephaga has a narrower xiphisternum (its least width divided by the least width between costal margins, 31.3 to 44.8 per cent) than Alopochen (66.5 to 66.9), and Neochen (50.5 to 54.6), whereas in Tadorna and Casarca the structure varies greatly in width with the different species.

Chloeshaga has a higher carina than Alopochen, and it extends farther back on the sternal plate. Neochen, Tadorna, and Casarca are more like Chloesphaga in this respect.

\section{Tribe Anatini. Dabbling Ducks}

In the dabbling ducks the sternum has the following characteristics. (1) The sternal basin is shallower than in the sheldrakes. (2) The single pneumatic foramen is elliptical or round. (3) The ventral manubrial spine 1 s usually present and typically long, thin, and peglike. (4) The sternum is narrow (Anas, Chaulelasmus, Mareca, Spatula, 37.5 to 48.9 per cent of total length; Callonetta, 43.3 ; Malaco- 
rhymchus, 44.4; Eymenolaimus, 44.5), narrower than in most members of the four diving duck tribes. Rhodonessa and Merganetta are exceptions. (5) The posterior lateral processes are straighter than in divers and only occasionally fused with the xiphisternum.

Within the tribe the sterna of all genera except Rhodonessa and especially Merganetta are very similar.

Callonetta has two weak features that support generic status. (1) The costal processes number six, whereas the vast majority of specimens of typical dabblers have seven, although the range 18 from $s i x$ to elght. (2) The ventral manubrial spine 18 thinner, with a weak dorsal area for the ligamental attachment.

Malacorhynchus has the ventral manubrial spine large and strong as in typical dabblers but aiffers in having $\mathbf{s i x}$ costal processes.

Eymenolaimus is also very similar to the typical dabblers, surprising when one considers 1ts habits. It has the following differences. (1) The costal processes number six. (2) The ventral manuburial spine is reduced to a weak projection. (3) The dorsal manubrial area has a prominent notch. (4) The carina is slightly reduced with its ventral edge only slightly curved.

Rhodonessa can be distinguished at once from the typical dabblers by several good sternal features. (1) The sternum 18 wider ( 50.8 per cent of basin length). (2) The dorsal manubrial area is notched. (3) The ventral manubrial spine 18 lacking. The one avallable specimen (U.s.N.M. 344802) 
lacks the spine as apparently did the one used by Verheyen (1955). Though occurring also in certain perching ducks, this feature is generally limited to the species with diving habits, but Rhodonessa does not habltually dive (Delacour, 1956)

In Merganetta the sternum has the following features. (1) It is wide, 52.7 to 52.9 per cent of the basin length.

(2) The ventral manubrial spine is lacking. (3) The carina is greatly reduced, the margin being straighter than in typical dabblers. (4) The posterior lateral processes curve more mediad. (5) The sternal notches are reduced to onequarter of the basin length (they measure approximately onethird in other dabbling ducks). (6) The dorsal manubrial area is deeply notched, and has two prominent lateral projections. The sternum of Merganetta diverges from those of typical dabblers to the extent that tribal status for the species may be justified.

The sternum of Salvadorina was studied by Mayr (1931), who found the element somewhat narrower than in Anas platyrhynchos, especially caudally, and with the interauscular line less clearly marked. In sternal characteristics he concluded that Salvadorina is closer to Anas platyrhynchos than to Aythya.

Tribe Cairinini. Perching Ducks

Perching ducks have a sternum that does not differ significantly from that of the dabbling ducks. It 1s, 
therefore, impossible to characterize the tribe as a whole on the basis of this element.

Within the tribe, Cairina, Aix, and Dendronessa have the ventral manubrial spine greatly reduced, whereas in Amazonetta, Chenonetta, Nettapus, and Cheniscus it is prominent. Pteronetta and Sarktdiornis are intermediate in this respect.

Calrina has numerous pneumatic foramina beneath the dorsal sulcal lip and costal margins, and along the midine of the basin. In other perching ducks, with the exception of the aberrant plectropterus, only the large, anteriorly and centrally located, foramen is present.

Plectropterus resembles the sheldrakes more closely than the perching ducks in the structure of the sternum. It has the following features. (1) The sternal basin is deeper than in all ducks except certain sheldrakes. (2) The pneumatic foramen is bordered laterally with struts as described for the sheldrakes. (3) The dorsal manubrial area is deeply notched and has the lateral processes found in certain sheldrakes.

Tribe Aythyint. Pochards

Sterna of the three genera of pochards are easily separable. Metoplana is the least specialized, Aythya the most specialized, and Netta is intermediate.

Metoplana has the following sternal characters. (1) The ventral manubrial spine is present as a prominent, single, peiglike process. When compared with dabbling ducks the 
spine of Metoplana is shorter and thinner. (2) The dorsal manubrial area is notched as in all pochards. This character separates the sternum of Metopiana from the similar nondiving ducks. (3) The wiath is less (43.2 to 47.4 per cent of the basin length) than in all other pochards, and also it is less than in Rhodonessa and Merganetta of the dabblers. (4) The pneumatic foramen is large (4 mm. wide), as in typical dabblers; it is much smaller in Aythya. (5) The posterfor lateral processes are longer, thinner, and straighter than in other pochards.

Netta, which is intermediate between Metoplana and Aythya, has the following features. (1) The ventral manubrial spine is lacking. (2) The width is intermediate $(51.5$ to 52.1 per cent) between Metopiana and Aythya. Only two of 71 specimens of Aythya had a relative width less than 53.0 per cent. (3) The pneumatic foramen is large ( $3 \mathrm{~mm}$. wide) as in Metopiana.

Aythya possesses the following sternal characteristics. (1) The ventral manubrial spine is usually a short, twopronged structure with the prongs flaring laterally. The length of the prongs varies as does the depth of the notch between them. This feature is the best means of separating the sternum of Aythya from those of all other ducks. (2) The relative width is greater ( 51.3 to 66.7 per cent) than in other pochards. (3) The pneumatic foramen is reduced (less than $3 \mathrm{~mm}$. wide) but $1 \mathrm{~s}$ almost always present. (4) The posterior lateral processes are shorter and wider, and curve farther mediad than in Metopiana. 
Tribe Somateriln1. Elders

The sternum of elders is typical of diving ducks. The element $1 \mathrm{~s}$ wide ( 53.0 to 58.6 per cent of the basin length). the dorsal manubrial area $1 \mathrm{~s}$ widely notched, and the posterfor lateral processes are wide and curve toward the midline. The sternum 1s most like that of the scoters, from which $1 t$ can be separated as follows. (1) The posterior lateral processes are wider, and more in line with the long axis of the element. (2) The notches are usually shallower. (3) There is less curvature throughout the entire element.

In Polysticta a small ventral manubrial spine is present as noted by shufeldt (1909), possibly indicative of a relationship with clangula. In Somateria and Lampronetta the spine is a very short, bilobed protuberance.

\section{Tribe Mergint. Sea Ducks}

As w1th other elements, the sternum of sea ducks exhibIts great structural variation. Moreover, several structures of the element are found nowhere in the Anatidae except in certain members of this tribe. For example, the genera Bucephala, Lophodytes, Mergellus, and Mergus are the only waterfowl that regularly have sternal fenestrae instead of notches. In addition, these genera and clangula are the only ducks with a pronounced abdominal plate extending beyond the postpectoral line.

As mentioned above, Bucephala and the mergansers agree in the presence of sternal fenestrae instead of notches, but they can be separated by the distance the carina extends 
anterlorly beyond the dorsal sulcal 11p. In order to obtain a measurement, a straight edge was lald along the midline, from the posterlor margin over the dorsal sulcal $11 \mathrm{p}$, and a perpendicular was extended from this line to the carinal apex. The distance along the stralght edge from the perpendicular to the dorsal sulcal 11p 18 cons1dered the amount of carinal overlap. The results are given as a percentage of the basin length. In Mergus the range 1825.6 to 35.6 (average, 31.59), whereas in Bucephala the range $1 \mathrm{~s} 11.4$ to 22.0 (average, 16.13). Mergellus (18.5) and Lophodytes (18.5 to 19.9, average, 19.39) are intermediate, but closer to Bucephala. Most taxonom1sts, if confronted with the sterna of Mergellus or Lophodytes, would probably place them w1th Bucephala and not Mergus.

The pneumat1c fossa is of limited use in distinguishing the mergansers from Bucephala. In Mergus the foramen is large, approximately $5 \mathrm{~mm}$. wide. Some specimens lack openIngs from the foramen into the carina as mentioned by Shufeldt (1909), but usually they are present. In Bucephala the foramen $1 \mathrm{~s}$ smaller, under $4 \mathrm{~mm}$. Sometines $1 \mathrm{t}$ is only a slight depression and frequently lacks openings into the carina. Lophodytes has a wide p1t, usually without openings Into the carina, and the one specimen of Mergellus has a prominent foramen.

The relat1ve w1dth of the sternum in Bucephala (50.5 to 56.1 per cent), Mergellus (52.3), Lophodytes (49.5 to 55.2), and Merqus (47.7 to 54.2 ) 1s of little use for 1dentification. The basin length used to figure the above percentages does 
not include the variable abdominal plate. The postpectoral line is used as the point from which the measurement is taken.

The sternum of clangula is easily distinguished from that of all other waterfowl by the combination of a large abdominal plate and sternal notches. The plate is relatively larger than in the Bucephala to Merqus series. The ventral manubrial spine varies from a short peglike process to a small bifid protuberance. The relative width of the sternum varies from 50.3 to 55.0 per cent.

Histrionicus has a relatively wide sternum (59.3 per cent) and a bifid ventral manubrial spine.

A greater curvature throughout the entire element characterizes the sternum of the scoters (Melan1tta and 어demia).

There is no flxed point from which to measure the curvature, but it can be seen by comparing the ventral edge of the carina or the juncture of the carina with the sternal plate. The sternal basin appears significantly deep in the scoters, because of the curvature of the element and the more abruptly rising dorsal sulcal lip.

The posterior lateral processes are thinner, and more flared laterally than in the elders. Furthermore, the notches are usually deeper.

The sternal width ( 48.8 to 55.9 per cent of basin length) and the diameter of the pneumatic fossa (less than $0.5 \mathrm{~mm}$. to over $4 \mathrm{~mm}$.) are poor taxonomic criteria. Scoters possess either a very short, bifid ventral manubrial spine or none at all. The dorsal sulcal area is broady notched. 
The sternum of the extinct Camptorhynchus was 111ustrated in ventral and lateral views by Rowley (1877). The specimen from which the drawing was made, including the coracolds and furculum, is still extant and is the only one known (Kumphrey and Butsch, 1958). The sternum resembles that of the eiders in that the posterior lateral processes are wide, and in line with the long axis of the element, and it lacks the basin curvature possessed by scoters. However, the sternum appears less specialized than in the eiders since the posterior lateral processes approach the xiphisternum, as in Bistrionicus.

Tribe oxyurint. Stiff-tailed Ducks

The sternum in the stiff-talled ducks has the following features. (1) The pneumat1c foramen is lacking or minute. (2) The ventral manubrial spine is present, and points more dorsad than in other ducks (except in plziura, which lacks the spine). (3) The basin is very shallow.

Oxyura 18 one of the most specialized members of the stiff-ta1ls. The sternum is characterized as follows. (1) The width varies from 59.5 to 68.4 per cent of the basin length. (2) The ventral manubrial spine is wide and bifurcate alstally. (3) The sternum has shallow notches in 으. fama1cens1s (12 specimens), fenestrae in 으 v1ttata (1 spec1men). (4) The posterior lateral processes are short, wide and flaring. (5) The xiphisternum is wide. (6) The costal processes number seven, or rarely elght. 
The sternum of Nomonyx is much less specialized. (1) It is relatively much narrower (48.0 to 54.1 per cent) than in oxyura. (2) The ventral manubrial spine is long, thin, and peglike. (3) The notches are deeper than in oxyura. (4) The posterior lateral processes are thinner and curve farther mediad. (5) The xiphisternum is narrower than in Oxyura. (6) The costal processes number six. (7) The carina is reduced, as is typical of the tribe.

The sternum of Heteronetta has the large, dorsally directed ventral manubrial spine that characterizes the tribe, but otherwise the species is much less speclalized than other members. The following sternal features occur. (1) It is relatively narrower (43.9 per cent) than in oxyura and Nomonyx. (2) The ventral manubrial spine 1s wide basally but becomes thin distally. (3) The notches are deeper in oxyura and Nomonyx. (4) The posterior lateral processes are thin and straight. (5) The xiphisternum is narrower than in oxyura and Nomonyx. (6) The costal processes number six, as in Nomonyx.

The aberrant sternum of Blziura has the following features. (1) The dorsal and ventral manubrial areas are widely and deeply notched. (2) The carina is greatly reduced, the posterior four-fifths of the margin being virtually a straight 1ine. (3) The carinal apex does not extend beyond the sulcal 1ips. (4) The posterior lateral processes flare and then curve mediad. (5) The sternal notches are shallow. (6) Two 5-min. foramina are present on either side of and adjacent to the carina, approximately one-third the basin length from 
the posterior end (only one specimen is avallable and this may not be a normal feature). (7) The width 18 apparently great, but only 41.4 per cent of basin length, because of reduction in the area posterior to costal margin. (8) The costal processes number seven.

\section{Coracoid}

The coracoid is an important taxonomic element. The angles between certain parts of the bone, as well as proportions and structural deta1ls, are useful.

\section{Anseranatinae}

The coracoid of Anseranas is vastly different from those of all other Anatidae. (1) A coracoidal fenestra is present as a clrcular foramen in the large procoracoid. The fenestra not only plerces the bone but opens into the shaft as well, (2) A pneumatic foramen is present on the dorsal surface anterior to the sternal facet. (3) The dorsal portion of the sternal facet has a prominent medial lip that is essentially perpendicular to the shaft. (4) The sternocoracoidal process has a prominent knoblike extension. (5) The surface of the triosseal canal is inflated, rather than depressed as in most other anatids, and lacks the pneumatic foramina found in geese and swans. (6) The angle formed between the axis of the head, best seen in anterior view, and the plane upon which the dorsal surface lies is 88 to 93 degrees. Swans are the only other waterfowl that have an angle greater than 87 degrees. (7) the head is wider, and (8) the neck is less constricted than in other anatids. 
(9) The depth through the scapular facet at 1ts narrowest point is 16.3 to 17.5 per cent of the length (measured from the head to the internal distal angle), greater than in all other Anatidae except certain swans and geese.

\section{Anserinae}

Although no single character of the coracold distinguishes the Anserinae from the Anatinae, a combination of features proves diagnostic. (1) The angle between the axis of the head and the plane upon which the dorsal surface lies is 79 to 93 degrees, greater than in most Anatinae. (2) The angle between the sternal facet and the shaft is small, with a range from 70 to 83 degrees (measured w1th one straight edge touching the internal distal angle and the median portion of the head, and the other lying along the posterior border of the element). (3) The ventral lip of the sternal facet 18 wide and concave, with the external edge essentlally perpendicular to the shaft. (4) The median edge of the sternal facet is typically broad and blunt, partially a result of the wide lips to the sternal facet.

Tribe Dendrocygnini.

Whistling Ducks

The coracold of wh1stling ducks resembles that of swans and geese in most characteristics, but its slender shaft gives it a decided ducklike appearance. Dendrocygna can be distinguished from the swans and geese by the following coracoldal features. (1) The depth 1 s 12.6 to 14.1 per cent of the length. A minimum of $15.01 \mathrm{~s}$ recorded for the swans 
and geese. (2) The width is 8.3 to 10.3 per cent of the length (measured at the narrowest point posterior to the procoracoid with the caliper legs perpendicular to the plane of the dorsal surface). Its minimum width $1 \mathrm{~s} 12.4$ per cent in the swans and geese. (3) The pneumatic foramina beneath the furcular facet are minute or absent. (4) The ventral surface has a pronounced depression inmediately anterior to the sternal facet and medial to the intermuscular 1 ine. This character makes the coracold of Dendrocygna separable at a glance from that of any other bird.

Tribe Anserint.

Swans and Geese

Although there are basic similarities in the coracoids of whistling ducks and of swans and geese, the two groups can be easily separated. Swans and geese have the following coracoldal properties. (1) The depth 1.515 .0 to 22.1 per cent of the length. (2) The width varies from 12.4 to 16.4 per cent. (3) The pneumatic foramina beneath the furcular facet are large and numerous.

The coracold supports the distinction of two groups, one belng swans and Coscoroba, the other the geese, as previously defined by other skeletal elements. The major difference between the two groups is in the form of the triosseal canal. (1) In swans the triosseal canal has no deep depression between the proooracold and the brachial tuberos1ty. In geese the depression is deep. (2) In swans pneumatic foramina are small and extend under the entire furcular facet. In geese, where they are larger, the foramina are 
normally restricted to the area beneath the brachial tuberosity. (3) The angle between the axis of the head and the plane of the dorsal surface ranges from 83 to 93 degrees in swans. In geese the range is 80 to 85 degrees. (4) The depth through the scapular facet ranges from 16.4 to 22.1 per cent of the length in owans. In geese the range 1815.0 to $\mathbf{1 7 . 6}$ per cent.

Coscoroba resembles the swans in the size and location of pneumatic foramina and the depth through the scapular facet (18.2 per cent). It is intermediate between swans and geese in the depth of the triosseal depression and the angle of the head ( 83 degrees). From the swans, to wh1ch 1t seems more closely allied, Coscoroba differs as follows. (1) The ventral edge of the shaft in internal view is virtually straight, whereas it is curved toward the ventral prominence of the head in swans. (2) The sternal facet in posterfor view is straighter, less arched, than in swans. (3) The width below the procoracold 1813.7 per cent of the length, swans range from 13.6 to 16.4 , but only three of 36 specimens are narrower than Coscoroba.

Four coracoidal features that ald in separating olor from cygnus were listed by Howard (1946). (1) The furcular facet is undercut for its full extent in olor. In cygnus the facet is flattened against the shaft ventrally with only a slight undercut near the brachial tuberosity. Chenopls resembles cygnus in this respect, although one of four spec1mens is intermediate. (2) The procoracold is larger in olor and smaller in Cygnus and Chenopis. (3) The coracoidal 
notch is absent in olor, although Howard noted some exceptions. In cygnus there is a more (c. olor) or less (c. melancoriphus) distinct notch located where the coracoidal fenestra. occurs. Two of four specimens of Chenopls have the notch sealed off as an elongate fenestra. (4) The scapular facet 18 broad and shallow in olor. In cygnus olor and Chenop1s the area 1s more evenly rounded. Cygnus melancor1phus is intermediate.

The coracoid exhlblts a feature that allows for a separation of the geese. Miller (1937) used it to separate Branta from Anser and Chen, but with the present seifies it has wider application. In Branta and Mesochen the furcular facet is undercut for 1ts full extent. In Anser, Chen, Cyqnopsis, Phllacte, and Eulabela the furcular facet is deeply undercut dorsally, flattened against the shaft in the middle, and only slightly excavated ventrally. Pneumatic foramina frequently occur under the ventral portion of the facet in Branta and Jesochen but are absent in this area in the other genera.

Nesochen differs from other geese in the following ways. (1) The depression in the triosseal canal between the procoracold and the brachial tuberosity is shallower. (2) The angle of the coraco-humeral surface is more nearly transverse to the shaft. Miller also mentioned that pneumatic foramina beneath the brachial tuberosity are greatly reduced, but this is not the case with my one specimen. 


\section{Anatinae}

The following features when compared with those listed for the Anserinae should identify coracolds of the many members of the Anatinae. (1) The angle between the axis of the head and the plane of the dorsal surface varies from 61 to 81 degrees, except in Cereopsis and Plectropterus. (2) The angle between the sternal facet and the shaft varies from 80 to 96 degrees, except in the gooselike sheldrakes. (3) The ventral ilp of the sternal facet is less prominent and slopes sharply toward the shaft. Certain sheldrakes are exceptions. (4) The flattened sternal facet has the ventral Iip projecting medially; thus, the median edge is pointed. Again certain sheldrakes are exceptions. (5) The prominent depression on the ventral surface in Dendrocygna is lacking. (6) The depth through the scapular facet (10.1 to 14.6 per cent of the total length) is usually less than in swans and geese. Cereopsis and Plectropterus are the exceptions. When studying duck coracoids difficulty arises from the extensive individual variation exhibited by such features as the depth of the depression in the triosseal canal, the length of the procoracoid, and the length of the sternocoracoidal process. Although other features of the element are rather useful, it is not possible to characterize all of the tribes, as defined by Delacour (1954, 1956, 1959). Reallocation of certain genera discussed below alleviates much of the difficulty. 
Tribe Tadornin1. Sheldrakes

Compared with the other Anatinae, the typical sheldrakes have the following properties. (1) The procoracoid averages larger than in other ducks. (2) The triosseal depression averages deeper. (3) The surface of the furcular facet has a depression ventral to the brachial tuberosity. (4) The furcular facet is undercut extensively near the brachial tuberosity. (5) The angle between the sternal facet and the shaft $1 \mathrm{~s}$ smaller, 75.5 to 81 degrees, the range for other ducks being 79 to 96 degrees.

Chlosphaga, Neochen, and Alopochen are all rather similar and agree in the following criteria. (1) The depression In the furcular facet folns the undercut of the brachlal tuberosity to form a notch in the facet. (2) Pneumatic foramina are usually prominent beneath the brachlal tuberosity.

The shape of the anterlor end of the coracold differentiates these three genera. Alopochen has the deepest triosseal depression. Neochen has the widest furcular notch, which occuples most of the facet, and 1 t also has the most prominent ventral tuberosity on the head. Chloephaga has the shallowest triosseal canal, essentlally lacking in some specimens, and the largest lateral protuberance on the head, located at the termination of the coraco-humeral surface.

Tadorna and Casarca can be characterized by the following features. (1) The furcular facet is entire because the depression and undercutting are less than in the three genera previously discussed.

(2) Pneumatic foramina are minute 
or lacking under the furcular facet. The genus casarca cannot be distingulshed from Tadorna by coracoldal features.

Cereopsis is an exception in all five properties of the coracold that aid in separating the Anserinae from the Anatinae. The genus is easily separated from the typical members of the sheldrake tribe. (1) The angle between the axis of the head and the plane upon which the dorsal surface 11 es is 83 to 85 degrees. A maximum of 81 degrees is found in the true sheldrakes. (2) The depth through the scapular facet var1es from 16.6 to 18.5 per cent of the length. The other genera range from 12.9 to 14.5 per cent. (3) The width posterior to the procoracold varies from 14.0 to 15.8 per cent of the length, true members of the tribe vary from 11.0 to 12.8. (4) The furcular facet is undercut for 1ts full extent. In the others the facet is undercut only dorsally. (5) Pneumatic foramina are present under the entire length of the furcular facet. In the true sheldrakes they are either absent, or present only under the brachlal tuberosity.

The coracoid shows much greater resemblance to the swans and true geese. From the swans Cereopsis differs in having the head of the coracold wider and not as deep. It differs from the geese in lacking the depression in the triosseal canal between the procoracold and the brachial tuberosity. Tachyeres can be distinguished from the typical sheldrakes as follows. (1) The angle between the axis of the head and the plane of the dorsal surface is 71 degrees. In the remaining sheldrakes the range 1872 to 81 degrees. (2) The depth through the scapular facet is 11.0 per cent of 
the length. The range for the typical sheldrakes is 12.0 to 14.5 per cent. (3) The width posterior to the procoracold is 10.6 per cent. The range for the true sheldrakes 1811.0 to 12.8 per cent. (4) The angle between the sternal facet and the shaft is 87 degrees. (5) The internal end of the sternal facet is elongated and pointed. In the other genera assigned to the tribe the area is short and blunt. (6) The dorsal and ventral 11ps of the sternal facet are essentially flush with the shaft, whereas in sheldrakes they are prominent. All of these features of Tachyeres Indicate a relationship to Anatinae other than the sheldrakes.

Iribe Anatini. Dabbling Ducks

The one feature that seems characteristic of the coracold of the dabbling ducks is the angle between the axis of the head and the plane of the dorsal surface. Th1s varies from 61 to 71 degrees. Exceptions are found in Merganetta and Rhodonessa, the two genera that differ significantly from the typical members of the tribe in other properties as well.

Merganetta can be distinguished by two features. (1) The angle between the axis of the head and the plane of the dorsal surface 1874 degrees. (2) the head is deflected ventrally in medial view.

Rhodonessa resembles the pochards in the form of the coracoid. It differs from the dabblers in the following ways. (1) The angle between the axis of the head and the plane of the dorsal surface is 72.5 degrees, above the 
maximum recorded for the typical dabblers but within the range of Aythya (72 to 75 degrees). (2) The head is similar to that of the pochards (see description under pochard tribe).

The remaining genera of dabbling ducks have no qualitative features that distinguish their coracolds.

Tribe Cairinini.

Perching Ducks

The coracolds of perching ducks are extremely similar to those of the dabblers, and it is impossible to differentiate the two tribes on the basis of this element. The one trend in the coracoid that occurs in most species assigned to the perching ducks pertains to the thickness of the head. The ventrolateral portion of the head, upon which the coracohumeral groove terminates, is enlarged and gives the head an over-all robust appearance.

The genera assigned to the tribe by Delacour (1959) fall Into four groups. The largest group contains Cairina, A1x, Dendronessa, Pteronetta, and Amazonetta. Another contains Chenonetta, Nettapus, and Cheniscus. The other two, very different from each other, cons1st of one genus each, Sarkidiornis and plectropterus.

The unifying features of the first of the aforementioned units are associated with the coracoldal head. (1) The anterior end is rather pointed. (2) The ventral prominence is deflected medially. (3) The furcular facet is 1ncised by a conspicuous groove. 
Cairina seems the most specialized of the group, and can be distinguished from the others as follows. (1) The groove in the furcular facet is very deep, notching the edge of the facet. (2) Pneumatic foramina are prominent and often large. (3) The depth of the shaft 1s 13.8 to 14.6 per cent of the length. The maximum for the other genera in the group 1 s 12.8 per cent.

Alx and Dendronessa have frequently been classified as dabbling ducks, but the coracoid shows a strong resemblance to that of Calrina. The critical features are those listed above that are associated with the head. An additional criterion is the less-curved median edge of the shaft found in these three genera.

Dendronessa cannot be separated from $\underline{A 1 x}$, but the two together differ from the other three genera in the group as follows. (1) The depth (12.0 to 12.7 per cent of the length) is greater than in Amazonetta (11.8 per cent), but less than in Pteronetta (12.1 per cent) and Cairina. (2) The groove in the furcular facet is generally deeper than in Amazonetta and Pteronetta, but not nearly as pronounced as in Cairina. Pteronetta is very different from Cairina and similar to Anas in the form of the coracold. (1) The head is wider and less pointed. (2) The groove in the furcular facet is wide and shallow. The ventrolateral portion of the head is enlarged, however, and shows its affinities to the perching ducks.

Anazonetta is intermediate between certain of the dabbling ducks, namely Anas discors and ㅌ.. Cyanoptera, and 
perching ducks such as A1x and Dendronessa, but the head seems more pointed than in Anas.

The second group, formed by Chenonetta, Nettapus, and Cheniscus agrees in most characters with the preceding group, but lacks the groove in the furcular facet. Coracoidal features that distinguish Cheniscus from Nettapus are not present, but they both differ from Chenonetta as follows. (1) The depth is 10.7 to 12.9 per cent of the length, whereas in Chenonetta it is 13.0 to 13.4 per cent. (2) The ventral prominence of the head is directed medially. In Chenonetta the prominence is directed ventrally.

In Sarkidiornis and plectropterus the depression in the triosseal canal 18 extremely deep. Sarkidiornis differs from plectropterus in having the triosseal canal only 16.7 per cent of the length, and the ventromedial lip of the sternal facet very short, the shortest of any waterfowl seen.

plectropterus differs markedly from other perching ducks. (1) The triosseal canal is 19.7 to 21.0 per cent of the length. The range for other perching ducks 1813.4 to 18.5. (2) The coracoidal head is wide and not pointed in medial view. (3) The ventrolateral portion of the coracoidal head is not enlarged, and (4) the neck is prominent.

\section{Tribe Aythyini. Pochards}

The pochards form a distinct tribe easily separable from the others, both diving and non-diving. Certain genera, however, indicate the derivation of the tribe was from the dabblers. The unique features of the tribe are associated 
with the head. (1) The ventral portion of the head is reduced. In medial view, the coracoidal head meets the ventromedial edge of the shaft by a straight or gently curved line. (2) The bicipital attachment is a thin groove instead of an elliptical facet. (3) The furcular facet extends farther posteriad along the shaft.

As mentioned above in the section on the dabbling ducks Phodonessa agrees entirely with all of these characteristics of the pochards.

Aythya has the most specialized coracold of the pochards, whereas Metoplana and Netta are 1ntermediate between Aythya and the dabblers in most features. As the following characteristics indicate, Rhodonessa also seems to be one of the less specialized pochards. (1) The relative width of the triosseal canal, given as a per cent of the length, is as follows:

\begin{tabular}{ll} 
Aythya & $11.6-14.7$ per cent \\
\hline Metoplana & $13.8-15.0$ \\
Netta & $14.6-15.1$ \\
\hline Rhodonessa & $14.8-17.9$
\end{tabular}

(2) The angle between the axis of the head and the plane of the dorsal surface has the following variation:

\begin{tabular}{ll} 
Aythya & $72-75$ degrees \\
Metopiana & $70-72$ \\
\hline Netta & $69=71$ \\
\hline Rhodonessa & 72.5 \\
\hline Dabbling Ducks & $61-71$
\end{tabular}


(3) The angle between the sternal facet and the internal edge of the element measures:

$\begin{array}{llll}\text { Aythya } & 86.5 & -91 & \text { degrees } \\ \text { Metoplana } & 85 & -87 & \\ \text { Netta } & 87 & -88 \\ \text { Rhodonessa } & 86 & \\ \text { Dabbling Ducks } & 82 & -86\end{array}$

Aythya is best distinguished from Metopiana and Netta by the depth of the element relative to its length. In Aythya the range is from 10.9 to 12.6 per cent. Metopiana (12.6 to 13.8$)$, Netta (13.3 to 13.4$)$, and also Rhodonessa (13.5) are relattvely deeper.

Metopiana and Netta are also easily separated by coracoldal features. (1) The width is 10.0 to 10.6 per cent of the length in Metoplana, 11.9 to 12.3 per cent in Netta. (2) The sternal facet is 38.1 to 40.4 per cent of the length in Metopiana, 44.5 to 44.6 in Netta. The relatively short length of the sternal facet in Metopiana is correlative to the presence of a ventral manubrial spine on the sternum. (3) The ventromedial edge of the head is straighter and more prominent in Netta.

\section{Tribe Somateriini. Elders}

The elders were considered an offshoot of the dabbling ducks (Delacour, 1956; Humphrey, 1958a), but the coracoid has striking similarities with that of the scoters. (1) The procoracoid flares dorsally and has the base enlarged in both groups. (2) The triosseal canal is wide, 17.1 to 19.9 per cent of the length in elders, 15.3 to 18.7 per cent in scoters. (3) The sternal facet is 43.3 to 47.1 per cent 
of the length in elders, 42.9 to 49.9 per cent in scoters. (4) The head has a large ventral prominence in both groups. The characters that separate the coracold of elders from those of scoters and the other sea ducks are less obvious. (1) The sternal facet has the ventromedial 11p essentially flush with the shaft. In scoters the 11p departs abruptly from the shaft. (2) The sternal facet, at the internal distal angle, is elongate and pointed. In the scoters this region is relatively blunt. (3) The angle between the axis of the head and the plane of the dorsal durface is 70 to 81 degrees. In scoters the range is 77 to 87 degrees. (4) The ventromedial edge of the shaft is a sharp ridge and the surface from the ridge through the triosseal canal is almost flat (a slight depression in many specimens). In scoters the ridge 1 s wider and it then curves abruptly toward the canal that normally houses a rather deep depression. (5) The ventral prominence of head is situated farther posteriorly than the brachlal tuberosity. In scoters the ventral prominence extends no farther back along the shaft than the tuberosity, and frequently it is more anterior than the latter.

The one available specimen of Lampronetta has no qual1tative features of the coracold that are useful in distingulshing it from somateria.

Polysticta is distinct from Somateria and Lampronetta, and certain of the coracoldal features indicate an affinity to Histrionicus and Clangula. (1) The axis of head $1 \mathrm{~s} 81$ degrees from the plane of the dorsal surface. The range for 
other eiders is 70 to 79 degrees. (2) The furcular facet is rounded. In other elders the facet is flat and usually has a depression ventral to the brachial tuberosity. The furcular portion of the head in Histrionicus is similarly rounded.

\section{Tribe Mergin1. Sea Ducks}

The sea ducks exhibit considerable variation in the conformation of the coracold, as is the case with other bony elements. A feature that is somewhat useful in defining the tribe is the procoracold, which tends to flare dorsally with 1ts base extending farther back the shaft. The elders share this feature. The tribe may be divided into two distinct groups on the basis of the element. One group contains Bucephala and the merganser genera Lophodytes, Mergellus, and Mergus; the other contains Clanqula, Histrionicus and the scoters, Melanitta, and ofdemia.

The following characters of the coracoid distinguish these two groups. (1) In Bucephala and mergansers the sternal facet varies from 33.2 to $39.7(42.2$ in 1 of 35 specimens) per cent of the length. In the others the range is 42.1 to 49.9 (39.6 in 1 of 17 specimens). (2) In Bucephala and mergansers the sterno-coracoldal process is less produced laterally and forms an angle of less than 45 degrees with the shaft. In the others the process 1s produced farther laterad to form an angle of more than 45 degrees with the shaft. (3) In Bucephala and mergansers the triosseal canal varies from 11.1 to 15.4 per cent of the length of the bone. The range for the other four genera $1 \mathrm{~s} 15.3$ to 18.7 . (4) In 
Bucephala and mergansers the angle between the axis of the head and the plane of the dorsal surface varies from 69 to 74 degrees, whereas in the others the range 1872 to 87 degrees. (5) In Bucephala and mergansers the furcular facet is frequently interrupted by a median depression. In the others the facet is usually distinct throughout its length. Histrionicus is an exception. (6) In Bucephala and mergansers the ventromedial edge of the shaft remains a sharp ridge to its termination at the furcular facet. In the others the anterior end broadens and underlies much of the furcular facet. Histrionicus is intermediate in this respect also. (7) The size of the ventral prominence of the head presents a sequence in which the mergansers, and particularly Lophodytes, have the smallest protuberance, Bucephala is intermediate, whereas Histrionicus, Clangula, and the scoters have the largest. The most natural break again seems to fall in the accustomed place.

The mergansers are distinct from Bucephala and the other sea ducks in only one inconstant feature of the coracold, namely that the ventral lip of the sternal facet in posterLor view is prominent as a broad curve to the internal distal angle. In other sea ducks there is a distinct concavity as the 11p approaches the angle, and beyond the angle the lip 18 no longer prominent. Two of ten specimens of Bucephala could not be identifled by this character, and one specimen of Melanitta $1 \mathrm{~s}$ aberrant.

The length of the sternal facet relative to the length of the coracoid is useful in separating Bucephala (37.2 to 
42.1) from Mergus (33.2 to 37.2 , one 39.69$)$. However, when Mergellus (37.2) and Lophodytes (34.8 to 38.6) are considered the character becomes weak.

Paleontologists have no difficulty in separating Lophodytes from Mergus on the basis of size. Qualitatively the coracolds of the two genera are very similar. A consistent difference in the configuration of the glenold facet is apparent. In Mergus the ventral rim of the glenoid facet is rather angular with the anteroventral leg somewhat rounded, the posterior leg essentially straight. In Lophodytes the anteroventral portion of the rim 18 broadly rounded, the posterior part concave. The glenoid facet of Mergellus, while not as rounded at the anterior end as in Lophodytes, has the greatest resemblance to this genus.

The four available specimens of Merqus merganser have deeper triosseal depressions than the 17 of $\underline{M}$. serrator.

The fossil duck Bucephala ossivalis Brodkorb (1955) from the Bone Valley formation, usually referred to the lower Pliocene, is known from the anterior half of a coracold. The bone is very similar to that of B. clangula and $\underline{B}$. albeola, particularly in the shape of the furcular facet and ventral prominence of the head, but perhaps it is of phylogenetic significance that certain of the distinguishing features evidence an affinity to the mergansers Mergellus and Mergus. These features are the shallower head (1.e., less pronounced ventrolateral prominence), more curved coracohumeral groove, and the general appearance of the glenold facet. 
In the second group of sea ducks, clangula has the most distinct coracoid. (1) The depth through the scapular facet varies from 12.3 to 13.1 per cent of length. The range obtained for Histrionicus and the scoters 1 s 13.2 to 14.3 per cent. (2) The axis of head has a smaller angle to the plane of the dorsal surface (71 to 79 degrees); in the scoters the range is 77 to 87 degrees, and in Histrionicus 78 degrees was recorded. (3) The sternal facet varies from 39.6 to 43.4 per cent of the length, whereas in the others it ranges from 42.9 to 49.9 . (4) The furcular facet has a triangular appearance, the smallest angle being at the ventral prominence. In the other three genera the facet presents a more ovoid shape.

Histrionicus is characterized by the following features. (1) The depression in the triosseal canal is very deep in the one available specimen. (2) The ventromedial edge of the shaft is thin. In Oidemia, where the triosseal depression 1 s usually deep, the edge is relatively wide, and constitutes about half of the shaft depth, measured between the procoracold and the head. (3) The head has a less protruding ventral prominence, but the rounded furcular facet appears more triangular than in the scoters. (4) The medien portion of the ventral lip of the sternal facet is inconspicuous, extending only a short distance up the shaft.

There are three features in oldemia that aid in its separation from Melanitta. (1) The sternal facet varies from 46.6 to 49.9 per cent of length. Melanltta varies from 42.9 to 44.9 per cent. (2) The depression in the triosseal canal 
is deep. Although variable, it is not as deep in Melanitta. (3) The ventral prominence of the head is smaller and results in an almost circular furcular facet. In Melanitta, because of the large ventral prominence of the head, the furcular facet is ovoid in shape.

Tribe oxyurini.

\section{St1ff-talled Ducks}

The stiff-talled ducks have a falrly distinctive coracoid. (1) The ventral portion of head extends far down the sha ft. (2) The brachial tuberosity is reduced. (3) The sterno-coracoidal process is prominent. (4) The sternal facet, in posterior view, is strongly arched throughout its length.

Heteronetta, the least specialized genus, has coracoldal features that indicate a close affinity to the other members of the tribe, but it may be distinguished as follows.

(1) The depth through the scapular facet is 11.8 per cent of the length. Nomonyx and oxyura range from 9.6 to 11.5 per cent. (2) The axis of the head is 67 degrees from the plane of the dorsal surface. In other members of the tribe the range is from 72 to 78 degrees. (3) The angle between the sternal facet and the internal edge of the shaft is 84.5 degrees. In other stiff-tails the range is from 86 to 96 degrees. In these three criteria Heteronetta is intermediate between more specialized stiff-tailed ducks and the dabbling ducks.

Nomonyx can be separated from other members of the tribe as follows. (1) The triosseal canal is narrow. The 
distance between the undercut of the brachial tuberosity and the procoracoid constitutes only 10.9 to 11.1 per cent of the length. In others the range is from 12.0 to 16.6 . (2) The width of the shaft varies from 8.4 to 8.7 per cent of the length. A range of 9.1 to 11.1 was obtained for other stiff-tails. (3) The depth through the scapular facet, 10.8 to 11.5 per cent, 18 intermediate between Heteronetta (11.8) and oxyura $(9.6$ to 11.0$)$. (4) The brachial tuberosity is reduced. Nomonyx is closest to oxyura, but the numerous characters outlined above speak for 1ts distinctness.

Oxyura is characterized as follows. (1) The relative depth 189.6 to 11.0 per cent. (2) The relative width $1 \mathrm{~s}$ 9.1 to 10.7. (3) The axis of the head to the plane of the dorsal surface is 72 to 75 degrees. (4) The angle between the sternal facet and the internal edge of shaft is 87 to 96 degrees. (5) The triosseal canal has a relative width from 12.0 to 15.2. This last feature best distinguishes oxyura from Nomonyx, which has a narrow trlosseal canal. Blziura has a unique coracold, with the ventral portion of the head larger and more ventrally directed than in any other anatid. In medial view the entire area above the glenold facet appears bent ventrally, which makes the ventral portion of the head even more distinct. The following features aid in characterizing the genus. (1) The depth through the scapular facet 1812.2 per cent of the length. A maximum of 11.8 was obtalned for the other genera. (2) The width of the shaft is 11.1 per cent of the length. A maximum of 10.7 was obtained for the others. (3) The axis of the 
head is closer to perpendicular to the plane of the dorsal surface (78 degrees) than in other genera (whose maximum is 75 degrees). (4) The trlosseal canal is 16.6 per cent of the length; 15.2 is the largest in the other stiff-tailed ducks.

Downs (1954) studied the coracold of several species of North American ducks. He concluded that the degree of angulation of the head is related to the method of taking flight. Those forms capable of steep ascent (dabbling and perching ducks) have lesser angulation between the axis of the head and the plane of the dorsal surface, whereas those which take off, at a low Incline (diving ducks) have greater angulation. The data obtained from the present series of ducks support Downs's theory. A range from 61 to 75 degrees was obtained from examples of the dabbling and perching ducks. The range for the specles assigned to the four trlbes of diving ducks was 69 to 87 degrees, except for Heteronetta (67 degrees).

The correlation between structure and function may have wider application. The pled goose, whistling ducks, swans, and geese have considerable angulation between the axis of the head and the plane of the dorsal surface $(79$ to 93 degrees), and apparently they take flight at a relatively low angle.

\section{Scapula}

The scapula has few features of taxonomic importance. Howard (1946) has already commented on the marked variability 
in the structural details of the element in swans. Since only qualitative features are considered, only a few genera and generic units can be characterized.

\section{Anseranatinae}

As with other elements, there are greater qualitative differences between the scapula of Anseranas and those of other waterfowl than there are between those of any two other members of the family. The following features of the scapula of Anseranas seem most important. (1) The acromion is short, barely extending beyond the coracoidal articulation. In other waterfowl the acromion is long and pointed. (2) The triosseal ridge (a dorsally situated prominence of the acromion) is a knoblike protuberance that extends over the anterior edge of the acromion. (3) The blade is narrow and convex ventrally and the apex is pointed. (4) A pneumatic fossa is present on the dorsal surface between the glenold facet and the acromion. Of the remaining anatids only true geese, Coscoroba, and Cereopsis possess this feature.

\section{Anserinae}

The subfamily Anserinae cannot be characterized adequately by features of the scapula.

\section{Tribe Dendrocygnini.}

\section{Whistling Ducks}

The scapula of whistling ducks cannot be separated consistently from those of most of the Anatinae. The one feature that seems fairly Characteristic of Dendrocygna is a 
narrow, polnted apex. The blade is also frequently narrow, although in some specimens it is wide. That Anseranas also has a pointed apex and a narrow blade may be of phylogenetic significance.

Tribe Anserint. Swans and Geese

The occurrence of the pneumatic fossa near the anterior end of the dorsal surface of the scapula is of taxonomic significance within the swan and goose tribe. Swans lack the fossa, whereas in Coscoroba and true geese it is present. Three scapular features that aid in separating olor from cygnus were 11sted by Howard (1946). (1) The muscular attachment on the ventral surface of the acromion forms a short crest slightly back from the internal border distally. In Cygnus the attachment follows the internal edge more closely. This character made possible the separation of all but 4 or 5 of the 36 avallable swan specimens. (2) The acromion 18 shorter and broader in 이아. Th1s feature, which is best understood by comparing the angle between the acromion and the shaft, is somewhat useful in distinguishing the two genera. In cygnus, and particularly $c$. melancoriphus, the angle is more acute between the acromion and the shaft; and, therefore, the acromion appears longer and more slender. (3) The shaft is thinner in 이아. This property does not seem applicable to my series of swans. Chenopis resembles Cygnus in all of the features discussed above. The scapula of coscoroba differs from those of geese in the following ways. (1) The pneumatic fossa is shallower. 
(2) The acromion and 1ts trlosseal ridge are smaller. The blade is wider.

Gener1c criteria are not present on the scapulae of geese. The only comment made by Miller (1937) for the five genera of true geese that he studied was that the scapula of Nesochen 1s proportionately smaller and weaker. The one Nesochen in the present series agrees with these generalizations.

\section{Anatinae}

It is not possible to separate any of the closely related tribes of Anatinae on the basis of the scapula. There are, however, features that aid in distinguishing certain tribes or tribal groups. These features are discussed under the classlfication of Delacour (1954, 1956, 1959).

\section{Tribe Tadornini. Sheldrakes}

Cereops1s differs from the sheldrakes and resembles the true geese in that the scapula possesses a pneumatic fossa. The genus can be separated from the true geese by the following additional scapular features. (1) The acromion is directed more mediad, and consequently the surface posterior to the acromion, including the glenold facet, is broad. (2) The anterior edge, between the coracoldal articulation and the acromion, is thicker. (3) A protuberance is present on the dorsomedial edge of the neck. Cereops1s, true geese, and most other waterfowl possess a dorsal protuberance that lies in the middle of the shaft; but true geese lack the more anterior and median prominence found in Cereopsis. 
(4) The gleno1d facet iles almost in the plane of the anterior portion of the shaft. In true geese the anterior portion of the facet is typically inclined lateroventrally.

The remaining genera of sheldrakes have no outstanding qualitative features to separate them from related groups of Anatinae, or from each other.

\section{Tribe Anatini. Dabbling Ducks}

A few minor differences between the scapulae of dabbling ducks and of diving ducks of the pochards, elder, and seaduck tribes are detectable when large series of the element are studied. (1) The acromion is shorter, with the ventral surface flat in dabblers. In diving ducks of the tribes listed above the acromion is longer, and in ventral view it usually reveals a knoblike process. As a result, the anterlor edge of the bone between the acromion and the glenold facet 18 concave; in dabblers the edge is straighter.

(2) The proximal portion of the scapula is not rotated. In the divers, including the stiff-tailed ducks, the rotation is such that the internal edge and the acromion appears depressed. (3) The blade is usually broadest near the midpoint. In pochards, and particularly Aythya, the blade is narrow and tapers near 1 ts apex. In the other diving tribes the blade is wide throughout.

Three genera among the dabblers have scapular features that enable them to be distinguished from other members of the tribe. 
In Hymenola1mus the acromion is almost parallel with the trend of the blade, whereas in other dabbling ducks it is more flaring. Furthermore, in Eymenolaimus the blade is of uniform width, with a blunt apex.

In Merganetta the triosseal ridge is reduced, and the anterior edge of the element is thick and forms almost a straight ilne. The blade is narrow, but rather thick.

In Rhodonessa the blade is narrow and the proximal portion is rotated as in the pochards, but the ventral surface of the acromion is flat Instead of knoblike. Thus another element can be added in which Rhodonessa shows affinities with the pochards.

Tribe Cairinini. Perching Ducks

The shape of the blade and acromion 1s, generally speaking, more like that of the dabblers than the divers. Plectropterus differs from other members of the tribe as follows. (1) The muscular line on the dorsal surface extends from the prominence at the posterior end of the neck to the internal edge. In other perching ducks the ridge curves anterolaterally and meets the glenold facet. (2) The acromion is shorter and thicker.

Cairina is typified by the following characteristics. (1) A wide depression is present on the dorsal surface between the glenoid facet and the triosseal ridge. The depression may contain small pneumatic foramina. (2) The blade 1s thick and rounded. 
pteronetta lacks the dorsal depression and thick blade of Cairina. It is similar to Aix, Dendronessa, Amazonetta, Cheniscus, and Nettapus, none of which is separable from the other.

Chenonetta possesses a wide, rounded acromion, whereas In Sarkidiornis the same structure appears to flare more than In the other perchers.

Trtbe Aythyint. Pochards

The pochards are characterized as follows. (1) The acromion is longer and with a knoblike ventral surface. (2) The proximal portion of the element is rotated so that the internal edge and acromion appear depressed. (3) The blade is relatively thin throughout.

Metoplana has the Slade usually tapering as in the dabblers, but the anterior end is rotated, and the ventral surface of the acromion is knoblike as in Aythya.

Netta has the acromion shorter than in other pochards, but it is still knoblike. The blade is narrow and the anterior end is internally depressed.

\section{Tribe Somaterilini. Elders}

The elders have the anterfor end rotated as in other divers, and the blade unlform in width and rather wide as in the sea ducks.

Lampronetta appears indistinguishable from Somateria in scapular characters.

Polysticta has an acromion that follows more closely the trend of the shaft. This makes $1 t$ appear longer and 
with a larger concave edge between it and the glenoid facet.

\section{Tribe Mergin1. Sea Ducks}

The scapulae of sea ducks can frequently be separated from those of other waterfowl except the eiders. (1) The anterior end is rotated as previously described. (2) The blade is unfform in width and rather wide with a blunt apex. There is often an abrupt bend in the blade near the posterior end that should not be confused with the tapering found In approximately the same place in the dabblers.

The various members of the tribe cannot be distinguished by qualitative features of the scapula.

Tribe oxyurint.

\section{St1ff-talled Ducks}

The four available genera of stiff-talls form a rather distinct group as evidenced by the following features of the scapula. (1) The acromion is directed more anteriorly than In any other ducks. (2) The blade is very uniform in width, falrly narrow, and often thick. (3) The glenold facet is laterally compressed.

From features of the scapula, Nomonyx seems the least specialized of the stiff-talls. The glenold facet is only slightly compressed and affords the best means of separating the genus from other members of the tribe. The thin, anteriorly directed acromion, and narrow but thick shaft serve to separate Nomonyx from Aythya, which 1t resembles in other scapular features.

Heteronetta is also not as extreme in specialization of 
the scapula as are oxyura and Blziura, but it is closer to these genera than to Nomonyx. It is readily distinguished from members of other tribes by the features 11sted for all st1ff-tailed ducks.

In Eeteronetta the glenold facet is more compressed medially than in Nomonyx, and the acromion 18 shorter than in Oxyura and Blziura.

In oxyura the internal edge of the acromion forms essentially a stralght line with the internal edge of the blade, and the glenold facet is greatly compressed, Furthermore, the blade is wider than in Nomonyx and Heteronetta.

Biziura is quite similar to Oxyura, from which 1 t can be separated by the presence of a thick anterior end and a more prominent triosseal ridge. In addition, the blade is curved such that there is a shallow, elongate concavity along the anterointernal edge.

\section{Furculum}

Considerable individual variation and a lack of art1culating surfaces make the furculum a very poor element taxonomically. As with all the elements studied, however, there are some features worthy of mention.

\section{Anseranatinae}

Even an element as poor taxonomically as the furculum Indicates that Anseranas is unique among the waterfowl. The following characteristics were noted. (1) The furcular process 1s large and truncate. (2) Pneumatic foramina are present in the crotch formed at the point of fusion of the two 
clavicles. (3) The clavicles are compressed, and relatively straight in lateral view. (4) The appearance in anterior view is V-shaped instead of $\mathrm{U}$-shaped. (5) The coracoldal tuberosity is small or lacking. The distinctive nature of the furcular process and shape of the furculum in anterior aspect were noted by Miller (1919) .

\section{Anserinae}

The Anserinae cannot be distinguished as a unit by features of the furculum.

Tribe Dendrocygnin1. Whistling Ducks

The furculum of wh1stling ducks is nonpneumat1c, w1th a small coracoldal tuberosity and rather deeply curved clavicles. In most cases it is indistinguishable from those of the Anatinae.

Tribe Ansertni. swans and Geese

Most genera in the swan and goose tribe have the furculum pneumatic, with the foramina occurring along the lateral surface of the clavicles. In addition, the clavicles tend to be more compressed, with the coracoidal tuberosity smaller than in the Anatinae.

The furcula of swans and geese can be separated in most cases. Swans and coscoroba have the following features. (1) An extended depression occurs along the lateral surface 
of the clavicles. It is lacking in some Cygnus melancor1phus. (2) Pneumatic foramina, one to several, frequently large, are located in the depression.

Coscoroba differs from true swans in a number of ways. (1) The symphysis is narrow and a furcular process is present. (2) The depression on the lateral surface of the clavicles is restricted to the area between the coracoidal and scapular tuberosities. (3) The ridge for the attachment of the interclavicular membrane crosses the lateral surfaces of the clavicles directly from the coracoldal tuberosity. In true swans the ridge runs a considerable distance along the anterolateral surface before crossing over to the posteromedial s1de. (4) The pneumatic foramina are mall and scattered throughout the depression.

The following features serve to separate olor from cygnus and Cnenopis. (1) The symphyseal area 18 extended posterodorsally to allow space for passage of the trachea ventrally Into the sternal carina. In other waterfowl, with the poss1ble exception of Anseranas, the trachea always remains dorsal to the furcular symphysis. In Cygnus and Chenopls the symphyseal area is broad and smooth. (2) The clavicular depression is longer, deeper, and with several large pneumatic foramina. In cygnus olor and Chenop1s the depression is less well developed, and in cygnus melancorlphus it is virtually absent. The pneumatic foramina, although typically large, usually number one or two, and in cygnus melancorlphus they are minute or absent. (3) The clavicles are thinner and more pointed. In cygnus and Chenop1s they are much thicker 
and with rather blunt scapular tuberosities.

In geese there is no extended depression on the lateral surface of the clavicle, and the pneumatic foramina are elther absent, or if present are restricted to the area between the coracoldal and scapular tuberosities.

Within the geese, there is taxonomic significance to the occurrence of pneumatic foramina in the furculum. Branta and Nesochen lack the foramina, whereas they are present in Anser, Cygnopsis, Eulabela, and Philacte, and in Chen except for one of nine specimens of $c$. ross11. No other criteria were noted for the geese, although Miller (1937) mentioned that in Nesochen the furculum is smaller and the processes weaker than in the North American genera.

\section{Anatinae}

Within the diverse subfamily Anatinae only a few genera or generic groupings are recognizable from the furculum.

\section{Tribe Tadornini. Sheldrakes}

In its furculum Cereopsis resembles the geese more closely than the sheldrakes. Three features easily distinguish it from the latter group. (1) Pneumatic foramina are present in the slight depression along the lateral surface between the coracoidal and scapular tuberosities. (2) The clavicles are compressed and appear straighter in lateral view.

The typical sheldrakes appear intermediate between the Anserinae and the remaining duck tribes. Sheldrakes have the coracoidal tuberosity poorly developed as in the geese, 
and the clavicles are only slightly compressed as is typical of ducks. Separation of the sheldrake genera from each other 18 not possible by qualitative features of the furculum.

\section{Tribe Anatini. Dabbling Ducks}

In dabbling ducks the furcular process and coracoidal tuberosity are typically large, and the clavicles are rather round in cross section. Exceptions are Rhodonessa, Bymenolaimus, and Merganetta, in which the furcular process is essentially lacking. In the latter two genera the clavicles are weak, and the element is broadly U-shaped.

Tribe Calrinini.

\section{Perching Ducks}

Plectropterus does not fit in well with the other genera of perching ducks. Its furculum differs in having the coracoidal tuberosity reduced and the clavicles compressed. Both of these are characteristics of the sheldrakes.

Cairina frequently possesses a small pneumatic foramen in one or both clavicles below the scapular tuberosity but is otherwise typical of the tribe.

Tribes Aythyini, Somateriint,

\section{and Mergini. Pochards, Eiders, and Sea Ducks}

Members of these three tribes have the furcular process small or absent, except in the pochard Metopiana where it is rather prominent. In Metopiana and in those individuals of the other species where a trace of the furcular process occurs, it is typically notched. The feature correlates with an expansion posteroventrally of the double sterno-furcular 
ilgament with a consequent reduction in the single median ligamentous membrane.

Merqus shows greater curvature throughout the length of the clavicles in lateral view, but otherwise it is not markedly different from other sea ducks.

\section{Tribe oxyurini.}

\section{Stiff-tailed Ducks}

The furculum of the stiff-tailed ducks is somewhat characteristic in that the element is thin and rather weak. Heteronetta, which was placed only provisionally in the tribe by Delacour (1959), agrees in the reduction of the element. The least reduced furculum occurs in Nomonyx. A prominent furcular process is lacking in all members of the tribe; this is typical of all divers.

\section{Pemux}

The leg seems more susceptlble to adaptive modifications than the wing. The femur in ducks that dive, for example, shows great uniformity even though other taxonomic criteria indicate many of the genera are only distantly related.

\section{Anseranatinae}

The long, slender femur of Anseranas has several unique properties. (1) The posterior intermuscular line swings from above the internal condyle to the external edge of the shaft, and thence continues to the obturator ridge. In other waterfowl the line is confined to the medial side of the shaft and fails to meet the obturator ridge.

(2) The 
internal condyle $1 \mathrm{~s}$ elongate and equal or subequal in distal extent to the external condyle. In other anatids the internal condyle is flattened and does not extend as far distally.
(3) The rotular groove is narrow.
(4) The element is less contorted so that the head is directed more posterlad than in other waterfowl. (5) The anterior surface of the shaft is convex at a point two-thirds the distance from the proximal end.

\section{Anserinae}

One property of the femur tends to link the whistling ducks, swans, and geese, and separate them as a group from the Anatinae. The external condyle has the anterior ridge elevated from the trend of the shaft. In other waterfowl the anterior surface in this region tends to form a straight or posterior curving line.

Tribe Dendrocygnini. Whistling Ducks

The femur of whistling ducks is easily distinguished from those of Anseranas, the other Anserinae, and the diving tribes in the Anatinae. It superficially resembles that of the nondiving Anatinae. The following criterion, in combination with the feature listed as common to all Anserinae, should 1dentify the femur of Dendrocygna. The whistling ducks have a convexity of the shaft similar to that described for Anseranas. In other Anatidae the shaft is curved in a similar direction at this point, but the curve continues onto the condyles instead of straightening out distally. 
Tribe Ansertint.

Swans and Geese

of all waterfowl swans and geese have the straightest femur. In lateral view, the long axis of the shaft is $v i r-$ tually a stralght 11ne. The bone also tapers markedly from the wide trochanteric end to the thinnest point, which lies Immediately proximal to the condyles. Cygnus melancor1phus shows some curvature.

Swans and geese are very similar in the form of the femur. One consistent criterion for separating the two is that the external and flbular condyles flare laterally in swans; In geese they are directed more posteriorly.

Coscoroba can be separated from other swans by characteristics of the femur. (1) The head is shorter and the neck is less distinct. (2) The trochanter, particularly at 1ts anterior tip, extends proximally. The proximal extent of the trochanter 18 obviously greater than that of the head.

Within the swans no feature of the femur $1 \mathrm{~s}$ strong enough to separate any genus completely, but the form of the neck as seen in proximal view is helpful. In cygnus and Chenopis there tends to be a depression on the anterior surface between the trochanter and the head. In olor a low ridge extends from the trochanter toward the head. Thus the neck appears more constricted in Cygnus and Chenopis than in 이오.

The shape of the femur is of little use in defining the genera of true geese. Miller (1937) 1isted the following features that ald in the separation of Chen and Branta. 
(1) In Branta the medial crest bordering the popliteal area is less deflected medially, and hence it is straighter and more in a line with the shaft. (2) In Chen the rotular groove is narrower, and thus appears deeper. (3) In Chen the outer surfacesof the condyles converge toward one another anterforly, whereas in Branta they are more nearly paral1el. (4) In Chen the internal condyle is narrower. In the present series the first of these four features is the most useful, but all are highly fallible. These features are made more obscure by the fact that the skeleton of Anser is extremely similar to that of Chen, as noted by Miller (1937) and Howard (1946).

Nesochen differs from other geese, as noted by Miller (1937), In the following ways. (1) The rotular groove is extremely broad. (2) The neck is short and directed more posteriad, less mediad.

Miller (1937) also commented on Philacte, which has the popliteal depression narrowed by inflation of the lateral margin.

To the features listed above one more can be added. In Branta and Nesochen the trochanter is extended slightly more proximad at its anterior tip, and the posterior rim straightens instead of curving toward the head. Chen, Anser, and Cygnopsis, in which the trochanter has its most proximal extent in the middle, and the posterior rim curves toward the head, are usually separable by this feature. Eulabela, and to a lesser extent Phllacte, resemble the latter group most In this respect. 
Anatinae

As a unit, as opposed to the Anserinae, the Anatinae have no significant elevation of the anterior edge of the external condyle from the shaft.

The seven tribes of Anatinae are divisible into two groups on the basis of femoral characteristics. One group contains the nondiving tribes, the sheldrakes, dabbling ducks, and perching ducks. The other group contains the diving tribes, the pochards, eiders, sea ducks, and stifftalled ducks. The distinguishing features are as follows. (1) The shaft is less curved in lateral and anterfor views in the non-divers. (2) The anterior ridge of the trochanter is larger in the non-divers, and the shaft in lateral view curves anterforly as it passes proximally to the anterior trochanteric prominence. (3) The popliteal fossa is shallow in the non-divers. (4) The outer surfaces of the condyles are nearer parallel, whereas in divers they diverge poster1orly. These differences cause the femur, when it is placed anterior surface down on a plane, to have the head elevated from the plane in the nondiving tribes, whereas it lies on the plane in the diving tribes. Merganetta of the dabblers and Metoplana of the pochards are exceptions. Heteronetta appears intermediate because the head is slightly elevated from the plane. In rachyeres, although the head is distinctly elevated, there are other features that cause it to resemble the diving assemblage. 
Tribe Tadornint. Sheldrakes

The following femoral characteristics while not diagnost1c, aid in separating the sheldrakes from the other nondiving ducks. (1) The head is directed more proximally, less laterally. (2) The trochanter in lateral view extends more anterforly, and in proximal view it curves more medially. In dabblers and perchers the posterfor portion of the trochanter tends to form an angle, whereas in the sheldrakes it is a smooth curve.

significant differences in the femur were not found among the sheldrakes, except for the aberrant genera cereops1s and Tachyeres.

Cereopsis resembles the Anserinae in that the anterior ridge of the external condyle is elevated from the shaft. The following additional features serve to distinguish the genus. (1) The externel and fibular condyles and the fibular groove are directed medially at the distal end. Thus, the fibular condyle extends farther distally than the point of its junction with the external condyle. The opposite 18 the case in all other waterfowl. (2) The shaft in anterior view is stralghter, as described for the true geese.

The femur of Tachyeres is unique. (1) A deep pit occurs on the posterior surface, medial to the obturator ridge and distal to the illac facet. (2) A depression is present in the rotular groove. The shaft is more curved, and the popliteal fossa 1s deep, adaptations for diving. It also has a prominent anterior ridge, and the condyles have the 
outer aurface 1ess divergent posterlorly, features of the nondiving ducks.

Tribes Anatint and Cairinint. Dabbling and Rerching Ducks

The numerous genera of dabbling and perching ducks, w1th but few exceptions, cannot be distinguished on the basis of femoral characteristics.

Bymenolaimus and Merganetta, two diving members of the dabbling-duck tribe, have the popliteal fossa deep. Dymenolaimus, the least speclalized of the two, possesses the following additional features. (1) The head 1s larger, and

(2) the rotular groove is wider.

Merganetta resembles the divers more than the other dabblers in the features 11sted to separate the two groups. It can be separated from the diving tribes in the following ways. (1) The internal condyle has the posterior end d1rected more mediad, a feature shared with the pochards. (2) The trochanter in proximal view has its anterior portion reduced more than in pochards. (3) The posterior intermuscular IIne forms a more prominent rldge to the base of the head.

Although Rhodonessa is very almilar to typical dabblers In the shape of the fermur, it 1s linked with the pochards by the first three characteristica 11sted for Metopiana.

Plectropterus is similar to the sheldrakes in the femoral features 1isted for that tribe. 
Iribe Aythyin1. Pochards

It is easy to separate the femur of pochards from those of other diving ducks. (1) The trochanter in proximal view extends farther anteriorly. (2) The head in proximal view 18 smaller. (3) The medial side of the internal condyle is less flared laterally.

Metoplana, as indicated by other taxonomic criteria, is a pochard. The form of the femur indicates it is poorly specialized for diving. On criterla used to differentiate the femora of diving and nondiving ducks Metoplana resembles the nondivers, but 1 t may be separated from nondivers as follows. (1) In lateral view the anterior edge of the condyles are more deflected. (2) The external and fibular condyles are produced distally. (3) The internal condyle is enlarged and flares medially to leave a distinct depression on the medial side of the shaft. (4) The posterfor surface of the shaft possesses a raised ridge to the external condyle, and the portion of the shaft lateral to the ridge is depressed. (5) The head is directed more proximad, less laterad. Metoplana, of course, is separable from other pochards by the features used to separate the nondivers from the divers.

Netta, although closer to Aythya than is Metopiana in the form of the femur, also appears less specialized for diving than Aythya. The popliteal fossa is shallower and narrower, and the anterior portion of the trochanter is produced farther anteriorly. 
Tribes Somater1ini and Mergin1.

Elders and Sea Ducks

The femora of the remaining diving ducks, the elders, sea ducks, and stiff-talled ducks, are very similar. A combination of the following features separates the more similar elders and sea ducks from the stiff-tails. (1) The anterior ridge of the internal condyle is approximately equal in size to that of the external condyle. In stiff-ta1ls the ridge of the external condyle is larger. (2) The fibular condyle is less flared laterally. (3) The pit for the tibialis anticus is more prominent than in the stiff-tails.

Tribe Somaterilni. E1ders

The following features of the femur tend to separate the elders from the sea ducks. (1) The shaft in lateral view is straighter. Although varying with the genera, in sea ducks the posterior curvature of the shaft is greater, and thus when the anterior surface is placed on a plane, the internal condyle is elevated from the plane Hergus is an exception). In elders the internal condyle typically touches the plane. (2) The anterior ridge of the internal condyle curves farther mediad as it extends distally. This feature is poorly developed in Polysticta. (3) The scar extending up the lateral surface of the shaft from the flbular condyle 1s shorter.

Lampronetta cannot be distinguished from Somateria by femoral characteristics, but Polysticta has several distingulshing features. (1) The anterior portion of the trochanter possesses a more prominent, medially directed 
protuberance. (2) The fibular groove is narrower. (3) The ligamental attachnent, on the medial surface of the internal condyle, is a more prominent projection. (4) The anterior ridge of the internal condyle is straighter, not flared as far mediad.

Tribe Mergini. Sea Ducks

The two groups of genera of sea ducks established on the basis of other elements st1ll hold with the femur, but the differences are less apparent. (1) In Bucephala and the mergansers the trochanter has more of the anterior edge inflected, and thus the notch between it and the head is narrower. In the other sea ducks more of the trochanter slopes away from the head as it passes anteriorly, only the tip is inflected, and the notch 1s correspondingly w1der. (2) In Bucephala and the mergansers the fibular condyle, particularly in anterior view, appears to flare more from the shaft. This feature is especially good for separating Clangula and Histrionlcus from Bucephala, but it is poor for the scoters. Generic characters are distinct within the Bucephala and merganser group. In Bucephala (1) the shaft has much greater posterior curvature, and (2) 1t is thinner. The least width, given as a percentage of the total length, varles from 7.1 to 8.0 per cent. Mergellus ( 7.5 per cent) also has a thin shaft, but Lophodytes ( 8.3 to 9.2 per cent) and Mergus $(7.9,8.3$ to 9.8$)$ are much stouter.

In other femoral features Mergellus and Lophodytes are intermediate between Bucephala and Mercpis. (1) The shaft is 
straighter, without the abrupt bend found in Bucephala. (2) The shaft is narrow, without the marked lateral compression found in Mergus. The least depth of the shaft, given as a percentage of the total length in Mergellus and Lophodytes ( 9.5 to 10.7 per cent), overlaps Bucephala ( 8.0 to 9.9), but 1s narrower than Mergus (11.0 to 12.6). Mergellus differs from Lophodytes in that the shaft is thinner and narrower. (1) The shaft width 187.5 per cent of the total length compared with a range from 8.3 to 9.2 per cent in Lophodytes. (2) The shaft depth is 9.5 per cent compared with a range from 9.8 to 10.7 per cent in Lophodytes.

The characteristics that distinguish the straight, stout, compressed fermur of Mergus from the other three genera are all listed above.

The remaining four genera of sea ducks, Melanitta, Oldemia, Histrionicus, and Clanqula, are very similar in the form of the femur. The shape of the shaft, however, divides them into two groups. In Melanitta and oldemia, In lateral view, there is a more distinct posterior curvature at the point two-thirds the distance down the shaft. In Histrionicus and clangula the shaft is much straighter. When femora of the four genera are placed anterior surfaces down on a plane, the condyles almost touch the plane in Histrionicus and clangula, whereas in Melanitta and oidemia the condylar region is elevated more than two millimeters.

only the relative shaft widths separate the remaining two pairs of these genera. Oldemia varles from 8.2 to 8.5 
per cent of the total length, whereas Melanitta ranges from 7.2 to 8.0 per cent. Histrionicus measures 8.6 per cent; the range in clangula is 7.8 to 8.2 per cent.

Tribe oxyurint. St1ff-ta11ed Ducks

Although other elements of the stiff-talled ducks are quite distinctive, only minor differences in the fermur separate them from the elders and sea ducks.

Heteronetta is the least specialized of the four ava11able genera of stiff-talled ducks and has the following femoral properties. (1) The anterior portion of the trochanter $1 \mathrm{~s}$ enlarged. (2) The condyles have the outer surfaces more nearly parallel. (3) The shaft $1 \mathrm{~s}$ thin $(6.9$ per cent of the total length). In the other three genera the range $1 \mathrm{~s} 8.1$ to 10.1 per cent. (4) The head $1 \mathrm{~s}$ small. (5) The ridge extending up the poster1or surface of the shaft from the external condyle 18 reduced.

Nomonyx is also 11ttle speclalized. (1) The anterior portion of the trochanter is larger than in oxyura and B1ziura, but smaller than in Heteronetta. (2) The internal condyle has the posterior portion directed more mediad. (3) The ridge extending up the posterior surface of the shaft from the internal condyle is reduced. (4) The shaft In lateral view is stralghter, and lacks the distinct posterior flexure. In characteristics of the femur, Nomonyx looks less 11ke Oxyura than does B1z1ura.

B1zlura and Oxyura are highly speclalized, but in different ways. (1) In B1z1ura the shaft is thicker, 10.1 per 
cent of the total length. The range in Oxyura is 8.1 to 8.5 per cent. (2) The trochanter extends proximally well beyond thé head, and 1ts distomedial surface is swollen in Biziura. (3) The posterior intermuscular line is indistinct, but the lobe near the midpoint is more prominent in Blziura.

\section{Tibiotarsus}

The tiblotarsus is a useful taxonomic element for certain waterfowl, but for others no distingulahing characteristics are present.

\section{Anseranatinae}

A few features, none of them striking, 1solate the t1blotarsus of the primitive pied goose, Anseranas. (1) The Iim of the internal condyle in medial view is more gently sloping and less extended posteriorly, and lacks the notch present in other waterfowl. (2) The posterior portion of the $\mathrm{rim}$ of the external condyle is gently sloping. (3) The posterlor ends of the rims of both condyles are elevated from the shaft more than in other waterfowl. (4) The Iigamental attachment 18 small. (5) The Inner cnemial crest is almost straight, with little lateral deflection.

\section{Anserinae}

It is impractical to attempt to define the whistling ducks, swans, and geese as a unit with so poor an element, taxonomically, as the tiblotarsus. 
Tribe Dendrocyanini.

Whistling Ducks

A combination of the following features usually allows for the identification of Dendrocygna. (1) The condyles are almost parallel. In other waterfowl they diverge more as they extend anteriorly. (2) The external ligamental prominence is smallex. (3) The external condyle 1s little produced anterlorly, and thus it appears circular in outline. In other waterfowl the outline is elliptical. (4) The fibulax crest is wide towards the distal end.

\section{Tribe Anserint.}

Swans and Geese

In swans and geese the lateral tip of the outer cnemial crest lacks the distally directed hook characteristic of other waterfowl.

The two groups within the tribe can be separated rather easily. In the swans and coscoroba the intermuscular line flares medially to reach the region of the ligamental attachment. In geese the line is straight and falls to reach the ligamental attachment. This feature possibly is correlated with the more terrestrial nature of the geese.

In Branta and Nesochen the Inner cnemial crest is straighter, whereas in the other genera it is deflected towards the lateral side.

A longer fibular crest, detected by Millex (1937), is useful for distinguishing Nesochen from the other geese. 
Anatinae

The Anatinae as a unit cannot be defined conveniently by characteristics of the tiblotarsus. Study of the element for the genera within the group indicates there are three primary sections: (1) sheldrakes; (2) dabbling ducks, perchIng ducks, and pochards; (3) elders, sea ducks, and stifftailed ducks.

Tribe Tadornini. Sheldrakes

The sheldrakes have the proximal portion of the intermuscular line straight and removed from the anteromedial edge proximally, as in the true geese. In this way they differ from the other Anatinae. The terrestrial habitat is suggested as a reason for the morphological feature. Tachyeres is an exception; it resembles the dabblers. The most obvious break in the characteristics of the tibiotarsi of the sheldrakes places Cereopsis, Chloephaga, and Neochen in one group, and Alopochen, Tadorna, and Casarca in another. The differences pertain to the distal condylar region. (1) The condyles are in line with the shaft in the first group, displaced medially in the other. (2) In the first group the internal condyle is essentially equal in anterior extent to the external condyle. In the other group the internal condyle is extended farther anteriorly.

Cereopsis has the hooked outer cnemial crest typical of the sheldrakes. It is intermediate between the sheldrakes and the true geese in the position of the intermuscular ine. Perhaps of greatest significance are several unique features. 
(1) A pronounced ridge extends from the outer cnemlal crest onto the anterior surface of the shaft, whose surface is convex. In other sheldrakes the anterlor surface is virtually flat. (2) The inner cnemial crest has little lateral flexure of the proximal tip. (3) The external articular surface has a much more prominent lobe, and the depression Immediately anterlor to $1 \mathrm{t}$ is much deeper. (4) The shelf medial to the external articular surface extends farther out over the posterior portion of the shaft. (5) The supratendinal bridge tapers toward the medial side, and 1 ts medial abutment is recessed from the medlal ridge of the shaft. (6) The tubercle for the oblique ligament, situated lateral to the supratendinal bridge, is enlarged (Wetmore, 1943).

Chlosphaga and Neochen resemble the other sheldrakes and differ from Cereopsis in lacking the pronounced ridge on the anterior surface of the tiblotarsus.

Chloephaga and Neochen may be separated by the relative width of the shaft. The width, which was taken with the callper legs parallel to the condyles, is reduced to a percentage of the length, which was taken with the exclusion of the cnemial crests. Chloephaga varies from 4.9 to 5.2 per cent; Neochen 1s 4.6 per cent.

Alopochen forms a link between Chlocphaga and Neochen and the genera of the other group. It has the following additional characteristic. The internal condyle has its posterodistal rim curving gently to the shaft. In Chloesphaga and Neochen the rim extends farther posteriorly and then curves abruptly to the shaft. 
Alopochen differs from Tadorna and Casarca as follows. (1) The internal condyle has the anterior protuberance almost parallel to that of the external condyle. In Tadorna and Casarca the internal condyle flares medially. (2) The shaft possesses less medial curvature.

Tachyeres is distinguishable from other sheldrakes in that (1) the Intermuscular Iine follows the anteromedial edge as in ducks other than sheldrakes; and (2) the condyles show greater medial deflection, with the external condyle extending farther distally and the internal condyle extendIng farther anteriorly, as in the section contalning the dabbling ducks. In Tachyeres the internal articular surface extends farther posterolaterally than in other imembers of the dabbling-duck section. Correspondingly the articular surface is supported by a raised ridge on the shaft.

Tribes Anatini, Catrinini, and

Aythyin1. Dabbling Ducks, Perching Ducks, and Pochards

In dabblers, perchers, and pochards the condyles of the tiblotarsus are displaced medially so that the external condyle obviously extends farther distad than the internal condyle. In addition the internal condyle tends to extend farther anterforly than the external condyle. Merganetta is not well defined by these features.

Tribe Anatini. Dabbling Ducks

Chaulelasmus, Spatula, and Mareca are not separable from Anas by qualitative features of the tibiotarsus, nor is Callonetta. Malacorhynchus, Rhodonessa, Eymenolaimus, and 
Merganetta, the other genera available in the present series are distinctive.

of the four definable genera, Malacorhynchus is most similar to the typical dabblers. The one available specimen, which has the cnemial crests eroded away, possesses a distinguishing feature in the enlargement of the ligamental attachment.

Rhodonessa has the following properties of the tibiotarsus. (1) The condyles are more in line with the shaft. (2) The internal condyle extends farther anteriorly, resenbling Netta. (3) The inner cnemial crest is directed more proximad, less anteriorly, as in pochards.

Eymenolaimus has the outer cnemial crest extending farther proximad, with the external edge directed more anterlorly, less laterad, and the shaft with a more distinct curvature, the medial side being concave.

Merganetta has the greatest number of distinctive features. (1) The inner cnemial crest is directed more proximad, less anteriorly. (2) The outer cnemial crest has the laterodistal end directed more anteriorly, less laterad. (3) The condyles are almost equal in distal extent. Tribe Cairinini. Perching Ducks

Diagnostic features of a qualitative nature are not well developed in the perching ducks. Apparent differences between certain genera usually break down in series. 
Plectropterus is the most distinct member of the tribe. The external condyle is almost in line with the external edge of the shaft, a feature typical of the sheldrakes.

Calrina has the condyles displaced farther medially than in most other perchers, and the shaft 18 robust, 5.9 to 6.7 per cent of the length; the maximum in other genera is 5.7 in pteronetta.

Tribe Aythyin1. Pochards

There is a tendency for the posterior intercondylar sulcus to be wider in pochards than in dabbling and perching ducks, but no additional features of the tiblotarsus are diagnostic of the tribe.

Metopiana has the following distinguishing characteristics. (1) The outer cnemial crest is broader and directed farther laterad. (2) The shaft is more robust; the width varies from 5.6 to 6.0 per cent of the length. In addition to these features, the shaft is significantly bowed, the medial surface being concave. The three avallable specimens are all from captives, however, where bowing of certain elements often occurs.

Netta and Aythya show closer resemblance to each other In the structure of the tiblotarsus than either does to Metoplana. In both genera the outer cnemial crest is narrower and directed more anteriorly. The shaft is thinner, the width being usually less than 5.0 per cent of the length.

Netta can be distinguished from Aythya as follows. (1) The outer cnemial crest lacks the prominent terminal 
apex and 1ts medial portion is less deeply concave. (2) The inner cnemial crest is shorter. (3) The condyles are more in line with the shaft, less deflected medially.

Tribes Somaterilini, Merqini, and oxyurint. Elders, Sea Ducks, and St1ff-tailed Ducks

Three duck tribes, the elders, sea ducks, and stifftalled ducks, compose a group in which the condyles of the tiblotarsus are typically equal in distal and anterior extent. Heteronetta and Nomonyx are exceptions and have certain resemblances to the nondivers.

Tribes Somateriini and Mergini. Elders and Sea Ducks

Eldexs and sea ducks are similar and differ from the stiff-tailed ducks as follows. (1) The internal condyle is less extended anteromedially. (2) The external ligamental prominence is small and does not extend as far laterad from the external condyle.

Tribe Somateriini. Fiders

The elders differ from the sea ducks and also from the stiff-talled ducks in the shape and direction of the outer cnemial crest, which is wider and directed more laterad, less anteriorly.

Polysticta can be distinguished from Somaterla and Lampronetta by a qualitative feature of the tibiotarsus. In polysticta the condyles lie more nearly in line with the shaft. 
Lampronetta shows no significant differences from Somateria, as has been the case with other elements. In both the internal condyle is deflected farther medially.

\section{Tribe Mergini. Sea Ducks}

The narrower, more posteriorly directed outer cnemial. crest separates sea-duck tibiotarsi from those of the similar elders.

The usual break in the sea-duck genera is evident from the tiblotarsus. In Bucephala, Lophodytes, Mergellus, and Mergus the proximal edge of the outer cnemial crest $18 \mathrm{vir}$ tually a straight, diagonal 1ine. In Melanitta, 이emia, Histrionicus, and Clanqula the proximal rim of the outer cnemial crest is distinctly bent towards the inner cnemial crest as 1t nears the juncture of the two.

Bucephala and the mergansers are very similar in the appearance of the tibiotarsus. They differ slightly in additional details of the cnemial crests. In Bucephala the inner cnemial crest appears narrower in medial view and it extends proximally as a prominent peak. When the element is placed with the posterior surface, including both condyles, lying on a plane the external articular surface extends farther laterad than the outer cnemial crest. In Mergus the inner cnemial crest is wider, and at its juncture with the outer crest it bends anteriorly. In the same view, in Mergus the outer cnemial crest usually extends farther laterad than the external articular surface. Lophodytes and Mergellus are closer to Mergus in the width of the inner cnemial 
crest and in the lateral extent of the outer cnemial crest, but they are more like Bucephala in that the peak is directed farther proximad. Lophodytes generally has a wider shaft (5.2 to 5.8 per cent of the length) than Bucephala (4.8 to 5.4). whereas Mergellus is thinner (5.0) than Lophodytes. Clangula and Histrionicus differ slightly from the scoters in that the enlarged external ligamental prominence protrudes beyond the rim of the external condyle.

In Histrionicus, but not in clangula, the anteroproximal portion of the external condyle is thicker, and in lateral view it appears more circular, less elliptical.

No significant differences were noted between the tibiotarsi of Melanitta and oldemia.

Tribe oxyurini. Stiff-tailed Ducks

The stiff-tailed ducks are separable from the eiders and sea ducks by the following properties of the tiblotarsus. (1) The internal condyle overhangs the anteromedial edge of the shaft to a greater extent than in the other two tribes. (2) The external ligamental prominence is enlarged so that it extends well lateral of the condyle.

Heteronetta is the least specialized of the four genera available. Itg tibiotarsus appears intermediate between those of the other stiff-talls and those of the nondivers and has the following properties. (1) The condyles are displaced farther medially than in nondiving ducks, but not to the extent found in other divers. (2) The external condyle extends farther distad than the internal condyle as in the 
nondivers. (3) The amount of anterfor overhang of the internal condyle is greater than in the nondivers, but less than in other stiff-tails. (4) The outer cnemial crest is directed more laterad, less anteriorly. In this respect Heteronetta resembles nondiving ducks, and not stiff-tails. (5) The shaft 18 thinner (4.1 per cent of length) than in other st1ff-tails (5.0 to 6.4 per cent).

Nomonyx appears less specialized for diving than either oxyura or Blziura. Its tiblotarsus has the following characteristics. (1) The external condyle extends farther distad as in the nondivers and Heteronetta. (2) The external ligamental prominence is obscure in anterior view. (3) The outer cnemial crest is intermediate in its direction between Heteronetta and the other stiff-tails. (4) The inner cnemial crest lacks the long rldge found in the more speclalized genera of the tribe. (5) The shaft width (5.4 per cent of length) is similar to that of oxyura (5.0 to 5.4), thicker than Heteronetta (4.1), and thinner than Biziura (6.4). oxyura and Bizlura have the following features of the tiblotarsus in common. (1) The distal extent of the two condyles is equal or subequal. (2) The external ligamental prominence is obvious in anterior view. (3) The outer cnemial crest is directed more anteriorly than in the two less spectaltzed stiff-ta1ls. (4) The inner cnemial crest possesses a ridge that extends distally beyond the proximal end of the fibular crest.

Although the tibiotarsi of Blziura and oxyura are quite similar, there are at least three good qualitative characters 
to separate them. (1) In B1zlura the shaft is thicker, 6.4 per cent of the length, as opposed to a maximum of 5.4 per cent in the other genera. (2) In Blziura the shaft, in lateral view 18 virtually straight. In oxyura and Nomonyx there is a distinct curvature so that the posterior side is concave. (3) In Blzlura the proximal edge of the outer cnemial crest is virtualiy a straight line. In oxyura it is deeply concave.

\section{Tarsometatarsus}

The tarsometatarsus is the best taxonomic element of the leg. The many articulating surfaces are no doubt part of the reason for 1 ts usefulness. As with other leg bones, however, adaptive modifications frequently obscure the more basic features.

\section{Anseranatinae}

Anseranas has many distinctive features of the tarsometatarsus. The following seeru most important. (1) The median calcaneal ridge of the hypotarsus is greatly enlarged. In all other waterfowl the median ridge is the largest of the four, but it is not proportionately as large as in Anseranas. (2) The facet for metatarsal I 1 s deep and prominent, possibly as a reflection of a stronger hind toe useful for perching. In other waterfowl there is virtually no evidence of the facet. (3) The shaft in lateral view is thin. In other waterfowl the shaft is thicker, especially distally. (4) The wing of the trochlea for digit II 1s greatly enlarged. (5) The trochlea for digit II lacks a pronounced median 
groove. (6) The external rim of the groave of the trochlea for digit IV is extended posteriorly.

\section{Anserinae}

One feature of the tarsometatarsus indicates a close relationship between the whistling ducks and the swans and geese. The trochlea for digit II has a prominent lobe on the anterior side at the point of the most proximal extent of the articulating surface.

\section{Tribe Dendrocygnin1.}

\section{Whistling Ducks}

The following distinguishing characteristics of the tarsometatarsus of Dendrocygna seem most important. (1) The anteromedial edge is sharply ridged. (2) The internal cotyla is deeply cupped by a proximal extension of the internal edge. (3) The shaft is rather unfform in width. (4) The trochlea for digit II lacks a prominent median groove, and the internal edge has a pit that extends distally to bisect the articular surface. Anseranas is the only other anatid without a groove in the second trochlea.

\section{Tribe Anserini.}

Swans and Geese

The tarsometatarsi of swans and geese show a marked resemblance to those of sheldrakes. From waterfowl other than sheldrakes the swans and geese can be separated by the following tarsometatarsal features. (1) The trochleae for diglts II and IV, and particularly II, are spread. (2) The shaft is narrow in anterior view, and the external edge has 
a prominent curve. In other waterfowl, the external margin Is usually a straighter line onto the trochlea for digit IV. The following additional features ald in separating swans and geese from sheldrakes. (1) The trochlea for dig1t I in internal view $1 \mathrm{~s}$ directed more posteriorly and proximally. (2) The distal foramen in posterior view appears more nearly perpendicular to the shaft.

True swans differ slightly from geese in that the groove in the trochlea for digit IV continues anteroproximally to the most proximal part of the trochlea. In geese the groove is Interrupted by a swelling. Coscoroba has a swelling, but this is smaller than in geese.

There are individual differences, and size differences that allow for the separation of many swan specimens, but consistent criteria of a qualitative nature are nonexistent. Howard (1946) remarked that in the swans generic distinctions are less apparent in the tarsometatarsus than in some of the other elements. My observations agree with hers. Dven Coscoroba cannot be satisfactorily characterized from this element.

In geese, as opposed to other waterfowl, the trochlea for digit IV has a prominent swelling at the proximal end of the anterior surface of the trochlear groove.

The present series of goose tarsometatarsi supports the statement made by Miller (1937) that no one feature serves to differentiate Branta, Anser, or Chen. It is even difficult to 1dentify tarsometatarsi of these three genera by a comblnation of characters, although Mlller felt this could 
be done. With Eulabela and Cygnopsis Included the task is even more difficult.

The characters for Branta, Anser, and Chen, according to Miller, are as follows. In Branta there is an inflation of the lateral margin just distal to the head, which is less pronounced in Anser and usually is lacking in Chen. In Branta the trochlea for digit II joins the shaft of the bone at a more abrupt angle and is shorter than in Anser and markedly shorter than in Chen. Branta nigricans is not typical of the genus in this respect.

In Anser the median side of the hypotarsus makes a less acute angle with the remainder of the medial surface; the tendinal groove of the anterior surface is more prominent, and the entire bone is slightly more stocky than in Branta or Chen. The tarsometatarsus of Anser averages wider (7.9 to 9.0 per cent of total length) than in Branta (6.3 to 8.0 ) and Chen (6.6 to 7.9 ), but it is difficult to substantiate any of the other characters 1isted above. Furthermore, no characters were found for Eulabela or Cygnops1s other than that they are both robust with widths 7.9 and 9.1 to 10.8 per cent of the total length, respectively. The extremely wide tarsometatarsus in the available specimen of Cygnopsis 1s possibly a reflection of the many centuries of domestication of certain strains of the species.

The tarsometatarsus of Nesochen is distinctive. The outer margin of the shaft is straighter than in any other goose, and the shaft is wide ( 8.0 per cent of total length). In addition, the trochleae are directly in line with the 
shaft. Miller remarked that this latter feature is to be assoclated with running habits.

Miller found the tarsometatarsus of Philacte markedly different from those of Anser, Chen, Branta, and Nesochen. The plantar surface, just proximal to the trochlea, is stated to be much flatter and broader and the trochlea for diglt II more sharply deflected medially. The one specimen in the present series, unfortunately poorly preserved, does not have these features.

\section{Anatinae}

Although the Anatinae are easily distinguished from Anseranas and Dendrocygna through the presence of a prominent groove in the trochlea for digit II of the tarsometatarsus, it 18 difficult to separate them from the swans and geese on this element. Only two features, both weak, can be 11sted. (1) The trochlea for digit II in internal view is slightly more in line with the other two instead of belng deflected more posteroproximad. (2) The distal foramen in posterior view is more oblique, less nearly perpendicular to the shaft.

The shape and position of the trochlea for digit II divides the Anatinae into two groups, the nondiving sheldrakes, dabbling ducks, and perching ducks, and the diving pochards, elders, sea ducks, and stiff-talled ducks. In the nondivers the trochlea for digit II is shorter (length measured parallel to the shaft), and it extends farther distad. The median ridge of this trochlea extends distally beyond the level of 
the proximal extent of the facet of the trochlea for diglt III, as seen in ventral view. In the divers the distal end of the median ridge of the trochlea for digit II falls to reach the level of the proximal end of the facet for digit III. Six of the 43 avallable genera do not fit the systen, namely: Tachyeres of the sheldrakes, Merganetta of the dabblers, Metoplana of the pochards, Polysticta of the eiders, and Heteronetta and Nomonyx of the stiff-tails. These forms are discussed under the tribes to which they were assigned by Delacour (1954, 1956, 1959). There 1s obviously a correlation between function and structure involved here, but nevertheless several of the tribes can be characterized as units on structures of more deep-seated phylogenetic significance.

\section{Tribe Tadornini. Sheldrakes}

The sheldrakes resemble the geese in the form of the tarsometatarsus and can be separated from other Anatinae because the trochleae for digits II and IV, and particularly the former, are spread, and the shaft is narrow in anterior view, with the external edge displaying a prominent curve out onto the trochlea for digit IV. They differ from the swans and geese by the characters 11sted under that tribe. W1thin the sheldrake tribe the features of the tarsometatarsus are most useful taxonomically. The relative distal extent of the trochlea for digit II separates the tribe Into two groups. In Cereopsis, Chlorphaga, and Neochen the trochlea for digit II lies farther distad; it extends beyond the base of the external intertrochlear notch. In Alopochen, 
Tadorna, Casarca, and Tachyeres the trochlea for digit II lies more proximad; it does not extend beyond the base of the external intertrochlear notch. Cereops $1 \mathrm{~s}$ and Tachyeres, the two genera that from other elements seem more closely related to other tribes, are the most widely separated, and Neochen is nearest to being intermediate between the two groups.

Cereops 1s differs from all other sheldrakes as follows. (1) The intercotylar prominence in anterior view is large and essentially symmetrical in outline. In other sheldrakes the prominence is skewed on the external side, to make the Internal cotyla appear deeper. (2) The trochlea for digit II in anterior view has the groove extending farther proximad, and (3) it has a more prominent proximomedial swelling. Neochen differs from Chloophaga in that the shaft and trochleae are thinner in anterior views the shaft measures 6.7 per cent of the total length. Seven specimens of Chlosphaga range from 7.2 to 7.9 per cent.

The tarsometatarsi of Tadorna, Casarca, and Alopochen are all rather similar in form. No useful features were found for separating Casarca from Tadorna, but there are some that allow for the separation of Alopochen from the others. These are as follows. (1) The shaft is thinner, its width ranging from 6.8 to 7.6 per cent of total length in three specimens. In nine specimens of Tadorna and Casarca the range is from 7.8 to 8.2 per cent. (2) The trochlea for digit II extends farther ventrad and has the proximal edge sloping gently to the shaft. In Tadorna and 
Casarca the trochlea is situated more mediad, and the proximal edge drops off abruptly to the shaft.

Tachyeres 18 easily separated from the other sheldrakes. (1) The trochlea for digit II is longer and 11 es more proximad; the distal tip does not extend beyond the proximal extent of the trochlea for digit III. (2) The shaft 1 s robust, 10.8 per cent of the length; the thickest shaft recorded for the other sheldrake specimens measures 8.2 per cent (Tadorna). (3) The lobe on the anterior side at the point of the most proximal extent of trochlea for diglt II is small. A prominent lobe in this position is typical of sheldrakes.

Tribe Anatini. Dabbling Ducks

The dabbling and perching ducks cannot be separated by tarsometatarsal features. Differences between the genera will be discussed within the arrangement of Delacour (1956, 1959), although some intertribal comparisons will be made. Chaulelasmus and Spatula are Indistinguishable from Anas, but Mareca is distinct. (1) In Mareca the shaft $1 \mathrm{~s}$ more robust at the proximal end just below the cotylar area. (2) In Mareca the anterolateral edge is less prominent. In anterior view the shaft appears to taper more because of these two features. (3) In Mareca the trochleae are usually smaller.

Malacorhynchus differs slightly from the typical dabblers in that the trochleae are spread more laterally.

Callonetta has a thicker and more elevated proximal portion of the anteromedial ridge in the one avallable specimen. 
Whether or not this feature would remain valid in a series remains questionable.

Bymenolaimus, although not differing markedly from typical dabblers, can be distinguished as follows. (1) The cotylae form almost a right angle with the anterior surface. In other dabblers and in the perchers the angle 18 smaller. (2) In distal view the posterior rims of the trochleae converge. (3) The trochlea for digit II in posterior view flares more medially.

The tarsometatarsus of Merganetta is the most distinct one found in the dabbling ducks. The median ridge of the trochlea for digit II does not quite reach the level of the proximal end of the facet for digit III, and thus it resenbles that of the divers. But the trochlea for digit II is shorter, and the shaft of the bone $1 \mathrm{~s}$ thinner $(7.3$ to 8.0 per cent of total length) than is typical of the divers. It is even thinner than in all the other members of the dabbling ducks ( 8.3 to 11.0 per cent). An additlonal character that 1solates Merganetta among the dabblers 18 that the anteromedial edge of the shaft $1 \mathrm{~s}$ much lower than the anteroexternal edge.

The tarsometatarsi of Calrina and pteronetta can be distinguished from those of other perching ducks and from the dabbling ducks by the shape of the middle groove of the hypotarsus. In these two genera it is shallower than the grooves on elther side. The floor of the groove does not reach the shaft. 
Calrina is unique because of its robust shaft with a width/length ratio of 12.5 to 12.6 per cent. The middle groove of the hypotarsus $1 \mathrm{~s}$ by far the shallowest in this form.

Pteronetta has a slimmer shaft, 10.9 per cent of the total length, and the groove, though shallow, is deeper than in Calrina.

Two perchers, Amazonetta (7.9 per cent of total length); and Plectropterus ( 7.7 to 7.8 per cent) have thin shafts. other than in Merganetta the next thinnest shaft recorded in either the perchers or the dabblers measures 8.0 per cent. The fact that the shaft in Amazonetta is relatively much thinner than in typical dabblers (minimum 8.3 per cent) speaks for 1 ts recognition as a genus apart from Anas. Qualitative features of the trochleae separate the large tarsometatarsus of Plectropterus from the small one of Amazonetta. In plectropterus the trochleae are directed medial1y, and the trochlea for dig1t II extends farther poster1orly.

Sarkidiornis is unique in that it has a massive outer trochlea. The lateral edge of the shaft swings out as a ridge to meet the trochlea.

Chenonetta has a tarsometatarsus similar in form to that of Aix and Dendronessa. It is considerably longer, however, and proportionately slimmer. The width varies from 8.0 to 8.9 per cent of the total length in two specimens. Dendronessa (5 specimens) varies from 9.3 to 10.2 per cent, and A1x (11 specimens) from 9.7 to 11.3 per cent. 
The four remaining genera fall into two groups on the bas1s of s1ze; the larger forms include $\underline{A 1 X}$ and Dendronessa and the smaller ones Nettapus and Cheniscus. None of these 1s separable on qualitative features of the tarsometatarsus.

Tribe Aythyini. Bochards

The tarsometatarsus of pochards is generally thicker than in elders (w1dth 9.5 to 12.0 and 8.5 to 9.8 per cent of length, respectively), and the external edge is almost straight instead of flaring sharply to meet the outer edge of the spread trochleae, as in eiders. It differs from that of stiff-tailed ducks in that the inner calcaneal ridge is proportionately smaller, and the shaft in the medial view curves up to meet the trochleae. The greatest similarity is to that of the sea ducks, from which 1 t can be distinguished as follows. (1) The shaft 18 wide proximally and with little lateral compression. (2) The trochlea for digit III in posterior view forms a slight angle with the shaft, so that the groove is directed laterally as it passes proximally. (3) The trochlea for digit II has a smaller gap between 1ts medial ridge and the proximal end of the facet of the trochlea for digit III.

Within the tribe, Metoplana and Metta differ from Aythya in that the trochlea for digit II in medial view is curved in outline. In Aythya the posteroproximal tip is extended proximally, and thus a distinct angle interrupts the curved outline. 
The median ridge of the trochlea for dig1t II surpasses the level of the proximal extent of the facet for digit III In Metoplana and Indicates the genus is less specialized for diving than elther Netta or Aythya.

Iribe Somaterilnt. Eiderg

The elders can be separated from other waterfowl guite easily by features of the tarsometatarsus. The shaft is thinner ( 8.5 to 9.8 per cent of total length) than in most other diverg. The large trochleae are spread, and the external edge of the shaft curves markedly in order to reach the spread trochlea for dig1t IV. In other diving ducks the external edge of the shaft is virtually a straight ine.

The tarsometatarsus of the one available specimen of Polysticta does not show a space between the levels of the medial rim of the trochlea for digit II and the posterior extent of the facet for dig1t III, because the facet tapers gradually to a point, this may not be typical of the genus. The trochlea for aigit II is long, as is typical of divers. The other two elder genera, Somater 1a and Iampronetta, possess no qualitative features to separate then.

\section{Trtbe Mergin1. Sea Ducks}

The external edge of the tarsometatarsus of sea ducks shows very little curvature, in distinction to that of the eiders. The inner calcaneal ridge is not enlarged as much as in the stiff-tailed ducks, and furthermore the ohaft in medial view curves up to meet the trochleae. The following several tarsometatarsal features in combination should 
separate the sea ducks from the pochards. (1) The shaft is laterally compressed and frequently the narrowest width is through a prominent groove that lies near the proximal end on the median side. (2) The trochlea for digit III in posterior view is essentially parallel with the shaft. (3) The gap between the described parts of the trochleae for digits II and III Is wider.

One feature suggests separation of the sea-duck genera Into the two usual groups. In Bucephala and the mergansers the external edge of the outer trochlea in anterlor view is stralght or inflected. In H1strionlcus, Clangula, and the scoters the external edge is concave and continuous with the arc of the shaft.

Bucephala can be separated from the mergansers by the size and direction of the distal foramen. In posterlor view particularly, the distal foramen is larger and more nearly perpendicular to the shaft. In the mergansers the smaller foramen lies at a more oblique angle to the axis of the shaft. In addition the shaft of Bucephala tends to show greater curvature, and the anterolateral edge is more elevated.

The three merganser genera are distinguishable by the relative width of the shaft. In the larger Mergus the width varies from 7.7 to 9.1 per cent of the total length; Mergellus is intermediate with a figure of 9.8 per cent; whereas Lophodytes is quite stout, ranging from 10.6 to 11.7 per cent. 
There are no good qualitative features for separation of the tarsometatarsus of Histrionlcus, Clangula, and the scoters, Melanitta and oldemia. The one avallable specimen of 뵤strionicus has a lower intercotylar prominence, a smaller distal foramen, and a less elevated anteromedial edge to the shaft; perhaps some of these are valld features.

Tribe Oxyurint. stiff-talled Ducks

The tarsometatarsus of stiff-talled ducks can be recognized without great difficulty. (1) The inner calcaneal ridge 18 enlarged more than in other Anatinae. (2) In median view the anterior surface of the shaft $1 \mathrm{~s}$ essentially at the same level as the trochleae. In other divers the shaft curves anterlorly to the elevated trochleae. (3) The ralsed anterolateral edge of the shaft is virtually straight out onto the trochlea for algit IV. (4) The trochleae for digit IV in distal view has the inner ridge higher and the outer ridge anteroproximally reduced. (5) The intercotylar prominence has a deeper anteroexternal notch. (6) The shaft 1 s wide, 10.8 to 16.3 per cent of the total length.

The tarsometatars1 of Heteronetta and Nomonyx have no space between the levels of the median rim of the trochlea for diglt II and the proximal extent of the facet for digit III. Features 1, 3, 5, and 6 above, however, are present in these two less specialized genera.

The narrower width (10.8 per cent of the length) of the shaft along with the lack of a space between the levels of 
the named parts of the trochleae for digits II and III 1dentify the tarsometatarsus of pleteronetta.

Nomonyx (12.6) and oxyura (11.6 to 12.8 ) are similar in the relative width of the shaft, but Nomonyx has no space between the levels of the named parts of the trochleae for digits II and III. Blziura is very similar in form of the tarsometatarsus, but the shaft is much stockier with the width 16.3 per cent of the total length.

\section{Pelvis}

The pelvis is of little use for classifying the waterfowl. This element displays remarkable similarity throughout the family, and those differences that appear are in the nature of individual variation.

One ratio proved somewhat useful, the least width through the acetabula divided by the length of the element. The length was measured from the most anterior point on the centrum of the first vertebra to the posterior end of the 11 um or 1schium.

\section{Anseranatinae}

Anseranas has the most distinct pelvis of all the waterfowl, as was noted by Miller (1919). The following features are characteristic of the genus. (1) The posterfor $111 \mathrm{ac}$ crest is broad, and sharply angled at a ridge running posterlad from the antitrochanter, with the larger portion lying in the horizontal plane. (2) The posterior edge of the 11 ium is much shorter than the 1schium. (3) The width through the acetabula 1828.0 to 31.5 per cent of the length, greater 
than in any of the superficially similar Anserinae, in which the range is from 15.7 to 26.9 per cent.

\section{Anser inae}

The Anserinae as a unit cannot be characterized by the structure of the pelvis.

\section{Tribe Dendrocyqnini.}

Whistiing Ducks

One feature of the pelvis occurring in Dendrocygna and Anseranas 1a found nowhere else in the Anatidae. In these two genera the 1lium is distinctly shorter than the 1schlum, with the posterlor border of the former lying considerably anterior to the posterodorsal corner of the latter. In other waterfowl the posterior edges of the two bones form an obl1que line, usually with a notch where the two bonea fuse.

\section{Tribe Anserint.}

\section{swans and Geese}

The relative width through the acetabula separates the true swans from the geese. The range for 36 swan specimens 1815.7 to 19.4 per cent of the length. For 34 goose spec1mens the range 1819.8 to 26.9 per cent. Coscoroba $(23.0)$ falls with the geese, but between the averages for the awans (17.6) and the geese $(24.2)$. The relatively greater w1dth of the goose pelvis may be related to the more terrestrial habits of these birds.

\section{Anatinae}

The pelvis is too poor an element taxonomically to allow for characterizing the diverse subfamily of ducks. 
Among the genera assigned to the sheldrakes Cereopsis has the relative width through the acetabula (21.8 to 22.5 per cent) below the range for the other, more typical, menbers of the tribe $(22.9$ to 32.9$)$, and within the range of the true geese. Chlorphaga, Neochen, and Alopochen (22.9 to 28.3 per cent) have relatively wider pelves than Tadorna and Casarca (28.9 to 32.9 per cent).

Within the remaining Anatinae the pelves are usually narrower in the diving species than in the nondivers. For example, the average relative width through the acetabula for 82 specimens of nondivers, Anas, Chaulelasmus, Mareca, and spetula, is 31.92 per cent; in 67 specimens of the divIng Aythya the average is 24.46 per cent. Rhodonessa_(27.7) and Metoplana (27.66) are intermediate in the width of the pelvis; Rhodonessa seldom dives and Metopiana dives less efficiently than Aythya (Delacour, 1956, 1959).

Bymenolaimus, although a diving species, has a rather wide pelvis (29.6 per cent), whereas in the torrent duck, Merganetta, 1t 18 very narrow (22.7 to 23.6 per cent). Although the elders are considered by Delacour (1959) to be closely allied to the dabblers, the pelvis is narrower. Seven specimens of Somaterla arid one of Lampronetta average 24.53 per cent. Th1s average 11 es outside the range for all. dabbling ducks except Merganetta, but within the wide range recorded for the sea ducks. Polysticta has a relative width of 27.0 per cent, beyond the range obtained for the large eiders ( 22.5 to 26.1 per cent), and near the flgures for 
Histrionicus (28.5 per cent) and Clangula (24.4 to 26.8 per cent).

The relative width through the acetabula is not useful for separating sea ducks from other Anatinae, nor does it support the intratribal groups (Bucephala and the mergansers, versus Histrionicus, Clanqula and the scoters) that, from other evidence, seem natural. Within the first of these groups, Bucephala (26.4 to 29.9) falls with Lophodytes $(22.8$ to 30.0$)$ in wide pelvis, in contrast to the narrow pelvis of Mergus (16.2 to 20.7) and Mergellus (21.6). In the other group the wide pelvis of Histrionicus (28.5) and clangula (24.4 to 26.8) contrast with the narrow pelvis of Melanitta (19.3 to 23.5$)$ and oldemia $(15.4,18.6$ to 20.8$)$.

on the basis of pelvic structure, as with several other structural elements discussed above, the stiff-tailed ducks are the most distinct group within the Anatinae. The pelvis is very narrow (14.7 to 21.1 per cent) and overlaps only a few genera from other tribes. Nomonyx (19.5 to 20.4 per cent) falls within the range of oxyura (17.4 to 21.1 per cent), but 1ts average is significantly broader, 19.91 per cent compared with 18.96 per cent, respectively. Biziura has the narrowest pelvis of any species of waterfowl (14.7 per cent).

\section{Vertebral Column}

Verheyen (1955) based his classification of the waterfowl primarily on the number of vertebrae in the various regions of the column. Although the present study is concerned 
malniy with qualitative features of the appendicular skeleton, counts of vertebrae in addition to those of Verheyen are presented in Table 2. It 1s interesting that many of the changes suggested by the present study are supported by these stat1st1cs.

The four regions in the column-cervical, thorac1c, sacral, and caudal-are defined as in Verheyen.

The cervical region begins with the axis and terminates with the most posterior vertebra lacking a complete $r i b$, one composed of both vertebral and sternal parts and an uncinate process. Usually the last cervical and occasionally the last two cervicals have incomplete rlbs composed of the vertebral. portion and a rudimentary uncinate process.

The thoracic region begins with the first vertebra supporting a complete $\mathrm{rlb}$ and terminates with the last free vertebra anterlor to the synsacrum.

The sacral region 1 s composed of the vertebrae that are fused to form the synsacrum. Older specimens tend to show greater fusion at the posterior end of the synsacrum. The fusion accounts for much of the variation in this region and in the caudal region.

The caudal region begins with the first free vertebrae posterior to the synsacrum and terminates with the pygostyle. Although the pygostyle is composed of several fused vertebrae, it is counted as one element. older specimens tend to have more vertebrae fused into the pygostyle to give add1tional variation in this region. 
The vertebrae of large series of a few specles were counted to make certain that the methods in the present study were comparable to those of Verheyen. When this was established, counts were generally made to bring the sample up to five individuals. In Table 2 the specimens counted by Verheyen are indicated by a $\mathrm{V}$ followed by the number. The additional counts are indicated by a w. 
TABLE 2

WATERFOWL VERTEBRAI COUNTS

ANSER INATINAE

Anseranas semipalmata

ANSER INAE

Wh1stling Ducks

Dendrocygna eyton 1

$\frac{\frac{\text { arcuata }}{\text { b1color }}}{\text { arborea }}$

Javanica

v1duata autumnalis

swans

Coscoroba coscoroba

Chenopis atratus

Cygnus olor

melancor Iphus

olor cygnus

buccinatox

columbianus

Geese

Cygnopsis cygnold

Anser anser

albifrons

erythropus

fab111s

Chen Eaerulescens

hyperborea

rossi

Philacte canag1ca

Eulabela Indiaca

Nesochen sandvicensis

$\begin{array}{llllll}20 & 5 & 16 & 6 & 47 & \text { (v1) } \\ 19 & 5 & 17 & 6 & 47 & \text { (w1+) }\end{array}$

$\begin{array}{llllll}18 & 5 & 15 & 7 & 45 & \text { (v1) }\end{array}$

$\begin{array}{llllll}18 & 5 & 15 & 7 & 45 & \text { (V1) }\end{array}$

$175 \quad 5 \quad 15-16 \quad 7-8 \quad 44-46$ (V4)

$175 \quad 5 \quad 15-16 \quad 7-8 \quad 44-45$ (v3)

$17 \quad 5 \quad 15-16 \quad 7 \quad 44-45$ (w2)

$\begin{array}{llllll}17 & 5 & 15 & 7 & 45 & \text { (v1) }\end{array}$

$\begin{array}{llllll}17 & 5 & 15 & 7 & 45 & \text { (v2) }\end{array}$

$175 \quad 5 \quad 15-16 \quad 7-8 \quad 44-46$ (v8)

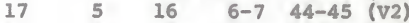

$\begin{array}{llllll}17 & 5 & 15 & 7 & 44 & \text { (W2) }\end{array}$

$\begin{array}{lccccc}21 & 5 & 18-19 & 6-7 & 51-52 & \text { (v5) } \\ 25 & 4-5 & 20-22 & 8-10 & 59-61 & \text { (v8) } \\ 24-25 & 5-6 & 20-21 & 9 & 59-60 & \text { (v7) } \\ 22-24 & 5-6 & 18-20 & 8-9 & 56-57 & \text { (v9) } \\ 24 & 5 & 20 & 7-8 & 56-57 & \text { (v2) } \\ 24 & 5 & 21 & 9 & 58 & \text { (W2) } \\ 23 & 5 & 21 & 8 & 57 & \text { (W1) } \\ 23 & 5 & 20 & 9 & 57 & \text { (v1) } \\ 22-23 & 5 & 19-20 & 7-8 & 54-56 & \text { (W4) }\end{array}$

$\begin{array}{llllll}19 & 5 & 18 & 7 & 49 & \text { (v) }\end{array}$

$19 \quad 5 \quad 17-19 \quad 7 \quad 48-50$ (w2)

$\begin{array}{llllll}18 & 5 & 17 & 7 & 47 & \text { (v1) }\end{array}$

$\begin{array}{llllll}19 & 5 & 17 & 8 & 49 & \text { (W1) }\end{array}$

$19 \quad 5 \quad 19 \quad 6-7 \quad 49-50$ (V2)

$\begin{array}{llllll}19 & 5 & 18 & 7 & 49 & \text { (W1) }\end{array}$

$19 \quad 5 \quad 18 \quad 6-7 \quad 48-49$ (V3)

19-20 $5 \quad 18-19 \quad 6-7 \quad 48-49$ (v3)

$\begin{array}{llllll}20 & 5 & 19 & ? & ? & \text { (WI) }\end{array}$

$19 \quad 5 \quad 18-19 \quad 6-7 \quad 48-50$ (v3)

$\begin{array}{llllll}18 & 5 & 19 & 7 & 49 & \text { (WI) }\end{array}$

$\begin{array}{llllll}19 & 5 & 19 & 6 & 49 & \text { (w1) }\end{array}$

$\begin{array}{llllll}19 & 5 & 17 & 7 & 48 & \text { (v1) }\end{array}$

$19 \quad 5 \quad 17-18 \quad 7-8 \quad 48-50$ (w4)

$\begin{array}{llllll}19 & 5 & 18 & 7 & 49 & \text { (v1) }\end{array}$

$\begin{array}{llllll}19 & 5 & 17 & 7 & 48 & \text { (W1) }\end{array}$

$\begin{array}{llllll}19 & 5 & 19 & 7 & 50 & \text { (v1) }\end{array}$

$\begin{array}{llllll}19 & 5 & 18 & 7 & 49 & \text { (w1) }\end{array}$

$\begin{array}{llllll}19 & 5 & 19 & 7 & 50 & \text { (v1) }\end{array}$

$\begin{array}{llllll}20 & 5 & 19 & 7 & 51 & \text { (w1) }\end{array}$


TABLE 2--Continued

Species

Cerv. Thor. Sacr. Caud. Total Auth.

Branta canadens1s

leucopsis

ruflcol11s

bernicla

ANATINAE

Sheldrakes

Cereopsis

novaehollandlae

Chloephaga melanoptera pollocephala
plcta
hybrida

Neochen jubata

Alopochen aegyptlaca

Casarca tadorno1des

var1egata

cana

Casarca ferrug1nea radjah

Tadorna tadorna

Tachyeres pteneres

Dabbling Ducks

Anas platyrhynchos

fulvigula

rubripes

poec1lorhyma

superc1110sa

luzontca

meller1

undulata

castanea

Flavirostris

crecca

formosa

falcata

Chaulelasmus streperus

$\begin{array}{lccccl}20 & 5 & 18 & 7-8 & 50-51 & \text { (V1?) } \\ 19-20 & 5 & 19-20 & 6-7 & 50-51 & \text { (W4) } \\ 19 & 5 & 17 & 7-8 & 48-49 & \text { (V2) } \\ 19 & 5 & 17 & 7-8 & 48-49 & \text { (V4) } \\ 19 & 5 & 17 & 8 & 49 & \text { (w1) } \\ 20 & 5 & 18 & 7-8 & 50-51 & \text { (V3) } \\ 20 & 5 & 18 & 8 & 51 & \text { (W2) }\end{array}$

$\begin{array}{llllll}19-20 & 5 & 16-17 & 7 & 48 & \text { (v2) }\end{array}$

$\begin{array}{llllll}19 & 4 & 18-19 & 6 \div 7 & 48 & \text { (W2) }\end{array}$

$16 \quad 5 \quad 17-18 \quad 6-7 \quad 45 \quad$ (w2)

$\begin{array}{llllll}17 & 5 & 17 & 6 & 45 & \text { (V1) }\end{array}$

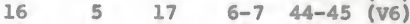

$\begin{array}{llllll}16 & 5 & 16 & 6 & 43 & \text { (V1) }\end{array}$

$\begin{array}{llllll}17 & 4 & 17 & 7 & 45 & \text { (VI) }\end{array}$

$\begin{array}{llllll}16 & 4-5 & 17 & 7 & 45 & (w 1+)\end{array}$

$16 \quad 5 \quad 17-18 \quad 7-8 \quad 45-46$ (v5)

$\begin{array}{llllll}16 & 5 & 18 & 7 & 46 & \text { (W1) }\end{array}$

$\begin{array}{llllll}17 & 5 & 18 & 7 & 47 & \text { (v1) }\end{array}$

$\begin{array}{llllll}17 & 5 & 18 & 8 & 48 & \text { (WI) }\end{array}$

$\begin{array}{llllll}16-17 & 5 & 17-18 & 7 & 45-47 & \text { (V5) }\end{array}$

$\begin{array}{cccccc}16-17 & 5 & 17 & 7-8 & 46 & \text { (W2) }\end{array}$

$\begin{array}{llllll}16 & 5 & 18 & 8 & 46 & \text { (v3) }\end{array}$

$\begin{array}{lllll}16-17 & 5 & 18 & 8 & 46-47 \\ (W 2)\end{array}$

$\begin{array}{llllll}16 & 5 & 17 & 7 & 45 & \text { (v3) }\end{array}$

$\begin{array}{llllll}16 & 5 & 16 & 7 & 44 & \text { (V1) }\end{array}$

$\begin{array}{llllll}17 & 5 & 17 & 7 & 46 & \text { (v6) }\end{array}$

$\begin{array}{llllll}16 & 5 & 17 & 8 & 46 & \text { (V1) }\end{array}$

$\begin{array}{llllll}16 & 5 & 17 & 9 & 47 & \text { (w1) }\end{array}$

$1655 \quad 16-17 \quad 7-8 \quad 45-46$ (v6)

$1655 \quad 16-17 \quad 7-8 \quad 45-46$ (W6)

$16 \quad 5 \quad 16-17 \quad 8-9 \quad 46-47$ (W5)

$\begin{array}{llllll}16 & 5 & 16 & 8 & 45 & \text { (V2) }\end{array}$

$\begin{array}{llllll}16 & 5 & 16 & 8 & 45 & \text { (WI) }\end{array}$

$\begin{array}{llllll}16 & 5 & 17 & 7 & 45 & \text { (v1) }\end{array}$

$\begin{array}{llllll}16 & 5 & 16 & ? & ? & \text { (W1) }\end{array}$

$\begin{array}{llllll}16 & 5 & 16 & 8 & 45 & \text { (w1) }\end{array}$

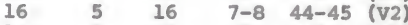

$\begin{array}{llllll}16 & 5 & 16 & 8 & 45 & \text { (W1) }\end{array}$

$\begin{array}{llllll}16 & 5 & 16 & 7 & 44 & \text { (W2) }\end{array}$

$16 \quad 5 \quad 15-16 \quad 7-8 \quad 43-45$ (v3)

$\begin{array}{llllll}16 & 5 & 16 & 7 & 44 & \text { (v9) }\end{array}$

$\begin{array}{llllll}16 & 5 & 16 & 7 & 44 & \text { (W1) }\end{array}$

$\begin{array}{llllll}16 & 5 & 17 & 7 & 45 & \text { (W1) }\end{array}$

$\begin{array}{llllll}16 & 5 & 17 & 7 & 45 & \text { (V1) }\end{array}$

$\begin{array}{llllll}16 & 5 & 17 & 7-8 & 45-56 & \text { (W4) }\end{array}$ 
TABLE 2--Continued

Species

Mareca penelope

americana

sibllatr1x

Anas bahamensis

$\frac{\text { spinacauda }}{\text { acuta }}$

erythrorhyncha

angust 1 rostr 18

versicolor

guercuedula

discors

Anas cyanoptera

Spatula platalea

clypeata

Callonetta leucophrys

Malacorhynchus membranaceus

Exmenolaimus malacorhynchos

Merganetta armata

St1ctonetta naevosa

Rhodonessa

caryophyllacea Pochards

Netta rufina

Metopiana peposaca

Aythya valisinerla

ferina

americana

nyroca

collaris

fullgula

Cerv. Thor. Sacr. Caud. Total Auth.

$\begin{array}{cccccl}16 & 5 & 17 & 7 & 45 & \text { (v5) } \\ 16 & 5 & 16-17 & 7-8 & 44-46 & \text { (w1) } \\ 16 & 5 & 18 & 7 & 46 & \text { (v1) } \\ 16 & 5 & 17 & 7 & 45 & \text { (w2) } \\ 16 & 5 & 17-18 & 8 & 46-47 & \text { (v3) } \\ 16 & 5 & 17 & 7 & 45 & \text { (w1) } \\ 16 & 5 & 16 & 7-8 & 44-45 & \text { (v2) } \\ 16 & 5 & 15-16 & 7-8 & 43-45 & \text { (w2) } \\ 16 & 5 & 16 & 8 & 45 & \text { (v1) } \\ 17-18 & 5 & 17 & 7 & 46-47 & \text { (v2) } \\ 17-19 & 5-6 & 16-17 & 7-8 & 44-48 & \text { (w12) } \\ 16 & 5 & 16 & 7 & 44 & \text { (v1) } \\ 16 & 5 & 16 & 7 & 44 & \text { (v1) } \\ 16 & 5 & 15-16 & 8 & 44-45 & \text { (v3) } \\ 16 & 5 & 16 & 7 & 344-45 & \text { (v4) } \\ 16 & 5 & 16 & 7 & 44 & \text { (v1) } \\ 16 & 5 & 16-17 & 7 & 44-45 & \text { (w4) } \\ 16 & 5 & 16 & 8 & 45 & \text { (v3) } \\ 16 & 5 & 15-16 & 8 & 45-46 & \text { (w3) } \\ 16 & 5 & 17 & 7 & 45 & \text { (v1) } \\ 16 & 5 & 16 & 8 & 45 & \text { (w1) } \\ 16 & 5 & 16 & 7 & 44 & \text { (v4) } \\ 16 & 5 & 17 & 7 & 45 & \text { (w1) } \\ 16 & 5 & 15 & 8 & 44 & \text { (v1) } \\ 16 & 5 & 15 & 8 & 44 & \text { (w1) } \\ 16 & 5 & 15 & 7 & 43 & \text { (v1) } \\ ? & ? & 15 & 7 & ? & \text { (w1) } \\ 16 & 5 & 17 & 7 & 45 & \text { (v1) } \\ 16 & 5 & 16 & 7 & 44 & \text { (w1) } \\ 16 & 5 & 16 & 7 & 44 & \text { (v1) } \\ 16 & 5 & 16 & 8 & 45 & \text { (w14) } \\ 18 & 5 & 17 & 7 & 47 & \text { (v1) } \\ 17 & 5 & 16 & 8 & 46 & \text { (v1) } \\ 17 & 5 & 17 & ? & ? & \text { (w1) }\end{array}$

$\begin{array}{lccccc}17 & 5 & 17 & 7 & 46 & \text { (v2) } \\ 17 & 5 & 17 & 8 & 47 & \text { (w2) } \\ 17 & 5 & 17 & 7-8 & 46-47 & \text { (v2) } \\ 17 & 5-6 & 17 & 7-8 & 47 & \text { (w3) } \\ 17 & 5 & 17 & 7 & 46 & \text { (w3) } \\ 17 & 5 & 17 & 8 & 47 & \text { (v5) } \\ 17 & 5 & 17 & 7 & 46 & \text { (v1) } \\ 17 & 5 & 17-18 & 7-8 & 46-48 & \text { (w4) } \\ 17 & 5 & 17 & 7-8 & 46-47 & \text { (v3) } \\ 17 & 5 & 16 & 8 & 46 & \text { (w1) } \\ 17 & 5 & 17 & 8 & 47 & \text { (v1) } \\ 17 & 5 & 16-17 & 7-8 & 45-47 & \text { (w5) } \\ 17 & 5 & 17-18 & 7-8 & 46-48 & \text { (v4) } \\ 17 & 5 & 17 & 8 & 47 & \text { (w1) }\end{array}$


TABLE 2--Continued

Species

Cerv. Thor. Sacr. Caud. Total Auth.

Aythya affinis

mar1la

Perching Ducks

Amazonetta bras1liensis

Chenonetta Jubata

Alx sponsa

Dendronessa galericulata

Nettapus auritus

Cheniscus pulchellus coromandelainus

Sarkidiornis melanotos

Calrina moschata

Pteronetta hartlaub1

Plectropterus gambens 1 s E1ders

Somateria mol11s:B1ma

\section{spectabilis}

Lampronetta fischer 1

Polysticta steller1 Sea Ducks

Melanitta fusca

Oidemia nigra

perspicillata

Histrionicus

histrionicus

Clangula hyemalis

Bucephala 1slandica

clangula

albeola
17

17

17

17

16

16

16

16

16

16

16

16

16

16

16

16

16

16

16

16

16

16

16

17

17

16

16

16

16

16

16

16

16

16

16

16

16

16

16

16

16

16

16

16

16 $\begin{array}{cccc}18 & 7 & 47 & \text { (v1) } \\ 17-18 & 7-8 & 46-47 & \text { (พ4) } \\ 18 & 8 & 47-48 & \text { (v9) } \\ 17-18 & 7-8 & 47-48 & \text { (W6) }\end{array}$

$\begin{array}{cccc}15-16 & 7 & 43-44 & \text { (v2) } \\ 16 & 7 & 44 & \text { (w1) } \\ 17 & 7 & 45 & \text { (v1) } \\ 16-17 & 7 & 44-45 & \text { (w2) } \\ 16 & 7 & 44 & \text { (v2) } \\ 16 & 7 & 44 & \text { (w3) } \\ 17 & 7 & 45 & \text { (v3) } \\ 16 & 7 & 44 & \text { (w2) } \\ 15 & 7 & 43 & \text { (v1) } \\ 15 & 7 & 43 & \text { (w1) } \\ 15 & 7 & 43 & \text { (v1) } \\ 15 & 7 & 43 & \text { (v1) } \\ 14 & 7-9 & 42-44 & \text { (w4) } \\ 16 & 7 & 44 & \text { (v2) } \\ 16 & 7 & 44 & \text { (w1) } \\ 16 & 7-8 & 44-45 & \text { (v3) } \\ 16-17 & 7-8 & 44-46 & \text { (w3) } \\ 16 & 8 & 45 & \text { (v1) } \\ 16 & 8 & 45 & \text { (w1) } \\ 17 & 7 & 46 & \text { (v2) } \\ 17 & 7 & 45 & \text { (w2) }\end{array}$

\section{7}

17

16

17

16

16

7-8

45-46 (v4)

8-9 46-47 (W5)

$\begin{array}{ll}7 & 44\end{array}$

7-8 $\quad 45-46$

$9 \quad 46$

$8 \quad 45$

(WI)

$\begin{array}{ccccc}5 & 16-17 & 7-9 & 44-46 & \text { (V?) } \\ 5-6 & 16-17 & 7-9 & 44-47 & \text { (w5) } \\ 5 & 17 & 8 & 46 & \text { (W1) } \\ 5 & 16-17 & 7-9 & 44-46 & \text { (V?) } \\ 5 & 16-17 & 7-9 & 45-46 & \text { (W4) } \\ 5 & 17 & 8 & 44 & \text { (V2) } \\ 5 & 16 & 8 & 43 & \text { (w1) } \\ 5 & 16 & 8 & 44 & \text { (V1) } \\ 5 & 15-16 & 8-9 & 44-46 & \text { (W4) } \\ 5 & 17 & 8 & 46 & \text { (V1) } \\ 5 & 16 & 8 & 45 & \text { (V4) } \\ 5 & 16 & 7 & 44 & \text { (w1) } \\ 5 & 15 & 8 & 44 & \text { (V1) } \\ 5 & 15-16 & 7-8 & 44-45 & \text { (w3) }\end{array}$


TABLE 2--Continued

Spec1es

Cerv. Thor. Sacr. Caud. Total Auth.

\begin{tabular}{|c|c|c|c|c|c|c|}
\hline Mergellus albellus & 16 & 5 & 16 & 8 & 45 & (v4) \\
\hline & 16 & 5 & 16 & 8 & 45 & (w1) \\
\hline \multirow{2}{*}{ Lophodytes cucullatus } & 16 & 5 & 17 & 8 & 46 & (vi) \\
\hline & 16 & 5 & $16-17$ & 8 & $45-46$ & (w4) \\
\hline \multirow[t]{2}{*}{ Merqus serrator } & 16 & 5 & 17 & 8 & 46 & (vi) \\
\hline & 16 & 5 & $17-18$ & $7-8$ & $45-47$ & (w4) \\
\hline \multirow{2}{*}{ merganser } & 16 & 5 & 17 & 8 & 46 & (vi) \\
\hline & 16 & 5 & $17-18$ & 8 & $46-47$ & (พ4) \\
\hline \multicolumn{7}{|l|}{ stiff-tailed Ducks } \\
\hline \multirow[t]{2}{*}{ Nomonyx dominica } & 16 & 5 & 15 & 7. & 43 & (v1) \\
\hline & 16 & 5 & 15 & ? & ? & (wI) \\
\hline \multirow{2}{*}{ Oxyura jama1censis } & 16 & 5 & 16 & 9 & 46 & (vi) \\
\hline & 16 & $5-6$ & $15-17$ & 8 & 46 & (W4) \\
\hline australis & 16 & 5 & 15 & 9 & 45 & (vi) \\
\hline vittata & 16 & 5 & 15 & 9 & 45 & (w1) \\
\hline Biziura lobata & 16 & 6 & 16 & $7+$ & $45+$ & (w1) \\
\hline Heteronetta atricapilla & 16 & 5 & 16 & 8 & 45 & (v1) \\
\hline & 16 & 5 & 15 & 9 & 45 & (พา) \\
\hline
\end{tabular}




\section{DISCUSSION AND CONCLUSIONS}

Study of the postcranial skeleton indicates that the current classification of the waterfowl is in need of reevaluation. Osteological characters of the taxa as here recognized are discussed below, and the proposed classification and hypothetical relationships are presented in Table 3 and Plate I, respectively.

\section{Family Anseranatidae}

Anseranas, the pied goose, has been variously regarded as belonging to a separate family (Stejneger, 1885; Miller, 1919, Verheyen, 1955), to a monotypic subfamily (Salvadori, 1895; Boetticher, 1943; Mayr and Amadon, 1951; Delacour, 1954), to a subfamily that otherwise Includes only Plectropterus (Peters, 1931), to the perching duck tribe of the Anatinae (Delacour and Nayr, 1945), and tentatively to the sheldrakes (Newton, 1896, p. 837).

The details of the postcranial skeleton show conclusively that Anseranas semipalmata is an isolated and primitive species. The genus is much more strongly differentiated than any of the other waterfowl. Furthermore, its osteological differences, sumnarized below, are far greater than those 11sted for many widely recognized nonpasserine familles, such as the Cochlearildae and Rynchopldae (Wetmore, 1960), and the Falconidae (Brodkorb, 1960a). Anseranas should be 
separated from the other waterfowl as a distinct family, the Anseranatidae, characterized as follows:

Humerus with (1) prominent medially situated capital shaft ridge, and correspondingly restricted proximal and lateral extent of external head of triceps.

Carpometacarpus with (2) no notch in external rim of carpal trochlea; (3) metacarpal. II distally curved upwards, (4) metacarpal III decidedly curved throughout 1ts length; (5) facet for digit III protruding distally. Sternum with (6) costal margin long, (7) basin deep, perforated by numerous foramina, and crossed by transverse ridges, its posterior end trilobed.

Coracold with (8) coracoidal fenestra opening into shaft, (9) sterno-coracoldal process prominent and knob-1.1ke; (10) head wide; (11) neck broad.

Scapula with (12) acromion short; (13) triosseal ridge a knob extending over anterior edge.

Furculum with (14) furcular process truncate; (15) pneumatic foramina in crotch (16) over-all appearance $V$-shaped. Fermur with (17) posterior intermuscular line displaced laterally; (18) internal condyle elongated distally; (19) head directed posteriad.

Tiblotarsus with (20) inner cnemial crest stralght. Tarsometatarsus with (21) median calcaneal ridge greatly enlarged; (22) facet for metatarsal I deep and prominent; (23) wing of trochlea for digit II greatly enlarged. 
Pelvis with (24) postacetabular llium broadened horizontally; (25) posterior border of 1llum shorter than that of ischiun.

To these osteologlcal characters can be added cranial features recorded by other authors. Palatines very narrow (Miller, 1919); prevomer without a posteroventral angle; lacrimal bone with short, descending process, not reaching half-way to jugal bar, occlput sloping upward and forward (McDowell, in Delacour, 1954).

In males the trachea 18 very long (approximately $150 \mathrm{~cm}$. ) and convoluted, situated outside the pectoral muscle on the left side, under the skin, and attached to both by cellular tissue (Gadow, 1891, p. 723, Delacour, 1954).

Other morphological traits typical of Anseranas are the following: b111 long and strong, deep at base; nostrils small, situated in middle and close together; lamellae much reduced; rostral nail large, very strong, curved pointed and overhanging; lower mandlble with a corresponding convex mental tip; forehead and lores naked; wings long; the first primary equaling the seventh, the second to fifth longest; no wing spur; tail long and square, of twelve rectrices, legs long, a large portion of the tibia naked, tarsus reticulates toes very long and slender, nalls long, curved, and sharp; hallux long and on a level with anterior toes (Delacour, 1954); webbling much reduced, extending only half length of toes (Gadow, 1893, p. 154).

The electrophoretic pattern of the egg-white protelns of Anseranas is readily separable from those of thixty of 
Peters's genera of waterfowl, although it does have certain characteristics in conmon with these birds (sibley, 1960).

To such exceptional properties are added biological pecullarities. Unlike all other waterfowl, the wing molt is gradual, and adults never lack the power of flight. Furthermore, the species exudes a strong, musky mell similar to that of certain parrots (Delacour, 1954).

Some of the characters of Anseranas, and particularly certain of those of the humerus, carpometacarpus, sternum, coracold, skull, and external morphology, show similarities to the Anhimidae. These characters indicate affinities between the Anhimidae and the Anatidae, with the Anseranatidae forming the connecting 11nk. Therefore, placing the families In the same order (Wetmore, 1960) better reflects their relationships than segregating them in two orders as was suggested by stresemann (1959).

\section{Family Anat1dae}

W1th the genus Anseranas afforded separate famillal rank, the remaining waterfowl, comprising the family Anat1dae, can be defined osteologically by the following features. Humerus with (1) capital shaft ridge lying farther laterad, and consequently depression for external head of triceps more extensive laterally and especially proximally. Carpometacarpus with (2) notch in external rim of carpal trochlea; (3) metacarpal II straight distally; (4) metacarpal III nearly straight throughout; (5) facet for digit III not protruding distally. 
Sternum with (6) costal margin short; (7) basin shallow with foramina restricted or absent, and no transverse ridges.

Coracold with (8) coracoidal feneztra lacking; (9) sternocoracoldal process compressed; (10) head narrow; (11) neck constricted.

scapula with (12) acromion long; (13) triosseal ridge elongate and not extending over anterior edge.

Furculum with (14) furcular process rounded; (15) no pneumatic foramina in crotch; (16) over-all appearance Ushaped.

Fermur with (17) posterior intermuscular line lying along medial edge; (18) Internal condyle short; (19) head directed laterad.

Tibiotarsus with (2) inner cnemial crest deflected laterally.

Tarsometatarsus with (21) median calcaneal ridge small, (22) facet for metatarsal I obscures (23) wing of trochlea for digit II lacking.

Pelvis with (24) postacetabular 11 ium greatly compressed horizontally.

The trachea falls to make a loop under the skin.

The adult sequence of molts includes a flightless stage.

The egg-white profiles of thirty of Peters's genera, distributed through the nine tribes of Delacour, are very similar (stbley, 1960).

Osteological features indicate there are two main branches of evolution within the family. These branches constitute the subfamilies Anserinae and Anatinae. With two 
exceptions the division supports the subfamilies as set up by Delacour (1954, 1956, 1959).

\section{Subfandly Anserinae}

The subfamily Anserinae includes the whistling ducks (Dendrocygna and probably stictonetta), and swans (Cygnus, Chenop1s, and Coscoroba of Peters, 1931), and true geese (Anser, Cygnopsis, Chen, Phllacte, Eulabela, Branta, and Nesochen of Peters). The postcranial osteology indicates that Cereopsis should also be included. The most important postcranial skeletal features are surmarized below.

Humerus with (1) prominent capital shaft ridge directed towards head; (2) capital groove short; (3) depression of external head of triceps restricted; (4) area of pectoral attachment on external tuberosity elevated and somewhat circular.

Carpometacarpus with (5) metacarpal II flat dorsally; (6) extensor attachment confined to tip of short but high process of metacarpal I.

Sternum with (7) basin relatively deep; (8) posterlor surface of dorsal sulcal lip extended posteriorly.

Coracoid with (9) angle between axis of head and plane of dorsal surface relatively large; (10) angle between sternal facet and shaft relatively small, (11) ventral lip of sternal facet wide and prominent.

Femur with (12) anterior edge of external condyle elevated from trend of shaft. 
Tarsometatarsus with (13) prominent lobe on anterlor surface of trochlea for digit II.

Cervical vertebrae 17 to 25 .

The following features, both morphological and behavloral were 11sted by Delacour (1954) neck long; posture and body shape gooselike; tarsus reticulate; plumage, volce, and structure of syrinx very similar for both sexes, speculum absent; plumage nometallic; displays simple and not sexually dimorphic; pairing for life; male assisting in care of young, and in some species in incubation; chief food vegetable.

The subfamily Anserinae is composed of four definable units, all of which are about equally distinct in osteology. These constitute the tribes Dendrocygnini, the whistling ducks; Cygnini, the swans; Anserin1, the geese; and Cereopsin1, the Cape Barren goose.

\section{Trlbe Dendrocygnini.}

\section{Whistling Ducks}

The whistling ducks of the genus Dendrocygna have a superficial reserablance to certain true ducks of the subfamily Anatinae, but the many trenchant characters, osteological and otherwise, previously listed for the subfamily Anserinae, to which the whistling ducks belong, indicates their true affinities are with the swans and geese. Summar1zed below are the most important postcranial skeletal features of the tribe.

Fumerus with (1) space between external condyle and facet for anterior articular ligament reduced. 
Carpometacarpus with (2) metacarpal II distinctly incurved; (3) external rim of carpal trochlea only slightly notched; (4) a prominent neck between carpal trochlea and metacarpal III.

Sternum with (5) costal margin long; (6) basin deep;

(7) dorsal and ventral manubrial spines lacking.

Coracold with (8) shaft thin; (9) pneumatic foramina minute; (10) ventral surface housing a unique depression. Furculum with (11) pneumatic foramina lacking. Femur with (12) anterior convexity on shaft. Tibiotarsus with (13) external and internal condyles nearly parallel; (14) external condyle circular in lateral outline.

Tarsometatarsus with (15) groove in trochlea for digit II obsolete.

Pelvis with (16) posterior border of llium shorter than that of ischium.

Cervical vertebrae 17 to 18 .

There are several characteristics of the postcranial skeleton that are found only in Dendrocygna and Anseranas, and 1 seembest to consider the whistling ducks as the nearest living relatives of the pied goose. The features indicating this relationship are as follows: carpometacarpus with external rim of carpal trochlea unnotched or only slightly notched; sternum with costal margin long, basin deep, both manubrial spines lacking; scapula with blade frequently narrow, apex frequently pointed; femur with anterior convexity of shaft; tarsometatarsig without prominent groove 
in trochlea for digit II; pelvis with posterior border of 1lium shorter than that of ischium.

The skeleton of the aberrant freckled duck, stictonetta naevosa, has not been avallable for the present study, but the published information, sparse as 1t 1s, indicates the species possesses the important features of the subfamily Anserinae listed by Delacour (1954). The tarsus is reticulate; the structure of the gyrinx is similar in both sexes, lacking a true bulla; the plumage is nonmetallic, lacks sexual dimorphism, and is without a speculum; the chief food is vegetable (Delacour and Mayr, 1945). Additional support is gained for this thesis from the fact that Verheyen (1955) placed stictonetta in a separate group between the whistling ducks and the geese.

Within the subfamily, Stictonetta 1s most like the whistling ducks and is tentatively transferred to this tribe. The form of the body and the bill is ducklike, but the cervical vertebrae number 18, the trachea has a slight swelling In the male, and the wing beat is slow (Delacour, 1956), as in the whistling ducks.

\section{Tribe cygnini. Swans}

The characteristics of the postcranial skeleton that separate the swans, genera cygnus, Chenopis, and Coscoroba of Peters (1931), from both the whistling ducks and the true geese are ttemized below.

Humerus with (1) space between external condyle and facet for anterior articular ligament wide (2) distal end 
narrow (12.2 to 13.9 per cent of total length); (3) entepicondyle not distally extended; (4) entepicondylar prominence extended laterally; (5) Internal tuberosity short, with tip rounded.

Carpometacarpus with (6) metacarpal II relatively straight; (7) external rim of carpal trochlea distinctly notched; (8) neck between carpal trochlea and metacarpal III obsolete; (9) external rim of carpal trochlea sloping sharply downward from process of metacarpal $I_{i}(10)$ pit on Internal side below and distal to pisiform process separated from intermetacarpal space by a raised area; (11) process of metacarpal I low; (12) external rim of facet for digit II widely rounded.

Sternum with (13) ventral manubrial spine present; (14) intermuscular line distinctly angling over plate and reaching carina anterior to its posterior end; (15) sternal notches shallow; (16) a pit, or even a large excavation, in dorsal portion of carinal margin in some specimens of all species.

Coraco1d with (17) shaft robust; (18) pneumatic foramina small and extending under entire furcular facet.

Scapula with (19) pneumatic fossa absent or reduced. Furculum with (20) extended depression along lateral surface containing one or more pneumatic foramina, frequently large.

Femur w1th (21) shaft straight. 
T1blotarsus with (22) external and internal condyles diverging anterlorly; (23) external condyle elongate in lateral outline.

Tarsometatarsus with (24) prominent groove in trochlea for diglt II.

Pelvis with (25) posterior borders of 111 um and 1schium approximately equal in posterior extent.

Cervical vertebrae 21 to 25.

Delacour and Mayr (1945) divided the subfamily Anserinae Into only two tribes, uniting the swans and geese under the tribe Anserin1. To support this arrangement Delacour (1954) made the following statement: "Swans and geese agree so closely in structure, pattern of downy chicks, general behavior, courtship and nesting habits that it is preferable to include them all in the same tribe." But he refuted his conclusion by saying, "Swans are larger and better adapted to acquatic life; consequently they have shorter legs, larger feet, and longer necks with more vertebrae (twenty-three to twenty-five, against elghteen to nineteen). But the latter feature is not very important, as it varies with the species. Certain of their habits, however, are at some varlance with those of the Geese, and their chromosone number is not the same."

Osteologically swans form no less distinct a tribe than the whistling ducks, although they are distinct in different ways. The most important of the criteria listed for the trlbe is probably the displaced intermuscular line on the sternum. It indicates a significant difference in the 
supracoracoldeus muscle. As Table 2 discloses, there is variation in the number of cervical vertebrae at the species level, but the fact that true swans have a minimum of 22 , true geese a maximum of 20 , and coscoroba l1es between w1th 21. seems significant.

\section{Genera of swans}

Two genera of swans, Chenopls for the black swan of Australla, and gygnus for the others, were recognized by Peters (1931); whereas Delacour and Nayr (1945) combined all the swans in a single genus. Wetmore (1951) felt that the genus olor 18 worthy of recognition, and gave osteological evidence in support. He mentioned the presence of the sternal loop of the trachea and the modified furculum in 이아. features that are lacking in cygnus.

There are additional skeletal differences between 이아 and cygnus, some of them seemingly not assoclated with the sternal tracheal loop. These features, many of which were 11sted by Howard (1946), are summarized below for 이아.

Humerus with (1) intermuscular line on capital shaft ridge turning inward about one-quarter inch below head;

(2) attachment of suprasplnatus poorly marked, spreading past median crest, and lacking ralsed bordering line at edge; (3) I1gamental furrow relatively narrow and deep; (4) attachment of anterior articular ligament long, narrow, and smoothly rounded at edges; (5) Impression of brachialis anticus short, broad, particularly at proximoexternal edge, clearly outlined, usually deeply depressed. 
Carpometacarpus with (7) cuneiform fossa lacking distinct proximal and medial rims; (8) metacarpal I with only a shallow depression on external surface immediately proximal to facet for digit II.

Coracold with (9) furcular facet undercut for 1 ts full extent; (10) procoracold larger; (11) coracoldal notch absent.

Scapula with (12) muscular attachment forming a short crest running from acromion along ventromedial edge of bone. Furculum with (13) clavicular depression long, containIng several large foramina.

Femur with (14) low ridge extending from trochanter towards head to make neck appear less constricted.

These features seem numerous and strong enough to consider olor a valid unit. The genus contains the species ㅇ. cygnus, ㅇ․ bew1ck11, ㅇ․ columb1anus, and ㅇ․ buccinator. possibly the changes that allow the trachea to pass Into the carina are more involved than realized. In Anatidae other than olor, and in most other birds, including the crane Grus, the trachea remalns dorsal to the furcular symphysis. In olor the trachea passes ventral to the furcuIun to reach the carina. After looping back and leaving the carina at the anterior end, the trachea curves around the furculum and passes posteriorly to the lungs.

Chenopis is so similar to Cygnus in the characteristics of the postcranlal skeleton that recognition of the genus does not seem warranted. 
Coscoroba, although certainly most closely related to the true swans, 1s less speclalized. The peculiarities of the genus indicated to Delacour and Mayr (1945) an affinity with the whistling ducks. Several osteological features, however, make Coscoroba appear intermediate between the true swans and the geese. The relative width of the distal end of the humerus is 13.9 per cent in Coscoroba, Intermediate between that of the true swans (12.2 to 13.9) and the geese (14.1 to 15.6$)$. In Coscoroba the intermuscular line of the sternal plate extends farther posteriad before reaching the carina than in true swans, although it does not extend as far as in geese or other waterfowl. In coscoroba the posterior lateral processes are intermediate in length between those of true swans and geese. The coracoid in coscoroba has a slight depression in the triosseal canal; in true swans there is none; in geese it is deep. The angle between the head and the plane of the dorsal surface of the coracoid 1s 83 degrees in coscoroba. The range for true swans is from 83 to 93 degrees, the range for geese from 80 to 85 degrees. In coscoroba the pneumatic fossa of the scapula is shallow. There is none in swans, but a deep one in geese. In Coscoroba the depression along the lateral surface of the furculum is shallower and more restricted than is typical of swans, whereas geese have none. In Coscoroba the groove in the trochlea for digit II is interrupted anteroproximally by a slight swelling, absent in true swans, but large in geese. The width through the acetabula is 23.0 per cent of the pelvic length in Coscoroba. In swans the range is 15.7 to 19.4 
per cent, with an average of 17.56. In geese the range is from 19.8 to 26.9 per cent, with an average of 24.19 . In Coscoroba the cervical vertebra number 21 , the range for true swans is 22 to 25, and for the geese 18 to 20. The total number of vertebrae varies from 51 to 52 in Coscoroba. The range for true swans is 54 to 61 and for geese 48 to 51 .

\section{Tribe Anserini. Geese}

The tribe Anserini is composed of the true geese, the genera Anser, Cygnopsis, Chen, Philacte, Eulabela, Branta, and Nesochen of Peters (1931). The osteological properties of the postcranial skeleton of the Anserini are sumarized below.

Humerus with (1) space between external condyle and facet for anterior articular ligament wide; (2) distal end wide ( 14.1 to 15.6 per cent of total length), (3) entepicondyle distally extended; (4) entepicondylar prominence not extended laterally; (5) Internal tuberosity long.

Carpometacarpus with (6) metacarpal II relatively straight; (7) external $\mathrm{rim}$ of carpal trochlea distinctly notched; (8) neck between carpal trochlea and metacarpal III obsolete; (9) external rim of caxpal trochlea forning relatively small angle with proximal edge of process of metacarpal If (10) pit on internal side below and distal to pisiform process confluent with intermetacarpal space; (11) process of metacarpal I high with proximal edge nearly perpendicular to shaft; (12) external rim of facet for digit II almost straight. 
Sternum with (13) ventral manubrial spine present; (14) Intermuscular line extending along plate essentially parallel to carina and curving onto carina at 1ts posterior end; (15) sternal notches deep; (16) no pit in dorsal portion of carinal margin.

Coracold with (17) shaft robust, (18) pneumatic foramina normally restricted to area beneath brachial tuberosity. Scapula with (19) pneumatic fossa prominent.

Furculum with (20) no depression on lateral surface, and pneumatic foramina either absent or located in area between coracoidal and scapular tuberosities.

Fenur with (21) shaft straight.

Tiblotarsus w1th (22) external and internal condyles diverging anterforly; (23) external condyle elongate in lateral outline.

Tarsometatarsus with (24) prominent groove in trochlea for digit II.

Pelvis with (25) posterfor borders of 111 um and Ischium approximately equal in posterior extent.

Cervical vertebrae 18 to 20 .

Genera of Geese

Three divisions of the true geese can be supported by their postcranial osteology: Anser, including Cygnopsis, Chen, Philacte, and Eulabela of Peters's clasisification, Branta, and Mesochen. Delacour and Mayr (1945) recognized only two genera, by combining resochen in Branta. While the osteology supports the views of Delacour (1954) and numphrey 
(1958b) that Nesochen 1s an offshoot of Branta stock, 1ts skeletal features are as distinct as, or in some instances more distinct than, those between Ansex and Branta.

The features that separate Branta and Nesochen from Anser, In the broad sense, are as follows. In Branta and Nesochen the humerus has the depression for the external head of the triceps distinctly bordered. In Anser it is obscure. In Branta and Nesochen the coracold has the furcular facet undercut for its full extent. In Anser the facet $1 s$ deeply undercut dorsally, flattened against the shaft in the middle, and only slightly undercut ventrally. In Branta and Nesochen the furculum has no pneumatic foramina. In Anser prominent pneumatic foramina are almost always present. In Branta and Nesochen the femur has the anter1or tip of the trochanter extended slightly more proximad, and the posterlor IIm straighter. In Anser the femur has the most proximal extent of the trochanter in the middle, and the posterior rim curves toward the head. In Branta and Nesochen the tibiotarsus has the inner cnemial crest straighter. In Anser the inner cnemial crest is deflected laterally.

In Branta the sternum has the ventral manubrial spine vertically spatulate. In Anser and Nesochen the spine is typlcally peglike.

From these comparisons Nesochen seems most closely related to Branta, but the following additional characteristics separate the genus from all other geese.

Sternum with (1) width narxow, varying from 37 to 40 per cent of basin length (a minimun of 41 per cent 18 
recorded for the other genera), (2) carina visjbly lower, (3) ventral manubrial splne less developed; (4) dorsal manubrial spine a transverse ridge (it is a buttonlike prominence In other genera), (5) pneumatic foramen very small; (6) intermuscular line less prominent.

Coracold with (7) depression in trlosseal canal shallow, (8) coraco-humeral surface more nearly transverse to shaft. Scapula with (9) processes generally smaller and weaker. Fermux with (10) rotular groove broad; (11) neck short, directed more posteriad.

Tiblotarsus with (12) fibular crest long. Tarsometatarsus with (13) outer margin stralghter; (14) trochleae more in line with shaft.

Tribe Cereopsini. Cape Barren Goose

Detalls of the postcranial skeleton require that Cereop8 is be removed to the Anserinae from the Anatinae, where it was tentatively placed by Delacour and Mayr (1945). It agrees with the Anserinae in all fourteen of the characteristics listed as diagnostic for this subfamily.

Features other than those of the postcranial skeleton support the placement of Cereopsis in the Anserinae. Most of the characters 11sted for the subfamily by Delacour (1954) are found in Cereops1s. The reticulate tarsus, the absence of a syrinx, and the long neck, composed of 19 or 20 cervical vertebrae, are probably the most important. As with stictonetta, the classification of Verheyen (1955) supports this 
decision, for he placed the genus in a separate group near the geese, swans, and Coscoroba.

Cereopsis if an aberrant genus with no close, living relatives, and it cannot be assigned to any of the recognized tribes. The following postcranial characteristics distinguish the monotypic tribe to which it is assigned.

Fumerus with (1) deltold crest evenly curved throughout its length; (2) head confluent with shaft on anconal side.

Carpometacarpus with (3) proximal edge of process of metacarpal I sloping forward, and distal edge concave, with t1p more pointed; (4) distal metacarpal symphysis greatly lengthened.

Sternum with (5) concavity beneath dorsal aulcal ip reduced; (6) dorsal manubrial area notched; (7) ventral manubrial spine lacking; (8) xiphisternum curving inward;

(9) carinal margin relatively more curved.

Coracoid with (10) depression in triosseal canal lackIng; (11) head relatively wider and shallower.

Scapula with (12) acromion directed more mediad, and consequently surface posterior to acromion, including glenoid facet, broad; (13) anterior edge between acromion and coracoldal articulation thick; (14) dorsonedial edge of neck With extra protuberance; (15) glenoid facet lying in plane of anterlor portion of shaft; (16) pneumatic fossa present. Furculum with (17) pneumatic foramina present in slight depression; (18) clavicles compressed.

Femur with (19) flbular condyle extending farther distally than point of its junction with external condyle. 
Tiblotarsus with (20) outer cnemial creat hooked;

(21) pronounced ridge extending from outer cnemial crest onto anterfor aurface of shaft, whose aurface is convex; (22) shelf medial to external articular surface extending relatively farther out over posterior portion of the shaft; (23) supratendinal bridge tapering towards medial side, and medial abutment recessed; (24) tubercle for oblique ligament enlarged.

Tarsometatarsus with (25) intercotylar prominence oynmetrical in outline; (26) trochlea for digit II more nearly in line with the other two.

\section{Subfamily Anatinae}

The subfamlly Anatinae includes 48 nominal genera 11sted by Peters (1931), plus two additional ones (Lophonetta and Amazonetta) recognized by Delacour and Mayr (1945). Th1s arrangement is similar to the subfamily Anatinae of Delacour (1954, 1956, 1959) except that st1ctonetta and Cereopsis have been removed to the Anserinae.

Elght of this total of 50 nominal genera (Cyanochen, Pseudotadorna, Lophonetta, Salvador1na, Nesonetta, Asarcorn1s, Camptorhynchus, and Thalassornis) were not avallable as skeletons, and therefore cannot be included in the following d1scussion.

The principal postcranial osteological features of the subfamily Anatinae, as here defined, are sumwarized below.

Humerus with (1) prominent capital shaft ridge lacking or directed towards external tuberosity; (2) cap1tal groove 
extended laterally over anconal surface deeply excavating head; (3) depression of external head of triceps extended laterally; (4) area of pectoral attachment on external tuberosity depressed distally and elliptical.

Carpometacarpus with (5) metacarpal II rounded dorsally, (6) extensor attachment typically extending distally onto distal edge of process of metacarpal I.

Sternum with (7) basin flattened; (8) posterior surface of dorsal sulcal lip reduced.

Coracold with (9) angle between axis of head and plane of dorsal surface relatively small; (10) angle between sternal facet and shaft relatively large; (11) ventral lip of sternal facet less prominent, sloping sharply toward shaft.

Femur with (12) anterior edge of external condyle not significantly elevated from shaft.

Tarsometatarsus with (13) lobe on anterior surface of trochlea for digit II obsolete.

Cervical vertebrae 16 to 17 (17 to 19 in Anas acuta). The following morphological features were listed as diagnostic of the Anatinae by Delacour (1954): tarsus scutellate in front; plumage and structure of syrinx sexually dimorphic; speculum present. The removal of stictonetta and cereopsis from the Anatinae reduces the exceptions to all of these features. It makes the type of tarsal sheath an Infallible subfamilial criterion.

Based on osteology, the subfamily Anatinae is divisible into six tribes, namely: the sheldrakes, tribe Tadornini, the pond ducks, tribe Anatin1; the torrent duck, tribe 
Merganettin1; the pochards, tribe Aythy1n1; the sea ducks, tribe Mergin1; the stiff-talled ducks, tribe oxyurini. The tribal assignments of the avallable genera are 11 sted below.

Tadornin1: Chloesphaga, Neochen, Alopochen, Tadorna, Casarca, and Plectropterus.

Anatin1: Anas, Chaulelasmus, Mareca, Spatula, Malacorhymchus, Bymenolaimus, Tachyeres, Chenonetta, Aix, Dendronessa, Nettapus, Cheniscus, Sarkidiornis, Cairina, Pteronetta, and Amazonetta.

Merganettin1: Merganetta.

Aythyini: Rhodonessa, Metoplana, Netta, Aythya.

Mergin1: Somater1a, Lampronetta, Polysticta, Melanitta, Oidemia, Histrionicus, Clangula, Bucephala, Lophodytes, Mergellus, and Mergus.

Oxyurini: Heteronetta, Nomonyx, Oxyura, and B1ziura. Delacour and Mayr (1945) recognized seven tribes of Anatinae, the additional group being the perching ducks, tribe Cairinini, containing genera herein included in the Anatin1. Delacour (1954) also recognized seven tribes, but they are somewhat different. He removed the elders from the Mergini as the tribe somateriln1, and included the torrent ducks in the tribe Anatini.

Tribe Tadornin1. Sheldrakes

The sheldrake tribe Includes the genera Chloephaga, Neochen, Alopochen, Tadorna, Casarca, and Plectropterus 11sted by Peters. The characteristics of the postcranial skeleton that define the tribe are 1temized below. 
Humerus w1th (1) falrly prominent capital shaft ridge directed toward external tuberosity; (2) area of origin of external head of triceps relatively narrow; (3) deltold crest relatively large and flaring, and in lateral view more rounded, or if an abrupt bend occurs, it lies more posterlad; (4) deltoid crest extending farther distad, (5) head rotated so that external tuberosity is higher.

Carpometacarpus with (6) external scapholunar ligamental attachment broad, usually prominent, situated relatively higher and more distad, (7) lobe at distal end of external rim of carpal trochlea relatively large; (8) process of metacarpal I relatively high, short, and with a rugose cap.

sternum with (9) costal margin tapering posterlorly and with six or less costal processes; (10) dorsal sulcal ilp rather prominent; (11) pneumatic foramina usual in basin; (12) pneumatic fossa large and bordered laterally by stout bars; (13) prominent posterior extension of sterno-coracoldal process.

Coraco1d with (14) procoraco1d somewhat enlarged; (15) triosseal depression somewhat deep; (16) depression in furcular facet ventral to brachial tuberosity; (17) brachlal tuberosity undercut extensively; (18) angle between sternal facet and shaft relatively small.

Furculum w1th (19) coracoldal tuberosity poorly developed; (20) clavicles relatively compressed. Femur with (21) head directed slightly more proximad; (22) trochanter extending slightly more anteriorly. 
Tlblotarsus with (23) proximal portion of Intermuscular Iine straight, removed from anteromedial edge.

Tarsometatarsus with (24) trochleae for digits II and IV, and particularly the former, spread; (25) trochlea for digit II more in line with other two: (26) distal foramen less nearly perpendicular to shaft.

Cervical vertebrae 16 to 17 .

Genera of sheldrakes

The recognition of Chlorphaga, Neochen, and Alopochen as distinct but closely related genera is supported by the deta1ls of the postcranial skeleton. All three genera have elements that are diagnostic, and all three have certain baaic similarities. These details are presented in the body of the paper.

The merging of Casarca in the genus Tadorna is advisable because of the absence of any good osteological feature for separating them. This has already been done by Delacour and Mayr (1945) on other grounds, and by Verheyen (1955).

plectropterus agrees with the sheldrakes in the many features listed as characteristic of the tribe, and should 1tself be considered an aberrant sheldrake.

Additional data from the 11terature support the move. Sheldrakes typically have a spurlike knob at the bend of the wing, and are quarrelsome (Delacour, 1954).

Plectropterus has the scapholunar enlarged as a spur (Rand, 1954), and 1s extremely pugnacious (Delacour, 1959). of the five genera with which Plectropterus has hybridized, 
three, Chloephaga, Alopochen, and Tadorna, are sheldrakes (Johnsgard, 1960). According to Verheyen (1955), who placed Plectropterus in a taxon with the genera here included in the Tadornini, there are similarities in the skull.

\section{Tribe Anatin1. Pond Ducks}

The tribe Anatini, as here defined includes the nominal genera Anas, Chaulelasmus, Mareca, Spatula, Malacorhynchus, Dymenola1mus, Tachyeres, Amazonetta, Chenonetta, Alx, Dendronessa, Nettapus, Chen1scus, Sark1diorn1s, Ca1rina, and Pteronetta (Peters, 1931, Delacour and Mayr, 1945). The postcranial characteristics of the tribe are summarized below.

Humerus with (1) capital shaft ridge obsolete; (2) pneumatic fossa open, contalning bony struts, (3) ectepicondyle typically equal or subequal in height to entepicondyle.

Carpometacarpus with (4) noticeable prominence on external rim of carpal trochlea, (5) cunelform fossa intermediate in depth between that of pochards and sea ducks;

(6) external scapholunar 11gamental attachment prominent and on a prominent ridge; (7) flexor attachment extending beyond proximal fornix, (8) process of metacarpal I relatively high and straight (in comparison with sea ducks).

Sternum with (9) basin shallow (in comparison with sheldrakes); (10) pneumatic foramen elliptical or round (in comparison with sheldrakes); (11) width relatively narrow, (12) posterior lateral processes relatively straight (in 
comparison with diving tribes, pochards, sea ducks, stifftalled ducks).

Coracold with (13) relatively small angle between axis of head and plane of dorsal surface.

Scapula (in comparison with the diving tribes) with (14) acromion relatively short; (15) proximal portion less rotated; (16) blade broadest at midpoint.

Femur (in comparison with diving tribes) with (17) shaft relatively straight, (18) anterlor ridge of trochanter relatively large; (19) outer surface of condyles more nearly parallel. In addition (in comparison with sheldrakes)

(20) head directed relatively farther laterad; (21) trochanter forming an angle.

Tiblotarsus with (22) intermuscular line following anteromedial edge (In comparison w1th sheldrakes); (23) external condyle extending farther distad than internal condyle (in comparison with sea ducks and stiff-talled ducks); (24) posterior intercotylar sulcus relatively narrow (In comparison with pochards).

Tarsometatarsus with (25) distal end of median ridge of digit II reaching level of proximal end of facet for digit III (In comparison with diving tribes), in addition (in comparison with sheldrakes), (26) trochleae approximate; (27) external edge relatively straight.

Cervical vertebrae 16, except 17 to 19 in Anas acuta. Delacour and Mayx (1945) recognized an additional tribe, the calrinini, for some of the genera here included in the tribe Anatinl. Only three skeletal features, all quite 
fallible, support this action. In perching ducks ("Cairinini") there is a trend towards a reduction of the pneumatic fossa In the humerus to a restricted, circular opening rimmed with heavy bone. In dabbling ducks (Anatint, sensu stricto) the fossa tends to be ovaloid through an upward extension into the internal tuberosity. In perching ducks the external scapholunar I1gamental attachment on the carpometacarpus tends to be obscure, and the process of metacarpal I is higher, shorter, and straighter. In dabbling ducks the ligamental scar is usually prominent, and the process of metacarpal I lower, longer, and inflected. In perching ducks the ventrolateral portion of the head of the coracold tends to be more enlarged than in dabbling ducks.

These features appear too inconstant to merit tribal recognition. The perching habit characteristic of these genera may not be a reflection of common group ancestry.

Genera of Pond Ducks

No features of the postcranial skeleton support the recognition of Chaulelasmus and Spatula as alstinct from Anas; and they should be merged with that genus, as was done by Delacour and Mayr (1945).

Mareca differs from 소as (‥s.) to some degree in the form of the tarsometatarsus and in the robustness of the humeral shaft, but these differences are too weak and Inconstant for generic recognition. This action has already been taken by Delacour and Mayr (1945) on the basis of external morphology. 
Malacorhynchus is distinct in several of the postcranial skeletal elements, and is aberrant in having a closed pneumat1c fossa in the humerus. The form deserves generic rank.

Bymenolaimus is distinct from the typical dabbling ducks for most of the postcranlal skeletal elements, as discussed at length in the body of the paper. R1pley (1947) suggested that Bymenolaimus may be a sheldrake, and the attachment of the external scapholunar ligament supports this suggestion. However, in spite of 1ts swift-water environment, it agrees with the typical pond ducks in many important characters.

In the well-marked genus Tachyeres the four best taxonomic elements of the skeleton, the humerus, carpometacarpus, coracold, and sternum, all possess characters that require placing the genus in the Anatini, as discussed in the body of the paper. None of the four elements show any of the numerous diagnostic features of the Tadornint, where Tachyeres was tentatively placed by Delacour and Mayr (1945). The properties of the fermur in particular indicate the genus is not closely related to any of the diving tribes. A possible relationship of Tachyeres to Anas has been suggested by Ripley (1957).

The recognition of the genus Amazonetta for the species Anas brasiliensis of Peters (1931), as proposed by Delacour and Mayr (1945), is substantiated by the postcranial osteology of the species. The details are summarized below. 
Humerus with (1) the shaft strongly sigmo1d; (2) deltold crest markedly flared; (3) head inflected; (4) ectepicondyle slightly elevated above entepicondyle.

Carpometacarpus with (5) process of metacarpal I high and straight; (6) distal portion of external rim of carpal trochlea lacking a swelling.

Coracold with (7) head relatively pointed.

Tarsometatarsus with shaft thin, 7.9 per cent of total length. The minimum recorded for other Anatin1, as here defined, is 8.0 per cent; the minimum recorded for Anas, as here defined, 188.3 per cent.

The detalls of the skeleton, summarized below, necessitate the recognition of a separate genus for the species Anas leucophrys, for which the name Callonetta Delacour (1936) 1s avallable. This name was originally proposed as a subgenus of Anas, and is here elevated to generic rank. Fumerus with (1) shaft sigmold; (2) ecteplcondyle elevated above entepicondyle; (3) entepicondyle distally elongate; (4) deltold crest more rounded distally from bend. Carpometacarpus with (5) proximal edge of process of metacarpal I sloping sharply proximally; (6) flexor attachment reduced; (7) base of metacarpal III relatively narrow, (8) external rim of carpal trochlea long and narrow. Sternum with (9) ventral manubrial spine relatively thin; (10) costal processes reduced to $s i x$. Tarsometatarsus with (11) anteromedial ridge relatively thick and elevated. 
The behavior of Callonetta suggested to Delacour and Mayx (1945) a relationship with the pochards, but skeletal features, and particularly those of the humerus, strongly oppose th1s hypothes1s. Delacour (1956) also ment1oned a possible affinity with the perching ducks. Dersheid (1938), Verheyen (1955), and Johnsgard (1960) saw such a relationship and placed the species in the genus Amazonetta along with A. bras1liensis. Although affinity to Amazonetta is supported by features of the humerus, other criteria, and in particular those of the carpometacarpus, Indicate that the species deserves separate generic ranking as callonetta leucophrys.

The postcranial skeletons of Nettapus and Cheniscus show no differences of generic worth, and the merging of Cheniscus in the genus Nettapus, as proposed by Delacour and Mayr (1945), 1s valid.

Pteronetta has a number of important differences in the postcranial skeleton, and the species deserves recognition from Calrina at the generic level. This opposes the procedure followed by Delacour and Mayr (1945). The most diagnostic features are listed below.

Humerus with (1) depression for external head of triceps relatively broad; (2) deltoid crest distally elongate.

Carponetacarpus with (3) process of metacarpal I higher; (4) lowest point of Internal rim of carpal trochlea below plsiform process; (5) depression along external edge of base of carpal trochlea lacking. 
Sternum with (6) basin nonpneumatic except for one anterlorly and centrally located foramen.

Coracold with (7) head relatively wide, rounded;

(8) groove in furcular facet wide and shallow.

Scapula with (9) dorsal depression lacking; (10) blade relatively thin.

A1x and Dendronessa are Indistinguishable by features of the postcranial skeleton, and the latter genus should be synonymized. Th1s action was taken by Delacour and Mayr (1945) on other grounds and agreed with by verheyen (1955). The lack of any hybrids for the two specles is usually cited as reason for recognizing Dendronessa, but Johnsgard (1960) reported that several alleged crosses have been recorded. The details of the postcranial skeleton of 서, sensu lato, reveal that the genus is closer to Cairina and Chenonetta than to Anas. This is evident in the humerus, carpometacarpus, coracold, and sternum. These similarities, which are discussed under the respective elements, support the behavioral evidence of Lorenz (no date) and serological evidence of cotter (1957).

Chenonetta and particularly Sarkidiornis have many diagnostic skeletal features and are both worthy of generic rank.

Tribe Rerganettinl. Torrent Duck

Merganetta may well be derived from pond-duck stock, as the form of the syrinx and aternum and the presence of a speculum suggested to Nlethammer (1952), but the structure of the skeleton, Including the sternum, is too much at 
varlance with the typical Anatinl to consider the genus a nember of the same tribe. It has more basic differences from Anas than do gymenola1mus, Tachyeres, or even Metoplana of the pochards. These differences, the most inportant of which are summarized below, demand tribal recognition for the genus, which was the original procedure followed by Delacour and Mayr (1945). Verheyen (1955) placed the genus in a separate family, one of sixteen, but had it imnediately following his family Anatidae.

Humerus with (1) ligamental furrow extremely shallow; (2) brachial depression relatively broad; (3) anterior articular ligament relatively low; (4) deltold crest reduced, (5) bicipital crest foining shaft at relatively wide angle. Carpometacarpus w1th (6) metacarpals greatly shortened, (7) rims of carpal trochlea enlarged; (8) cuneiform fossa very deep; (9) base of metacarpal III narrow, and restricted laterally; (10) tuberosity of metacarpal II greatly reduced; (11) process of metacarpal I enlarged, curving sharply proximad, and frequently knobbed.

Sternum with (12) basin wide; (13) carina greatly reduced; (14) dorsal manubrial area deeply notched.

Coracold with (15) angle between axis of head and plane of dorsal surface relatively large, 72 degrees; (16) head deflected ventrally.

Scapula with (17) triosseal ridge reduced; (18) blade narrow and thick.

Furculum with (19) clavicles weak, connected in the form of a broad $U$. 
Pelvis with (20) acetabular width very small, 22.7 to 23.6 per cent of pelvic length.

Cervical vertebrae 16 .

\section{Tribe Aythyini. Pocharda}

The pochards, Metoplana, Netta, and Aythya, w1th the inclusion of Rhodonessa, form a closely knit tribe easily distinguished from the other diving tribes. The characteristics of the postcranial skeleton that support this view are sunmar1zed below.

Humerus (In comparison with other diving tribes) with (1) impression for brachialis anticus distinct; (2) entepicondyle higher than ectepicondyle; (3) Intercotylar furrow and olecranal fossa essentially confluent. In addition (in comparison with pond ducks), (4) shaft relatively thin; (5) facet for anterior articular ilgament relatively low.

Carpometacarpus with (6) distal portion of external rim of carpal trochlea without swelling; (7) cunelform fossa shallow: (8) external scapholunar 11gamental attachment prominent but small; (9) flexor attachment proximal to proxImal fornix; (10) process of metacarpal I high and straight (in comparison with other diving tribes).

Sternum (in comparison with pond ducks) with (11) basin relatively wide; (12) ventral manubrial spine lacking (Netoplana is an exception).

Coracold with (13) ventral portion of head reduced; (14) bicipital attachment a thin groove; (15) furcular facet extending farther posteriad along shaft. 
Scapula with (16) blade narrow; (17) proximal portion rotated.

Furculum (in comparison with pond ducks) with (18) furcular process reduced.

Femux (In comparison with the other diving tribes) with (19) trochanter extended farther anteriorly, (20) head smaller; (21) medial side of internal condyle less flared laterally.

Tlblotarsus (in comparison with the other diving tribes) with (22) external condyle extending farther distad than internal condyle.

Tarsometatarsus (in comparison with the other diving tribes) with (23) external edge almost straight, (24) trochlea for digit II forming slight angle with shaft.

Cervical vertebrae 17.

General behavior and color and pattern of the downy, young were cited by Delacour (1959) as important evidence of only a distant relationship between the pochards and the other diving ducks. The skeleton supports this view.

Rhodonessa discloses 1 ts affinities to the other pochards by numerous skeletal characteristics. Of particular importance are the form of the coracoid, humerus, and sternum. These deta1ls are discussed at length under these respective elements. Unfortunately, the distal limb elements were unavallable. The total of 17 cervical vertebrae 18 also important, as pointed out by Verheyen (1955), who al so united the four genera here considered the pochards under one taxon. Therefore, Rhodonessa 1 is transferred from the dabbling 
ducks, where it was placed by Delacour and Mayr (1945), to the pochards.

Metoplana and Netta have numerous skeletal differences, and it is a mistake to consider the two as congeners, as Delacour and Mayx believed (1945). These differences are summarized below for Metopiana.

Eumerus with (1) bicipital crest more prominent;

(2) head more robust.

Carpometacarpus with (3) tuberosity of metacarpal II and external rim of facet for digit II produced laterad.

Sternum with (4) ventral manubrial spine present;

(5) basin relatively narrow; (6) pneurnatic foramen relatively large; (7) postertor lateral processes longer, thinner, and straighter.

Coracold with (8) shaft relatively narrow; (9) sternal facet relatively short.

Scapula with (10) blade tapering.

Femux with (11) shaft less curved; (12) anterior edge of trochanter enlarged; (13) popliteal fossa shallow.

Tiblotarsus with (14) outer cnemial crest relatively broad; (15) shaft more robust.

Tarsometatarsus with (16) median ridge of trochlea for digit II extending beyond level of proximal end of facet for digit III.

The eight available species of the genus Aythya are extremely similar in skeletal features. Furthermore, the modifications of Aythya indicate it is better adapted for divIng than are Metopiana, Netta, or Rhodonessa. Netta seems 
closest to Aythya in most respects, but in a few Metoplana Is more similar.

Tribe Mergini. Sea Ducks

The diverse tribe of sea ducks includes the nominal genera Somater1a, Lampronetta, polysticta, Melanitta, o1demia, H1strionicus, Clangula, Bucephala, Mergellus, Lophodytes, and Merqus. The principal skeletal characteristics of the tribe are listed below.

Humerus w1th (1) pneumatic fossa closed (two exceptions), (2) internal tuberosity short, deep; (3) facet for anterior articular ligament low; (4) pit for origin of pronator longus extending proximad; (5) pit for origin of pronator brevis situated farther distad; (6) external condyle elevated above entepicondyle; (7) impression for brachialis anticus distinct, (8) Intercotylar furrow and olecranal fossa separated by a transverse bar.

Carpometacarpus w1th (9) distal portion of external xim of carpal trochlea possessing a prominent swelling; (10) cube form fossa relatively deep; (11) external scapholunar ligamental attachment obscure.

sternum with (12) basin wide; (13) ventral manubrial spine reduced or absent.

Coracoid with (14) procoracold flared dorsally and base enlarged; (15) triosseal canal wide; (16) head with large ventral prominence.

Scapula with (17) anterior end rotated; (18) blade un1formly wide. 
Femur w1th (19) shaft curved; (20) anterior portion of trochanter reduced; (21) popliteal fossa deep; (22) fibular condyle less flared laterally, (23) pit for tiblalis anticus prominent.

Tiblotarsus with (24) condyles equal in distal extent; (25) external 1igamental prominence small; (26) Internal condyle shorter anteromedlally.

Cervical vertebrae 16 .

Genera of Sea Ducks

It has long been the custom of avian taxonomists to consider the mergansers a separate subfamily of ducks, with features such as the narrow, serrated bill, long neck, and supposedly compressed tars1 listed as diagnostic (Phillips, 1926). But the postcranial skeleton clearly shows the mergansers to be close relatives of the genus Bucephala, as pointed out by Delacour (1936), and indeed, that Bucephala and the mergansers form a more distinct unit than do the mergansers by themselves. The numerous features that set Bucephala and the mergansers apart from the other sea ducks are IIsted below.

Carpometacarpus with (1) process of metacarpal I relatively high, and with extensor attachment relatively short; (2) pollical facet in line with or proximal to internal rim of carpal trochlea, and with only a small lateral lobe. Sternum with (3) both fenestrae and abdominal plate. Coracold with (4) sternal facet short, 33.2 to 39.7 per cent of length, (5) sterno-coracoidal process less produced 
laterally; (6) trlosseal canal narrow, 11.1 to 15.4 per cent of length.

Femur with (7) anterlor edge of trochanter decidedly inflected; (10) fibular condyle widely flaring.

Tiblotarsus with (8) proximal edge of outer cnemial crest virtually a stralght, diagonal line.

Tarsometatarsus with (9) external edge of outer trochlea straight or inflected.

The skeletal anatomy of the mergansers does not allow the merging of elther Mergellus or Lophodytes in the genus Mergus, as proposed by Delacour and Mayr (1945). All three are far more distinct osteologically than many recognized genera of waterfowl, and with certain elements Mergellus and Lophodytes are closer to Bucephala than to Mergus (s.s.). Clearly the proposed synonymizing of these two generlc names would obscure relationships.

Mergus. the most speclalized of the four genera, is characterized by the skeletal features listed below.

Humerus with (1) shaft relatively straight; (2) deltoid crest large and sharply angular; (3) pneumatlc fossa open.

Carpometacarpus w1th (4) process of metacarpal I low, 17.9 to 22.6 per cent of total length.

Sternum with (5) carinal overlap long, 25.6 to 35.6 per cent of basin length (average 31.6).

Coracoid with (6) ventral rim of glenold facet rather angular with anteroventral leg somewhat rounded, and posterlor leg essentially straight.

Furculum w1th (7) clavicles deeply curved. 
Femur w1th (8) shaft stralght, stout, and compressed, depth 11.0 to 12.6 per cent of length.

T1biotarsus with (9) inner cnemial crest relatively wide, and bent anterlorly at 1ts juncture with outer cnemial crest, (10) outer cnemial crest produced laterally beyond external art1cular surface.

Tarsometatarsus with (11) distal foramen relatively small and obliques (12) shaft narrow, 7.7 to 9.1 per cent of total length.

Pelv1s (13) narrow, acetabular width 16.2 to 20.7 per cent of pelvic length.

Lophodytes and Mergellus are both less specialized than Mergus, but frequently in different ways. The sum total of the differences between these two genera and Mergus ind1cates that Lophodytes may be somewhat closer to Mergus than is Mergellus. The features that characterize Lophodytes are 11sted below.

Fumerus with (1) shaft sigmold and width 7.1 to 7.7 per cent of total lengths (2) deltold crest large and sharply angular; (3) pneumatic fossa open.

Carpometacarpus with (4) process of metacarpal I relatively low, 23.2 to 23.6 per cent of total length.

Sternum with (5) carinal overlap short, 18.5 to 19.9 per cent of basin length (average 19.39).

Coracold with (6) anteroventral portion of rim of glenold facet broadly rounded, posterlor part concave.

Furculum with (7) clavicles relatively straight (in comparison with Mergus). 
Femur w1th (8) shaft depth 9.8 to 10.7 per cent of total length; (9) shaft wide, 8.3 to 9.2 per cent of total length. Tiblotarsus with (10) shaft wiath 5.2 to 5.8 per cent of length.

Tarsometatarsus with (11) distal foramen relatively amall and oblique; (12) shaft wide, 10.6 to 11.7 per cent of total length.

Pelvis (13) wide, acetabular width 22.9 to 30.0 per cent of pelvic length.

Mergellus can be distinguished from the other three genera in this group of sea ducks by the following list of characters.

Humerus with (1) deltoid crest angular, but reduced, (2) pneumatic fossa closed; (3) width 6.4 per cent of total length.

Carpometacarpus with (4) process of metacarpal I relatively low, 22.8 per cent of total length.

Sternum with (5) carinal overlap short, 18.5 per cent of basin length.

Coracold with (6) anteroventral portion of $\mathrm{rim}$ of glenold facet somewhat rounded.

Furculum with (7) clavicles relatively straight (in comparison with Merqus).

Femur with (8) shaft depth 9.5 per cent of total length;

(9) shaft narrow, 7.5 per cent of total length. Tibiotarsus with (10) shaft width 5.0 per cent of length. Tarsometatarsus with (11) distal foramen relatively 
small and oblique; (12) shaft narrow, 9.8 per cent of total length.

Pelvis (13) narrow, acetabular width 21.6 per cent of pelvic length.

Bucephala can be separated from the merganser genera by the following combination of skeletal characteristics.

Humerus with (1) shaft sigmoid; (2) pneumatic fossa closed; (3) deltold crest relatively small.

Carpometacarpus with (4) process of metacarpal I relatively low, 22.5 to 23.9 ; (5) lobe at distal end of external rim of carpal trochlea relatively large.

Sternum with (6) carinal overlap short, 11.4 to 22.0 per cent of basin length (average 16.13); (7) pneumatic foramen relatively small.

Coracold with (8) ventral 11p of sternal facet usually with distinct concavity near internal distal angle.

Furculum with (9) clavicles relatively straight (in comparison with Mergus).

Fermur with (10) shaft strongly curved; (11) shaft width 7.1 to 8.0 per cent of total length.

Tiblotarsus with (12) inner cnemial crest narrow, and prominently peaked.

Tarsometatarsus with (13) distal foramen relatively large and perpendicular to shaft.

Pelvis (14) wide, acetabular width 26.4 to 29.9 per cent of pelvic length.

The remaining genera of sea ducks can be separated from 
Bucephala and the mergansers by the following list of skeletal characters.

Carpometacarpus with (1) process of metacarpal I relatively low, and with extensor attachment relatively long, (2) pollical facet distal to internal rim of carpal trochlea, and with a large lateral lobe.

Sternum w1th (3) hotches.

Coracold with (4) sternal facet long, 42.1 to 49.9 per cent of length, (5) sterno-coracoidal process produced laterad; (6) triosseal canal relatively wide, 15.3 to 18.7 per cent of length.

Femur with (7) anterior edge of trochanter less inflected.

These genera may be divided into two groups, either one of which is less well-defined osteologically than the group containing Bucephala and the mergansers. The features that separate Clangula, Histrionicus, and the scoters from the elders are listed below.

Carpometacarpus with (1) flexor attachment relatively short, approximately half as long as in eiders; (2) upper surface of metacarpal II straight.

Sternum w1th (3) large abdominal plate or greater curvature throughout length, or small ventral manubrial spine.

Coracold with (5) sternal facet at internal distal angle relatively blunt; (6) ventromedial edge of shaft possessing a wide ridge; (7) trlosseal canal possessing a deep depression. 
Femur with (8) shaft relatively more curved; (9) scar on lateral surface proximal to flbular condyle relatively long.

Tiblotarsus with (10) outer cnemial crest relatively narrow, and directed farther anteriad.

Tarsometatarsus with (11) external edge of shaft almost a straight line.

The sea ducks Clangula and Histrionicus are generally recognized as distinct genera, and it does not seem necessary to sumarize their many skeletal characteristics. The study of their postcranial osteology has borne out the oonclusion of Delacour and Mayr (1945) that they form a central group among the sea ducks. It appears that evolution has proceeded In one direction from Clangila through Bucephala to the mergansers, and in another through H1strionicus to the scoters. The third direction, to the elders, is discussed below.

Whether one or two genera of scoters should be recognized has been a difficult decision to make. Since genera, as well as other taxonomic units, are arbitrary divisions of the continuum of evolution, it is only logical that all degrees of distinctness will be found among the existing blota. The scoters represent an intermediate stage between the concepts of species and genera, and perhaps should be consldered as two subgenera. Since the majority of the differences are proportions and since the species of scoters exhlbit a trend in some of these proportions, they are treated as a single genus, Melanitta, as in Delacour and Mayr (1945). According 
to Hartert (1923), Melanftta Bole, 1822 (apparently published in May), has prlority over 01demla Fleming, 1822 (apparently published in June).

The differences between "이demia" and Melanitta (s.․․) are 11sted below. In "Oldemia" the w1dth through the distal condyles varies from 13.9 to 14.4 per cent of the total length of the humerus; the range for Melanitta (s.․․) is from 14.5 to 15.8 per cent. In "Oidemla" the width through metacarpal II varies from 6.5 to 7.1 per cent of the total length of the carpometacarpus; the range for Melanitta (s.․․) is from 7.0 to 7.9 per cent. In "0idemia" the sternal facet varles from 46.6 to 49.9 per cent of the length of the coracold; the range for Melan1tta (‥s.) 1s from 42.9 to 44.9 per cent. In "이demia" the depression in the triosseal canal is usually deeper than in Melanitta (․․․․). and the furcular facet is circular in outline, instead of ovold as in Melanitta (s.s.). In "이dem1a" the width of the shaft of the femur varies from 8.2 to 8.5 per cent of the total length of the element; the range in Melanitta (s.g.) Is from 7.2 to 8.0 per cent. And finally, in "O1demia" the acetabular width varies from 15.4 to 20.8 per cent of the pelvic length; in Melanitta (s.s.s.) the range 1 from 19.3 to 23.5 per cent. Delacour (1956, 1959) and Humphrey (1958a) belleved the eiders form a tribe somaterilni, more closely related to the dabbling ducks than to the sea ducks, and give the structure of the tracheal bulla, plumage patterns, food hab1ts, and diving habits as evidence. Not a single feature of the postcrantal skeleton supports this view, however, and the 
similarity of the skeletons of eiders to those of other sea ducks is so great that it seems best to include the eiders within the Mergini.

The characteristics that tend to set the eiders apart from other two groups of sea ducks are 11sted below.

Humerus with (1) pneumatic fossa closed, but relatively deep.

Carpometacarpus with (2) flexor attachment relatively long, approximately twice as long as in other sea ducks; (3) upper surface of metacarpal II arched.

Sternum with (4) notches, no significant abdominal plate, and wide posterior lateral processes.

Coracold w1th (5) sternal facet elongate at internal distal angle; (6) ventromedial edge of shaft a sharp ridge; (7) triosseal canal with essentially no depression. Femur with (8) shaft relatively straight; (9) scar on lateral surface proximal to flbular condyle relatively short. Tibiotarsus with (10) outer cnemial crest relatively wide, and directed farther laterad.

Tarsometatarsus with (11) external edge of shaft distinctly curved. This character is the most diagnostic.

There are no skeletal features to support the recogn1tion of the genus Lampronetta, and it should be merged in the genus Somateria, as was done by Delacour and Mayx (1945) on other grounds.

Polysticta was synonymized with Somateria by Delacour and Mayr (1945), but Humphrey (1958a) revived the genus because of the presence of a speculum and differences in the 
tracheal bulla, adult plumage patterns, shape of the bill, characteristics of flight, and skeletal proportions, which although not explained he onsidered striking. Delacour (1959) later followed Humphrey. The following qualitative features of the skeleton strongly support the recognition of Polysticta.

Humerus w1th (1) distal condyles strongly rotated, w1th external condyle elevated above enteplcondyle.

Carpometacarpus with (2) notch in external rim of carpal trochlea reduced; (3) lobe at distal end of external rim of carpal trochlea relatively small; (4) cunelform fossa relatively shallow.

Sternum w1th (5) ventral manubrial spine small but single.

Coracold with (6) angle between axis of head and plane of dorsal surface relatively large, 81 degrees compared to 70 to 79 degrees; (7) furcular facet rounded.

Scapula w1th (8) acromion more in line with shaft, therefore, appearing relatively long, and with larger concav1ty between 1 t and shaft.

Femur with (9) anterior portion of trochanter possessing more prominent, medially directed protuberance; (1) flbular groove relatively narrow: (11) ligamental attachment on medial surface of internal condyle a prominent projection; (12) anterior ridge of internal condyle relatively straight 1nstead of flaring mediad.

T1biotarsus with (13) condyles more in line with shaft. 
Tarsometatarsus with (14) median $\mathrm{rim}$ of trochlea for digit II extending beyond level of posterior extent of facet for digit III.

Most of the skeletal features that distinguish polysticta from the large elders also show that the genus is near the central group of sea ducks, Clangula and Histrionicus. Particularly worthy of note are the rotation of the distal end of the humerus, manubrial spine of the sternum, and angle of the head of the coracold. Furthermore, 旦strionicus has a speculum similar to that of Polysticta, and according to Humphrey (1958a) the flight behaviors of Clangula and Polysticta are similar. Thus 1 t appears that the third direction of evolution in the diverse tribe of sea ducks has been from Histrionicus and Clangula through Polysticta to Somater1a, as originally suggested by Delacour and Mayx (1945).

The published figure of the sternum of Camptorhynchus further Indicates the derivation of the eiders from a Histrionicus-11ke stock.

Tribe oxyurint. St1ff-tailed Ducks

The genera Heteronetta, Nomonyx, Oxyura, and Biziura form a very distinct tribe of Anatinae easily characterized by features of the skeleton. Those skeletal properties believed to be most important are summarized below.

Humerus with (1) pneumatic fossa very shallow, and wall perforated by numerous foramina, (2) scar for latissimus 
dors1 posterioris situated farther laterad; (3) entepicondyle and pit for flexor carpi ulnaris reduced.

Carpometacarpus with (4) distal margin of internal rim of carpal trochlea nearly parallel to shaft; (5) metacarpal III narrow at base; (6) area on external surface below external ligamental attachments deeply grooved.

Sternum with (7) pneumatic foramen lacking or minute;

(8) ventral manubrial spine directed steeply dorsad (except in Blzlura, where spine is lacking); (9) basin very shallow. Coracoid with (10) ventral portion of head extending far down shaft; (11) brachial tuberosity reduced.

Scapula with (12) acromion directed more anteriorly: (13) blade very uniform in width, fairly narrow, and often thick; (14) glenold facet laterally compressed.

Furculum with (15) clavicles thin and rather weak.

Tarsometatarsus with (16) Inner calcaneal ridge enlarged (17) trochlea for digit IV with inner ridge elevated. Pelvis with (18) acetabular width very small.

Cervical vertebrae 16 .

Heteronetta possesses all of the many striking skeletal features listed above for the tribe oxyurin1, and thus there remains no doubt about the relationships of the genus. However, with most of the elements Heteronetta shows a lesser degree of specialization than occurs in the other genera, and in certain instances there 18 indication of an ancient tie with the pond ducks. The detaj 18 are discussed at length in the body of the paper. 
In external morphology, Nomonyx is similar to oxyura, with which it was synonymized by Delacour and Mayr (1945); but the skeletal anatomy is very distinctive. The many skeletal features that define the genus, most of which show a lesser degree of spectalization in comparison with oxyura, are 1temized below.

Humerus with (1) Internal tuberosity elongate; (2) depression for external head of triceps less excavated;

(3) shaft relatively thick.

Carpometacarpus with (4) process of metacarpal I relatively narrow; (5) distal margin of internal $\mathrm{I}$ im of carpal trochlea deflected slightly laterally; (6) tuberosity of metacarpal II small; (7) groove in external rim of carpal trochlea shállow.

Sternum with (8) basin relatively narrow; (9) ventral manubrial spine long, thin, and peglike; (10) notches relatively deep; (11) xiphisternum relatively narrow.

coracold with (12) triosseal canal narrow; (13) shaft width reduced; (13) brachial tuberosity relatively small. Scapula with (14) glenold facet only slightly compressed.

Furculum with (15) clavicles more massive (in comparison with the other three genera of stiff-talled ducks). Femur with (16) shaft relatively straight. Tibiotarsus with (17) external condyle extending relatively farther distad; (18) inner cnemial crest lacking long ridge found in the more spectalized oxyura and Biziura. 
Tarsometatarøus with (19) median rim of trochlea for digit II extending beyond level reached by proximal extent of facet for digit III.

The two most specialized of the four available genera, oxyura and Bizlura, and particularly the latter genus, have many unique properties of the skeleton. 
TABLE 3

CLASSIFICATION OF THE ANSERIFORMES

Suborder Anhimae

Family Anhimidae

Anhima

Chauna

Suborder Anseres

Family Anseranat1dae

Anseranas

Family Anatidae

Subfamily Anserinae

Tribe Dendrocygnin1

Dendrocyana

stictonetta

Tribe Cygnin1

Coscoroba

Cygnus

이아
Tribe Anserini

Anser

Branta

Nesochen

Tribe Cereopsini

Cereopsis
Tribe Tadornin1

Plectropterus

Chloesphaga

cyanochen

Neochen

Alopochen

Tadorna

Lophonetta*

Tribe Anatin1

Sarkidiorn1s

Pteronetta

Asarcornis*

Cairina

Nettapus

Aix

Chenonetta

Amazonetta

Callonetta

Anas

Salvadorina"

Malacorhynchus

Hymenolaimus

Tachyeres

Subfam1ly Anatinae

Tr1be Merganett1n1 Merganetta

Tribe Aythyini

Rhodonessa

Metoplana

Netta

Aythya

Tribe Mergin 1

Melanitta

Somater1a

Polyst1cta

Camptorhymchus*

Histrion1cus

Clangula

Bucephala

Mergellus

Iophodytes

Mergus

Tribe Oxyurin1

Heteronetta

Nomonyx

Oxyura

Thalassorn1s"

Bizlura

wot examined 
PLATE I

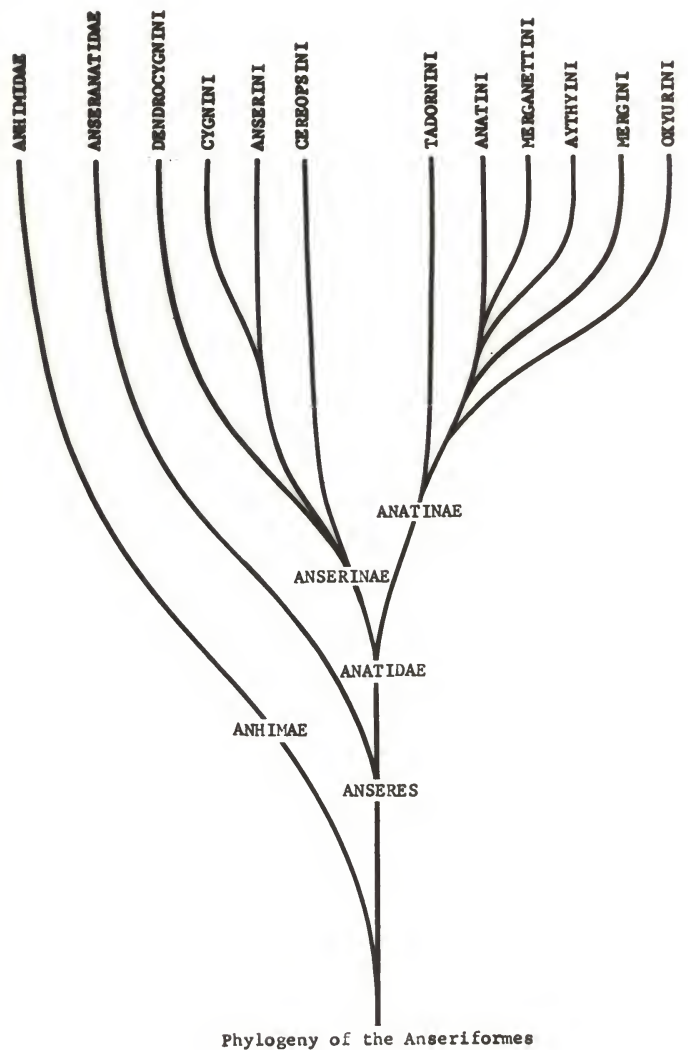




\section{SUMMARY}

Postcranial osteology of nearly all the genera of waterfowl of the world is described. On the basis of this study certain changes in the classiflcation within the order are proposed. The order Anseriformes is considered to include two suborders, the Anhimae, composed of the family Anhimidae, and the Anseres, composed of the familles Anseranatidae and Anat1dae. The family Anseranatidae is monotypic, contalning the genus Anseranas. The family Anatidae 1s composed of two subfamilies. The subfamily Anserinae conta1ns the following tribes: Dendrocygnin1, Cygnin1, Anserin1, and Cereopsini. The subfamily Anatinae contains the following tribes: Tadornin1, Anatin1, Merganett1n1, Aythyin1, Mergin1, and oxyurint.

In comparison with the most recent classification of the waterfowl, the following changes have been made: Anseranas is placed in a monotypic family; Stictonetta is moved from the Anatini to the Dendrocygnin1 of the Anserinae; Cereopsis is moved from the Tadornint to a monotypic tribe of the Anserinae; plectropterus is moved from the Cairinini to the Tadornini; Tachyeres is moved from the Tadornini to the Anatini; the tribe Cairinini is merged with the Anatini; Merganetta is moved from the Anatini to a monotypic tribe; Rhodonessa is moved from the Anatini to the Aythyinis the 
tribe Somaterilni is merged with the Mergini. The following genera are resurrected: 이or, Nesochen, Callonetta, Pteronetta, Metopiana, Mergellus, Lophodytes, and Momonyx, and, tentatively, Asarcornis and Salvadorina. 


\section{LITERATURE CITED}

Ashley, James $F$.

1941. A study of the structure of the humerus in the Corvidae. Condor, vol. 43, no. 4, pp. 184-195, 7 pls.

American Ornitholog1sts' Union

1945. Twentieth Supplement to the American Ornithologists' Union Check-11st of North American Birds. Auk, vol. 62, no. 3, pp. 436-449.

Boett1cher, Hans

1943. Die phylogenet1sch-systemat1sche stellung von Anseranas. Zool. Anz., vol. 142, pp. 55-58.

Brodkorb, Pierce

1955. The avifauna of the Bone Valley formation. Florida Geol., Surv., Report Invest., no. 14, pp. 1-57, $11 \mathrm{pls.}$

1958a. Birds from the middle Pllocene of McKay, Oregon. Condor, vol. 60, no. 4, pp. 252-225, $1 \mathrm{flg}$.

1958b. Foss1l blrds from Idaho. Wilson Bull., vol. 70 , no. 3, pp. 237-242, 1 flg.

1960a. The skeleton and systematic position of Gampsonyx. Auk, vol. 77, no. 1, pp. 88-89.

1960b. Blrds from the Pllocene of Juntura, Oregon. In press.

Cotter, William B. Jr.

1957. A serological analysis of some anatid classifications. W1lson Bull., vol. 69, no. 4, pp. 291-300.

Delacour, Jean

1936. Note sur la classification des Anat1dés. L'O1seau, n. s., vol. 6, pp. 366-379.

1954. The waterfowl of the world. Vol. 1, pp. 1-284, 16 pls., 33 maps, Country L1fe Ltd., Iondon.

1956. The waterfowl of the world. Vol. 2, pp. 1-232, 24 pls.. 29 maps, Country IIfe Ltd., London. 
Delacour, Jean

1959. The waterfowl of the world. Vol. 3, pp. 1-270, 20 pls.. 46 maps, Country Life Ltd., London.

Dealcour, Jean, and Ernst Mayr

1945. The family Anatidae. Wilson Bull., vol. 57, no. 1, pp. 3-55, 1 pl., 24 figs.

Dershe1d, J. M.

1938. Description of a new species of teal (Amazonetta vittata) from South America, together with a note on the systematic position of Amazonetta and Calonetta. Bull. Brit. Ornith. Club, vol. 58, pp. 59-63.

Downs, Theodore

1954. Pleistocene birds from the Jones fauna of Kansas. Condor, vol. 56, no. 4, pp. 207-221, 5 figs.

Fisher, Harvey I.

1940. The occurrence of vestigial claws on the wings of birds. Amer. Mddl. Nat., vol. 43, no. 1, pp. 234-243, $1 \mathrm{fig}$.

1946. Adaptations and comparative anatomy of the locomotor apparatus of new world viltures. Amer. Midl. Nat., vol. 35 , no. 3 , pp. 545-727, 13 pls.. 28 figs.

Gadow, Hans

1891. V\&gel. In Klassen und Ordnungen des Thier-Reichs. vol. 6, pt. 4, subpt. 1, pp. 1-1008, 59 pls., many figs. in text, Ed. H. G. Bronn, C. F. Winter'sche Verlagshandlung, Leipzig.

1893. v8gel. Ib1d., vol. 6, pt. 4, subpt. 2, pp. 1-303.

Goodman, Donald C., and Harvey I. Fisher

1960. Functional anatomy of the feeding apparatus in waterfowl. Southern Il11nois Univ. Press, Carbondale. In press.

Hartert, Ernst

1923. Die vơgel der paluararktischen Fauna. pp. 1-92. R. Friedländer \& Sohn, Berlin.

Howard, Hildegarde

1929. The avifauna of the Emeryville shellmound. Univ. Callf. Publ. Zool., vol. 32. no. 2, pp. 301-394, 4 pls., 55 figs.

1946. A review of the Pleistocene birds of Foss1l Lake, Oregon. Carnegie Inst. Wash. Publ. 551, pp. 141-195, 2 pls. 
Humphrey, Ph111p S.

1958a. Classification and systematic position of the elders. Condor, vol. 60 , no. 2, pp. 129-135, 1 f1g.

1958b. The trachea of the Hawa11an goose. Condor, vol. 60, no. 5, pp. 303-307, 1. E1g.

Humphrey, Ph111p S., and Robert S. Butsch

1958. The anatomy of the Labrador duck, Camptorhynchus labradorlus (Gmelin). Sm1thsonian M1sc. Coll., vol. 135, no. 7, pp. 1-23, 5 pls.

Johnsgard, Paul A.

1960. Eybridization in the Anatidae and 1ts taxonomic implications. Condor, vol. 62, no. 1, pp. 25-33, 1 flg., 7 tables.

Lorenz, Konrad

n.d. Comparative studies on the behaviour of the Anatinae. Pp. 1-87, f1g. 1-54, Avicultural Soc1ety, Iondon.

Mayr, Ernst

1931. On the anatomy and systernatic position of Salvador1's duck (Salvadortna wa1g1uensis Rotsch. and Hartert). Orn. Monatsb., vol. 39, no. 3, pp. 69-70.

Mayr, Ernst, and Dean Amadon

1951. A classification of recent birds. Amer. Mus. Novit., no. 1496, pp. 1442 .

M1ller, Alden $\mathrm{B}$.

1937. Structural modif1cations in the Hawa11an goose (Nesochen sandvicens1s). A study in adapt1ve evolut1on. UnIv. Cal1f. Publ. Zool., vol. 42, no. 1 , pp. $1-80,6$ pls.. 6 figs, in text.

M111er, Dew1tt

1919. Notes on the structure of Anseranas semipalmata. Auk, vol. 36 , no. 4, pp. 562-564.

Newton, Alfred

1896. A dictionary of b1rds. Pp. 1-x11, 1-1088. Adam and Charles Black, London.

Niethammer, G.

1952. Zur Aratomie und systemat1schen ste.1lung der Sturzbach-Ente (Merganetta armata). Jour. fur orn., vol. 93, p. $357-360$.

Parkes, Kenneth c.

1955. The gener1c name of the spectacled e1der. Auk, vol. 72 , no. 1, pp. 85-86. 
Peters, James L.

1931. Check-11st of birds of the world. Vol. 1, pp. 1-xvi11, 1-345. Harvard Un1v. Press, Cambridge.

Phillips, John C.

1926. A natural history of the ducks. Vol. 4, pp. 1+489, 32 pls.. 23 maps. Houghton-M1fflin Co.., Boston and New York.

Rand, Austin I.

1954. On the spurs on birds' wings. Wilson Bull.., vol. 66, no. 2, pp. 127-134., 1 fig.

Ripley, S. Dillon

1957. A paddling of ducks. Pp. 1-256. Harcourt, Brace and Co.., New York.

Rowley, George Dawson

1877. Somateria labradoria (J. F. Gnelin). Ornitholog1cal Miscellany, vol. 2, pp. 205-223, 6 pls.

Salvador1, Tomuna so

1895. Catalogue of the Chenomorphae (Palamedeae, Phoen1copteri, Anseres), Crypturi, and Ratitae in the collection of the British Museum. Pp. 1-xv, 1-636, 19 pls. British Museum, London.

Shufeldt, R. W.

1892. A study of the fossil avifauna of the Equus beds of the oregon desert. Jour. Acad. Nat. Sc1. Phila., ser. 2, vol. 9, pp. 389-425, 8 pls.

1909. Osteology of b1rds. Bul1. N. Y. state Mus.. vol. 130, pp. 1-135, 16 pls.. 65 figs. in text.

slbley, Charles G.

1960. The electrophoretic patterns of avian egg-white protelns as taxonomic characters. Ib18, vol. 202, no. 2, pp. 215-259, 15 f1gs.

Stefneger, Leonhard

1882. Outlines of a monograph of the Cygninae. Proc. U. S. Nat. Mus., vol. 5, no. 275, pp. 174-221.

1885. The standard natural history idirds. Vol. 4, pp. 1-v111, 1-558, 25 pls., 273 flgs. in text. S. E. Castino and Co., Boston.

Stresemann, Erwin

1959. The status of avian systematics and 1ts unsolved problems. Auk, vol. 76, no. 3, pp. 269-280.

Stettenheim, Peter

1958. Bird fossils from the late Pleistocene of Kansas. W1lson Bull., vol. 70, no. 2, pp. 197-199. 
Verheyen, René

1955. Ia systématıque des Ansériformes basée sur 1 'ostéolog1e comparée. Bu11. Inst. roy. Sc1. nat. Belg1que, vol. 31, no. 35, pp. 1-18; no. 36 , pp. $1-16$; no. 37 , pp. $1-22$; no. 38 , pp. $1-16$.

Wetmore, Alexander

1924. Fossil birds from southeastern Artzona. Proc.

U. S. Nat. Mus. vol. 64, art. 5, pp. 1-18, 9 flgs.

1943. An extinct goose from the 1sland of Hawai1. Condor, vol. 45 , no. 4, pp. 146-148, $1 \mathrm{flg}$.

1944. Remains of birds from the Rexroad fauna of the upper P11ocene of Kansas. Univ. of Kans. Sc1. Bull., vol. 30, pt. 1, no. 9, pp. 89-105, 19 flgs.

1948. A Pleistocene record for Merqus merganser in I111no1s. W1lson Bull., vol. 60 , no. 4, p. 240.

1951. Observations on the genera of the swans. Jour. Wash. Acad. Sc1.. vol. 41, no. 10, pp. 338-340.

1960. A classification for the birds of the world. Smithsonian Misc. Coll., vol. 139, no. 11, pp. 1-37.

Woolfenden, Glen $\mathbf{E}$.

1959. A Ple1stocene avifauna from Rock Spring, Florida. w11son Bul1.. vol. 71, no. 2, pp. 183-187. 


\section{APPEIDIX}

\section{Ligaments of the Pectoral Girdle \\ Plate II}

In order better to understand the functional significance of the various processes on the bones of the pectoral girdle, it was necessary to study the ligaments connecting the three elements to each other and to the sternum. since nowhere in the literature are the ligaments in this area concisely explained, and since some of the ligaments appear to be unnamed, these detalls are summarized as follows.

Membrana sterno-coraco-clavicularis. Gadow, 1891

Lames latérales and Lame médiane postérleure ou verticale de

l'apparell épisternal combined. Hart1ng, 1864, see Gadow, 1891.

Ligamentum sterno-furculare. Gadow, 1891 (may be a synonym for only a part of the membrane)

Composed of a single posteroventral sheet and a pair of anterolateral sheets.

The single ligamentous sheet (Lame médiane postérieure) extends posteriorly from a line between the anterior tip of the ventral manubrial spine of the sternum and the furcular process of the furculum to the anterior carinal margin of the sternum. In species lacking a prominent spine the extent of the single sheet is reduced. 
The sheet becomes double (Lames latérales) as it passes from the tip of the ventral manubrial spine onto the lateral ridges on the dorsal surface of the spine and from the furcular process onto the clavicles. Each sheet stretches from the ventral manubrial spine to the coracold, where it attaches along the internal margin, from the midpoint of the shaft to the procoracold and brachlal tuberosity. From the brachial tuberosity the sheet passes to the lateral ridge on the coracoldal tuberosity of the furculum (an anteriorly directed process near the scapular tuberosity) by means of the anterlor portion of Ligamentum coraco-furculare. Thence, it soon passes posterolaterally to the medial side, where it reaches the symphysis of the furculum and joins the sheet from the other clavicle. A ligamentous line on the lateral surface of the sheet extends from the intermuscular line of the carina to the triosseal canal, to separate 쏘. supracoracoldeus dorsomedially from 쓰. pectoralls ventrolaterally.

\section{Membrana interclavicularis}

Lame médiane antér1eure ou horizontale. Harting, 1864, see Gadow, 1891.

Interclavicular membrane. Humphrey, $1958 \mathrm{~b}$.

A membranous sheet stretching between the arms of the furculum, attaching along the medial edge of the bone from the symphysis almost to the tip of the scapular tuberosity of the furculum whence it extends to the short medial ridge of the acromion of the scapula and thence to the axial musculature. It 18 plerced in the middle by the trachea, and 
more dorsally by the esophagus. The tracheal bulla, when present, lies posterior to this membrane.

L1gamentum coraco1deo-scapulare externum. Gadow, 1891

Attaches the glenold facets of the coracold and scapula, respectively, and forms a U-shaped groove for the head of the humerus. It 18 very thick.

\section{Ligamentum coracoldeo-scapulare infer1us. Gadow, 1891}

Extends from the ridge on the dorsal edge of the procoracold and the rim of the scapular facet of the coracold to the anterior edge of the scapula. It holds the coracoldal articulation of the scapula in the scapular facet of the coracold.

\section{L1gamentum coraco-capsulare. Gadow, 1891}

Extends from the brachlal tuberosity of the coracold to the triosseal ridge on the dorsal surface of the acromion of the scapula.

\section{L1gamentum coraco1deum intrins1cum}

Connects the procoracoid and the brachlal tuberosity of the coracold. Th1s 11gament and L. coraco-capsulare are very strong and closely parallel each other and Membrana sterno-coraco-clavicularis. The two 11gaments seal off the medial side of the triosseal canal. In some b1rds L. coracoideum intrinsicum is osseous. 
LIgamentum sterno-coraco1deum. Gadow, 1891

Extends from the most anterior rims of coracoldal sulcus of the sternum to the most anterlor ridges of the sternal facet of the coracold.

\section{Ilgamentum sterno-coracoldeum dorsale}

Extends from the lateral prominence of the dorsal manubrial area of the sternum to the uppermost scar on the dorsal surface of the coracold.

\section{L1garnentum coraco-furculare. Gadow, 1891}

Extends from the most anterior portion of the brachial tuberosity of the coracoid to the lateral ridge of the scapular tuberosity of the furculum, and from the ventral portion of the furcular facet of the coracold to the coracoidal tuberosity of the furculum. The tissue between these two strengthened portions of the ligament is membranous. Merrbrana sterno-coraco-clavicular1s attaches to the latter described of the two ligamentous portions as it passes from coracold to furculum. In geese the portion that extends to the coracoldal tuberosity is considerably broadened, and the coracoldal tuberosity forms a ridge instead of a tubercle.

\section{IIgamentura furculo-scapulare. Gadow, 1891}

Extends from the posterfor surface of the scapular tuberosity of the furculum to the dorsal aurface of the acromion of the scapula. 


\section{ilgamentum furculo-scapulare dorsale}

Extends from the extrene t1p of the scapular tuberosity of the furculum to the sometimes obscure ridge lying anteromediad from the dorsal protuberance (a swelling in the middie of the dorsal surface of the neck) of the scapula.

In waterfowl the furculum plainly makes no direct articulation with elther of the other elements of the pectoral girdle, but instead is held in close proximity medially by several strong 11gaments. The freedom of movement of the furculum can be detected in fresh specimens. 
PLATE II

LIGAMENTS OF PECTORAL GIRDLE

Anterodorsal view of Anas penelope

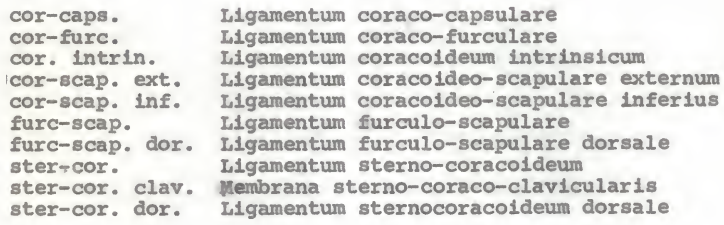

Above ligaments removed from left side.

Membrana sterno-coraco-clavicularis removed from right side. Membrana interclavicularis completely removed. 


\section{PLATE II}

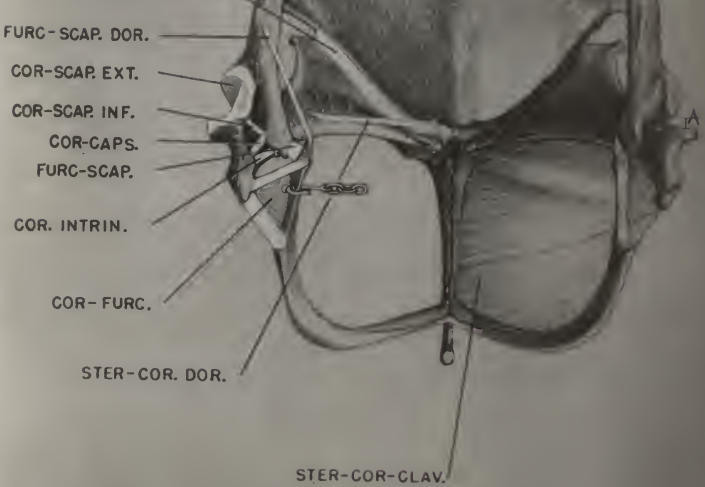




\section{BIOGRAPHICAL SKETCH}

Glen E. Woolfenden was born at El1zabeth, New Jersey, on January 23, 1930. He graduated from Peddie school. Hightstown, New Jersey, in 1949. Undergraduate study in zorlogy at Cornell University resulted in the degree of Bachelor of Science in June, 1953. The degree of Master of Arts was received from the University of Kansas in June, 1956. Graduate study was contInued at the University of Florlda. Graduate, research, and teaching assistantships, and an interim instructorship were held. He is married and has two children. He is a member of the American ornitholog1sts' Union, Cooper Ornitholog1cal Soclety, W11son Ornithological society, Society of Vertebrate Paleontology, Malne Audubon Soclety, Florida Audubon Society, the Society of the sigma $X 1$, and Phi sigma Blological society 
This dissertation was prepared under the direction of the chairman of the candidate's supervisory committee and has been approved by all merbers of that comittee. It was submitted to the Dean of the College of Arts and Sciences and to the Graduate Council, and was approved as partial fulfillment of the requirements for the degree of Doctor of Philosophy.

August, 1960

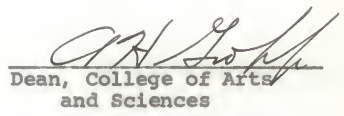

Dean, Graduate school

Supervisory Comittee:

Pevin Broohosh
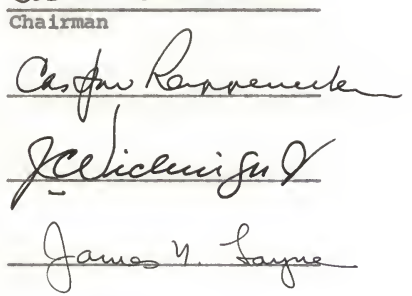

Fland F. Hussey 